\title{
Application Activities Designed to Prepare Preservice Special Education Teachers for Response and Prevention of Bullying Behaviors
}

\author{
Crystal Smith \\ West Virginia University
}

Follow this and additional works at: https://researchrepository.wvu.edu/etd

\section{Recommended Citation}

Smith, Crystal, "Application Activities Designed to Prepare Preservice Special Education Teachers for Response and Prevention of Bullying Behaviors" (2014). Graduate Theses, Dissertations, and Problem Reports. 646.

https://researchrepository.wvu.edu/etd/646

This Dissertation is protected by copyright and/or related rights. It has been brought to you by the The Research Repository @ WVU with permission from the rights-holder(s). You are free to use this Dissertation in any way that is permitted by the copyright and related rights legislation that applies to your use. For other uses you must obtain permission from the rights-holder(s) directly, unless additional rights are indicated by a Creative Commons license in the record and/ or on the work itself. This Dissertation has been accepted for inclusion in WVU Graduate Theses, Dissertations, and Problem Reports collection by an authorized administrator of The Research Repository @ WVU.

For more information, please contact researchrepository@mail.wvu.edu. 
Application Activities Designed to Prepare Preservice Special Education Teachers for Response and Prevention of Bullying Behaviors

\author{
Crystal Smith
}

\author{
Dissertation submitted \\ to the College of Education and Human Services \\ at West Virginia University \\ in partial fulfillment of the requirements for the degree of \\ Doctor of Education in \\ Special Education
}

\author{
Kim Floyd, Ph.D., Chair \\ Michael Mayton, Ph.D. \\ Christan Grygas Coogle, Ph.D. \\ Ugur Kale, Ph.D. \\ Richard Walls, Ph.D. \\ Department of Special Education
}

Morgantown, West Virginia
2014

Keywords: bullying, disability, virtual simulation, role play, case study, preservice teachers Copyright 2014 Crystal Smith 


\title{
ABSTRACT \\ Application Activities Designed to Prepare Preservice Special Education Teachers for \\ Response and Prevention of Bullying Behaviors
}

\author{
Crystal Smith
}

The effects of bullying on individuals involved in bullying situations (i.e., the bully, the target, and bystanders), has prompted nationwide interest in the field of education. Identifying students at-risk of being involved in bullying situations has led to awareness of high prevalence rates among students with disabilities. Understanding the potentially devastating effects of bullying on the academic, social, and emotional well-being of students with disabilities is disconcerting. Therefore, the goal of this study was to answer questions related to effectiveness of application activities designed to prepare preservice special education teachers for response and prevention of bullying behaviors. All activities related to this study took place on campus at West Virginia University. Participants who completed the full requirements of this study were eight undergraduate students enrolled in SPED 304, Special Education in Contemporary Society, during the Spring 2014 semester. A single subject alternating treatments design was employed to measure the effects of each type of application activity on participants' accuracy in responding to bullying behaviors. Data were analyzed utilizing quantitative and qualitative measures. Specifically, this study analyzed the effectiveness of Case Study/Automated Feedback activities, Role Play/Peer Discussion Activities, and Virtual Simulation/Instructor Feedback activities for preparing preservice special education teachers to respond appropriately when confronted with bullying behaviors. The results of individual participant analysis did not reveal significance of effect for specific types of intervention. However, analysis of all participants during pre- and post-feedback phases did reveal significance of effect. Prior to participating in feedback activities, statistical analysis demonstrated significance of effect for accuracy of responding during the Virtual Simulation condition. Further, analysis of theme collected from participant open-ended and likert-type responses on the social validity questionnaire, also indicated that participants preferred virtual simulation activities: they reported feeling more prepared for real interaction with students as a result of their experience in the TeachLive ${ }^{\mathrm{TM}}$ lab, which is where virtual simulation activities were conducted. Application activities were designed to include three different types of feedback (i.e., automated, peer discussion, and instructor). Analysis of effect during pre- and post-feedback phases did not provide evidence that any one type of feedback was better than the other, but it did report significance of effect across all activities from pre- to post-feedback. The results of this study support virtual simulation and participation in feedback activities as a highly effective means of preparing preservice special education teachers for response and prevention of bullying behaviors. 
This dissertation is dedicated to my kids whose smiles, laughs, tears, and even stubbornness fill my heart with unsurmountable love and joy.

To my daughter, Layla, who taught me exactly how much love the heart can give when she blessed me by becoming my beautiful, smart, energetic and inspiring "Laylabug."

To my son, Cody, who reminds me every day how much joy comes from being spontaneous. You are clever, determined, and sneaky: a true "spy kid."

Thank you so much for being patient with Mommy. Someday you'll understand that although this was my dream to accomplish, you were the two little lights leading me through the tunnel: my motivation to keep on chugging. I can't wait for the day that you realize your own dreams and go after them.

"So be sure when you step, Step with care and great tact. And remember that life's A Great Balancing Act. And will you succeed? Yes! You will, indeed! (98 and 3/4 percent guaranteed) Kid, you'll move mountains." Dr. Seuss, Oh, The Places You'll Go! 


\section{Acknowledgements}

When I started this journey, I had no idea I would need the support of so many people. I would like to begin by thanking my husband, Rob. If it were not for your patience and support, I could not have fulfilled this dream. I never truly understood the heartfelt thanks that you offered to me during your deployments. Yes, I made sacrifice. Yes, I took care of our baby girl, but I did that because she was my daughter, and because her daddy had no choice; he was "at the army." You, on the other hand, have made tremendous sacrifice. Alone, you took care of our house and kids, often times, while I was in the next room tuning everything out: from homework, to dance, gymnastics, cheerleading, and so much more. It was a lot to ask! Not to mention, you sat back while I made the decision to leave my job only to take another paying half as much as the income we had become accustomed to living with. Why? I wanted more time with our kids and more time for my studies. I hope you know that I have not taken one second of your sacrifices for granted. Thank you so much for being the husband you are to me and the father you are to our children. You have stood by me without question, and in doing so; you have helped me to teach Layla and Cody a valuable life lesson: to dream big and work hard to achieve big dreams.

Thank you to my dissertation chair, Dr. Kim Floyd. You never allowed me to lose sight of what is important. I was not part of a group of candidates who would begin this program together, turn to one another for support, and build lasting friendships. In fact, it could be said that I was alone in this journey, but because of your confidence in me, encouragement, and willingness to listen, I have never felt alone. Thank you for your support and guidance as you have led me onto the path of realizing my dream: I am forever grateful. To Dr. Michael Mayton, thank you. You have gone above and beyond to support me from the initial design stages of this study all the way through to analysis. To Drs. Christan Coogle, Ugur Kale, and Richard Walls, 
you have all contributed to my successful completion of this program. Thank you for your part in making my road to dissertation a valuable learning experience. To Dr. Naomi Rahn, you were instrumental in helping me find volunteers. Thank you for opening up your classroom to me. Thank you to Dr. Barbara Ludlow and the rest of the Special Education faculty at WVU for giving me this opportunity. As I embark upon my career in higher education, I look forward to interacting with all of you as a peer and colleague.

To my family and friends, even those not mentioned, I am humbled. To my parents, Mary Ann and Roger Dilley, you have turned your world upside down to give me anything I need in life. Throughout this doctoral program, I have called upon you for help numerous times and without reservation you have been there. I'm very fortunate to have such great parents. To my inlaws, Loretta and Bob Smith, thank you for believing in me, and going out of your way to take care of my babies. Layla and Cody have the best grandparents a mother could ask for. To my sister, Beth Bowman, you have listened to me when I needed to vent, taken care of my kids when you could, and you have been patiently waiting for me to complete this program so you can “hang” with your sister again: can’t wait! To my sister-in-law, Brenda Lego, you only recently moved back home, but you continuously offer your help, and I truly appreciate the little you have been able to do. To my best friend, Emily Duke, you have often times been the voice of reason that I needed to stay on track. You are the person that I turned to every time I was questioning my decision to go back to school. You have listened, you have encouraged, and you have given incredible advice. Thank you for never letting me give up, and thank you for making me "smile."

Finally, to the eight individuals who volunteered to participate in this study and followed it through to the end, thank you for your support. You are all amazing! I am forever thankful to you and your commitment to this study. I wish you well in your future endeavors. 


\section{TABLE OF CONTENTS}

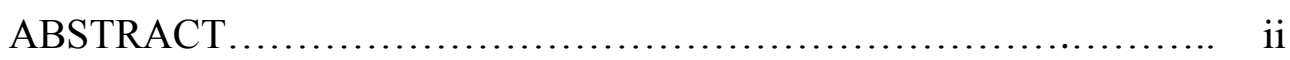

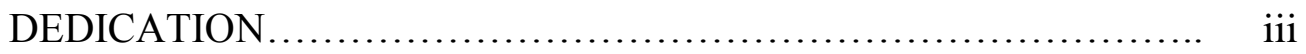

ACKNOWLEDGEMENTS ..................................... iv

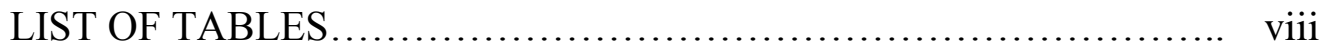

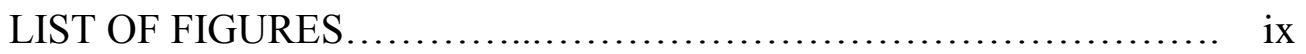

Chapter 1..................................................................... 1

Introduction.................................................... 1

Significance of the Study......................................... 1

Purpose of the Study ........................................... 2

Chapter 2................................................................ 4

Review of Literature............................................. 4

Bullying in Special Education................................ 5

Effects of Bullying on Students with Disabilities................ 6

Modifying Prevention Programs to meet Student Needs........... 7

Bullying and Olweus Bullying Prevention Program................. 8

Special Education Preservice Teacher Training Programs............ 8

Application Activities: Preparing Preservice Teachers for the Field... 9

Case Study/ Automated Feedback............................ 11

Role Play/ Peer Discussion................................... 12

Virtual Simultaion/Instructor Feedback....................... 12

Research Questions............................................ 13

Chapter 3............................................................... 15

Research Design.............................................. 15

Procedures.................................................... 16

Experimental Controls.......................................... 21

Sampling and Description of Participants....................... 23

Description of Setting........................................ 24

Data Collection............................................. 25

Instrumentation........................................... 26

Data Analysis.............................................. 28

Individual Performance Analysis............................ 29

Group Performance Analysis................................. 31

Chapter 4................................................................ 34

Results....................................................... 34

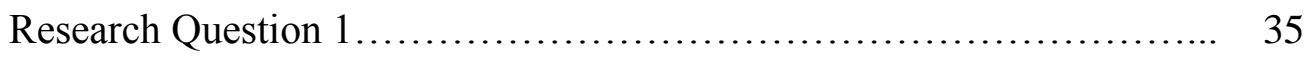

Participant A1 ............................................. 35

Participant A3 ............................................. 39 
Participant B1............................................ 42

Participant B2 .............................................. 45

Participant B3............................................... 47

Participant C1............................................. 49

Participant C2 ........................................... 51

Participant C3................................................. 54

Group Analysis.............................................. 56

Research Question 2.......................................... 56

Results of Chi Squared Test.................................. 57

Results of Cochran's Q Test.................................. 57

Results of the McNemar Test................................. 58

Participants' Reasons for Choosing Specific Responses.............. 58

Research Question 3............................................ 64

Question 3, Part 1............................................. 64

Question 3, Part 2........................................... 65

Question 3, Part 3......................................... 66

Chapter 5........................................................... $\quad 69$

Discussion................................................... 69

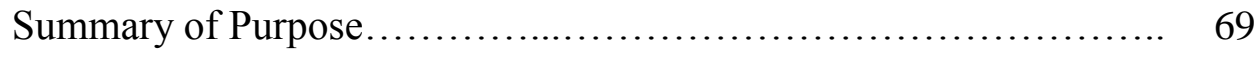

Accuracy in Responding..................................... 69

Pre- and Post-Feedback....................................... 73

Participants' Perceptions..................................... 74

Social Validity............................................ 76

Implications for Practice.................................... 77

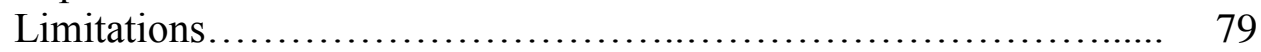

Future Research............................................. 81

Conclusion................................................... 84

References........................................................... 85

Appendices.............................................................. 91

Vita............................................................... 143 


\section{LIST OF TABLES}

Table 1. Administration of Three Interventions Balanced Across Three Scenarios and Three Groups of Participants......................... 15

Table 2. Steps for Computing Statistical Differences Among Datasets... 31

Table 3. Breakdown of Accurate Responses Pre- and Post-Feedback...... 58

Table 4. Themes to Describe Reasons Participants Chose to Respond by Gesture

Table 5. Themes to Describe Reasons Participants Chose to Respond by Verbal Directive

Table 6. Themes to Describe Reasons Participants Chose to Respond by Ignoring the Behavior Completely.....

Table 7. Themes to Describe Reasons Participants Chose to Respond by Ignoring in the Moment with the Intention of Addressing the Behavior at a Later Time.

Table 8. Themes to Describe Difference in Application Activities........ 66

Table 9. Effectiveness Rating for Each Type of Application Activity.... 68 


\section{LIST OF FIGURES}

Figures

Page

Figure 1. Participant A1: Celeration Line........................ 38

Figure 2. Participant A1: Trend, Level, and R-squared Values......... 38

Figure 3. Participant A3: Celeration Line....................... 41

Figure 4. Participant A3: Trend, Level, and R-squared Values......... 41

Figure 5. Participant B1: Celeration Line........................ 44

Figure 6. Participant B1: Trend, Level, and R-squared Values......... 44

Figure 7. Participant B2: Celeration Line........................ 46

Figure 8. Participant B2: Trend, Level, and R-squared Values.......... 46

Figure 9. Participant B3: Celeration Line......................... 48

Figure 10. Participant B3: Trend, Level, and R-squared Values........ 48

Figure 11. Participant C1: Celeration Line......................... 50

Figure 12. Participant C1: Trend, Level, and R-squared Values........ 50

Figure 13. Participant C2: Celeration Line....................... 53

Figure 14. Participant C2: Trend, Level, and R-squared Values......... 53

Figure 15. Participant C3: Celeration Line....................... 55

Figure 16. Participant C3: Trend, Level, and R-squared Values......... 55 


\section{Chapter 1}

\section{Introduction}

As a result of tragedies such as the Sandy Hook shooting, bullying has become an issue of national interest. According to The Nation's Report Card, Indicators of School Crime and Safety (National Center for Educational Statistics, 2012), 28\% of students ages 12 to 18 reported being bullied at school, and 9\% reported being cyber-bullied during the school year. Because students with disabilities have been identified as at-risk for being targeted by bullies, the issue holds specific relevance in the field of special education. Pacer's National Bullying Prevention Center (2013) reported on 10 US studies conducted to examine the connection between bullying and prevalence rates among individuals with disabilities. All of the studies reported that individuals with disabilities were two to three times more likely to be bullied than their nondisabled peers.

In accordance with recent demands to address safe school legislation, the Council for Exceptional Children (CEC) Initial Level Special Educator Preparation Standard 2 addresses safe, inclusive, and culturally responsive learning environments by suggesting that beginning special education professionals know how to intervene safely and appropriately with individuals with exceptionalities (Council for Exceptional Children, 2013). This study addressed the effectiveness of application activities designed to prepare preservice special education teachers to respond appropriately when confronted with bullying behaviors.

\section{Significance of the Study}

The researcher aims to contribute to the growing literature related to bullying in special education. Students with disabilities already face the stereotypes that are often associated with their disabilities. Bullying, in many instances, pushes students who already lack self-confidence 
to the point of emotional instability, which provides rationale for why bullying response and prevention should be addressed with teachers prior to entering the classroom. The researcher hopes by providing data and describing findings that support improvement in accuracy of responding to bullying behaviors among preservice teachers, this study will lead to further research addressing the need for bullying prevention training in preservice teacher education programs; therefore, giving the study focus and purpose.

\section{Purpose of the Study}

The purpose of this study was to examine evidence-based activities which could potentially be applied to future courses in special education teacher education programs. The activities described in this study were designed to prepare preservice special education teachers for critical decision making which is essential to addressing safe school policies related to bullying. Specifically, the study examined the effectiveness of the following three types of application activities designed to prepare preservice special education teachers for response and prevention of bullying behaviors: case study/automated feedback, role play/peer discussion, and virtual simulation/instructor feedback.

Participants were randomly placed into three groups, and they participated in nine activities over the course of the study. Activities were designed to give participants the opportunity to respond to bullying situations that might occur in an actual school setting. Participants were asked to reflect upon their choices and after participating in feedback, determine whether or not they would choose to change their original responses to bullying behaviors. Bullying scenarios and recommended responses are grounded in literature. They were derived from an exhaustive search of literature relating to bullying prevention, bullying response, 
bullying referral, and evidence-based bullying programs combined with the researcher's expertise gained from experience in the field. 


\section{Chapter 2}

\section{Review of Literature}

According to Ysseldyke and Algozzine (2006), policy addressing issues in special education work together to combine social, political, and economic structure. Ysseldyke and Algozzine (2006) discussed National Education Goals to be attained by the year 2000. The goals were originally stated in 1984 and reemphasized in 1994. National Goal 7 addressed Safe, Disciplined, and Alcohol- and Drug-Free Schools. Specifically, it stated that all local education agencies should develop and implement policy to ensure schools are free of violence, and schools should work with community and parents to ensure students' rights to study in a safe, secure and healthy environment.

Whereas the described goal is broad and appropriate for all children (Ysseldyke \& Algozzine, 2006), the issue holds specific relevance in the field of special education. Students with disabilities are not only at-risk for becoming targets of bullying, but they have also been reported as at-risk of becoming perpetrators (Rose, Espelage, \& Monda-Amaya, 2009). Rose and colleagues (2009) studied bullying perpetration and victimization by analyzing data collected from approximately 21,000 middle and high school students in both general and special education programs. The authors reported greater rates of perpetration and victimization among the special education population. The long term outcome of bullying can be detrimental to a student's well-being and ability to learn. Reiter and Lapidot-Lefler (2007) studied harassment and bullying among 186 students with intellectual disability, of ages 12 to 21 years. Findings indicated $83 \%$ of the student participants had experienced some type of bullying. Participants reported bullying behaviors ranging from having personal property stolen or being sworn at to being pushed, beaten, threatened with harm, told nasty rude things, forced to do things they did 
not want to do, and even being sexually touched without consent. Students who are bullied at school are in turn deprived of their right to learn in a safe and secure environment. In order to assure students are able to view school as a "safe haven," preservice special education teachers need to be prepared to adequately address bullying situations.

\section{Bullying in Special Education}

Several studies have reported a connection between students with disabilities and involvement in bullying (Blake, Lund, Zhou, Kwok, \& Benz, 2012; Estell, Farmer, Irvin, Crowther, Akos, \& Boudah, 2009; Pacer's National Bullying Center, 2013; Rose, MondaAmaya, \& Espelage, 2011). In an attempt to identify those students at-risk for becoming involved in bullying situations, Rose, Espelage, Aragon, and Elliott (2011) studied 1,009 students from four middle schools. The authors reported that students with disabilities have significantly higher rates of involvement than their peers without disabilities, thereby increasing the likelihood they will either become bullies or targets of bullying. The authors also reported students with disabilities had significantly higher rates of fighting than their peers without disabilities. The unfair treatment and devastating consequences of bullying constitute strong rationale for addressing bullying in special education preservice teacher training programs (Blake et al., 2012).

Rose, Swearer, and Espelage (2012) reported international research on bullying and students with disabilities as dating back to the early 1990s. The authors reported the earliest study identifying students in special education curriculum at-risk of being both a target and perpetrator as coming from a seminal study published in the United Kingdom in 1994. Because of the potential long-term effects of bullying on a student's well-being and ability to learn, 
stakeholders have and will continue to conduct research in an effort to identify which groups of students are most at-risk of becoming involved in bullying situations.

Defining bullying in relation to specific disability types remains an open issue of concern in the field (Rose et al., 2012). The variability of definitions for disability status makes it difficult to determine when a student is acting as a result of his/her disability or if the student is acting out in a way that is not a manifestation of his/her disability. Rose and colleagues (2012) suggested that until federal standardized definitions are set, defining bullying in relation to students with disabilities will continue to be a challenging task. Although controversy surrounding the definition of bullying in relation to students with special needs still exists, there is a plethora of resources available for teachers to describe the effects of bullying on students with disabilities.

\section{Effects of Bullying on Students with Disabilities}

Individuals targeted by bullying may develop character traits that have long-term consequences on their social emotional or academic development (Rose et al., 2012). A serious concern when considering students with disabilities is they might develop bullying traits of their own as a result being targeted, and overtime they may become the perpetrator. Estell and colleagues (2009) studied participants across eleven elementary schools in two school districts consisting of 369 general education students, 74 academically gifted students, and 41 students with mild disabilities. The authors reported students with disabilities were more likely to be perceived as being a bully as reported by both their teachers and their peers, and they were also rated by their teachers as more likely to be bullied by their peers. Students with mild disabilities who had aggressive and perceived popular associates received more peer nominations for being bullies than any other students. 
Bullying may affect some students by causing them to become withdrawn. This is especially applicable to students who already suffer from lack of self-esteem and social/emotional deficiencies. There are many ways bullying can effect students. Some possible signs directly affecting the health or well-being of the target may include frequent headaches or stomachaches, changes in eating habits, difficulty sleeping, nightmares, feeling of helplessness, avoidance, destructive behaviors, and decreased self-esteem (American Institutes for Research, 2013).

\section{Modifying Prevention Programs to meet Student Needs}

The key to a successful bullying prevention program is the whole-school approach where children feel safe to report instances of bullying and where staff is prepared to appropriately intervene (Raskauskas \& Modell, 2011). The authors described three means of modifying wholeschool prevention programs to address the needs of students with disabilities. First, the authors described modifications that should be made to needs assessments. A needs assessment survey should include students with disabilities. It should allow students with disabilities to not only participate in the survey collection, but it should also provide the opportunity for students with disabilities to accurately report about their own experiences. Although the survey must be the same as the rest of the schools, the delivery can be modified. Second, the authors described modifications to program components. Components of the whole-school approach include awareness, efficacy, and practice. Students and teachers should be aware of disability needs and sensitive to bullying, teachers working with students who have disabilities may need specialized training in order to assure efficacy of practice. Finally, the authors described modifications to practice by suggesting the content of an anti-bullying program can be delivered to students with disabilities considering the same modifications teachers already use for academic content. 


\section{Bullying and Olweus Bullying Prevention Program}

The definition of bullying has evolved over several years. Olweus and Limber (2010) described bullying as negative behavior toward another person that is repeated overtime. Negative actions can be carried out through physical contact, words, gestures, or intentional exclusion from a group (Olweus and Limber, 2010). The authors suggested there must be an imbalance of power between the target and the perpetrator for a behavior to be considered bullying.

The key components of bullying prevention programs being implemented at the school level begins with the word, community. The Olweus Bullying Prevention Program (OBPP) is among the most recognized evidence-based programs (Olweus \& Limber, 2010; Hong, 2009; Coyle, 2008). The first component to a successful program described by Olweus and Limber (2010) is community. All stakeholders among the community must be educated and understand the phases of development which will become the next components of a bullying prevention program. Other key components of the OBPP include individual level interventions, classroom level interventions, and community interventions (Bowllan, 2011).

Specific topics that should be addressed during training should include a definition of bullying behaviors and cyber-bullying which would allow responsible adults to understand the signs of bullying. Other topics of training might include warning signs, strategies for intervening immediately in bullying situations, and an explanation of how to take preventative measure (American Institutes for Research, 2013) at the individual, classroom, and community levels (Bowllan, 2011; Olweus \& Limber, 2010).

\section{Special Education Pre-Service Teacher Training Programs}


Preparing preservice special education teachers for field experiences is an issue of interest in higher education. The professional literature supports a variety of methods for delivering instruction to preservice teachers. Hixon \& So (2009) reviewed current literature to address the potential roles of various technologies in supporting early field experiences. The authors reported that virtual learning experiences and reflection are an effective means of ensuring preservice teachers meet the intended goals of participating in field experiences. Virtual learning environments (VLEs) create opportunities for observation, participation and practice in simulated environments that model real world scenarios, allowing outcome to be reviewed during the reflection process. This type of approach allows preservice teachers to make mistakes without real world repercussions (Savin-Baden et al., 2010). As stated by Inoue (2008), rather than being passive observers, in simulated, real world environments, preservice teachers are fully engaged in their own learning.

Zaretsky (2009) described how preservice physical education teachers can create their own simulated learning experiences with Case study presentations. The authors reported enhanced performance as a result of participating with simulated activities. Although VLEs are described as effective in preparing preservice teachers for authentic interaction in real world situations, the following questions still exist: How can teacher education programs ensure that students are getting the maximum benefit from field experiences? What role can technology play in preparing preservice teachers to transition from student, to intern, to teacher? What is the best method of preparing preservice teachers for engaging in real world experiences?

\section{Application Activities: Preparing Preservice Teachers for the Field}

It is critical that teachers understand the importance of their role in ensuring students receive an education in a healthy and stress-free environment. Teacher education programs are 
responsible for preparing preservice teachers to respond appropriately to situations that threaten the maintenance of a safe learning environment. Bullying is not only harmful to students, but it is also harmful to teachers, as it can elicit extreme stress (Kahn, Jones, \& Wieland, 2012). Kahn and collegues (2012) studied teachers' coping styles in relation to how they responded to bullying situations and determined that there is a need in preservice education to positively influence coping styles, in order to effectively prepare preservice teachers to respond appropriately to bullying situations.

The ultimate goal of influencing coping styles is to increase the likelihood that preservice special education teachers will effectively respond to bullying situations during field experiences and in their own classrooms. Duong and Bradshaw (2013) surveyed 1,980 school staff members in Maryland public school district regarding their attitudes and responses to bullying. The authors determined that perceived threat and perceived efficacy positively affected the likelihood that teachers would intervene in bullying situations. Because perceived efficacy among teachers seemed to be more strongly associated with response to bullying, this study suggests that bullying interventions should focus on building teachers' confidence in addressing bullying situations by increasing their ability to demonstrate recommended strategies. Case study/automated feedback, role play/peer discussion, and virtual learning environments/instructor feedback are three types of application activities supported in literature as effective in accomplishing this task and was therefore addressed as a part of the current study.

An exhaustive search of literature related to content delivery methods in higher education and preservice teacher education programs was conducted. As a result, the following application activities were determined to be appropriate for this study. There are several content delivery methods that range from traditional lecture, to mini lectures, peer supported activities, and total 
emersion. The activities described in this study were analyzed in literature and determined to be the most appropriate for preservice education. This study will analyze how effective the application activities are for bullying response and prevention.

\section{Case Study/Automated Feedback}

Preservice special education teachers are often given sample case files to read and discuss. Because parents and students with disabilities have the right to confidentiality, it is not always possible for preservice teachers to have the opportunity to participate in authentic interaction with actual students. Case studies have been utilized as a means of preparing preservice teachers for the types of interactions they are likely to face in the actual classroom. Burden, Tinnerman, Lunce, and Runshe (2010) described three video case studies that modeled Individualized Education Plan (IEP) meetings and were utilized during a 5-week field experience with preservice teachers. Students viewed the videos independently and discussed them during class. Preservice teachers reported that the case studies were helpful in highlighting and expanding communication and collaboration skills. Use of the video case studies provided opportunity for reflection and provided a means of discussion in which the professor was able to comment or respond to student observations, thus guiding their learning in appropriate directions.

Floyd and Bodur (2008) studied use of case study analysis and case writing in undergraduate teacher education. Findings of this study indicate that structured case study activities increase preservice teachers' informed decision making in the field. The authors suggested that often content delivered to preservice teachers is too abstract. Through use of case study analysis, preservice teachers have the opportunity to identify problems and issues as well as consider multiple views for the future of informed decision making. 


\section{Role Play/Peer Discussion}

Role play has been utilized in both face-to-face and online environments. Russell and Shepherd (2010) described role play as an opportunity for participants to assume a role in someone else's situation, complete authentic tasks in an authentic context, and participate in substantial human interaction. According to the authors, role play is an effective means of learning through action, experience, reflection, and theory. In higher education, participating in role play scenarios can also lead to the opportunity for discussion among peers. Role play scenarios must be well planned and support social interaction among participants, student involvement in elaboration of roles, and, perhaps most importantly, student exploration of resolution through discussion (Russell \& Shepherd, 2010).

Clapper (2010) described role play as an immersion into learning. The learner becomes actively involved in the construction of his/her own learning experience, and in turn, builds critical thinking skills. The author suggested such interaction also allows for the possibility of processing information at multiple levels of understanding. In a study examining sixty students enrolled in two separate child development courses and the effectiveness of role play to facilitate engagement, reflection, collaboration, and positive learning outcomes, Poling and Hupp (2009) reported evidence of significantly greater percentages of improvement from students in a course utilizing role-play than a course utilizing traditional lecture.

\section{Virtual Learning Environments (VLE's)/Instructor Feedback}

Simulated VLEs provide live interaction with student avatars, representing scenarios almost identical to those that preservice teachers are likely to face in the classroom. One valuable feature of these environments is that they provide opportunity for preservice teachers to interact in difficult situations without negatively impacting real students (Andreasen \& 
Haciomeroglu, 2009). TeachLive ${ }^{\mathrm{TM}}$, the VLE used for this study, is a platform utilizing virtual avatars to represent a classroom of five elementary or middle school students. Interactions with these live avatars allow preservice teachers to practice and refine targeted skills (Abdreasen $\&$ Haciomeroglu, 2009; Dieker, Hynes, Hughes \& Smith, 2008).

In considering the National Council for Accreditation of Teacher Education's (NCATE) push for improved field experiences, Sawchuck (2011) predicted stakeholders would begin to look deeply into the idea of virtual simulation to meet the growing demands of field experiences. The intended outcome of participating in a virtual classroom is to prepare preservice teachers for situations they may encounter in real world settings and to teach them how to reflect upon their experiences once they are in the field. Virtual simulation should not be considered a replacement for true experience in the field, but rather a tool to prepare for interaction with real students. Bell and Morris (2009) studied a practice-based approach to preparing tutors to use simulated and authentic practice. The authors' findings supported authentic interaction as an effective means of delivering instruction to students in higher education.

\section{Research Questions}

The purpose of this study was to compare the efficacy of three types of application activities for preparing preservice special education teachers to respond to bullying situations that they are likely to face in the classroom. Application activities are intended to prepare preservice special education teachers for authentic interaction in real world situations. The study aimed to answer the following questions:

1. How does each of the three types of application activities influence the accuracy of participant responding in regard to their responses to bullying situations? 
2. Across the three types of application activities, what are the differences in participant responses between both pre- and post-instructor feedback?

3. What are participants' perceptions related to counter-balanced order, pros and cons of each type of application activity, and aspects of application activities considered most and least beneficial?

- What are participants' perceptions regarding the relationship between order of participation in application activities for each scenario and accuracy of responding?

- What are participants' perceptions related to differences in the three types of application activities, such as various participation tools, type of feedback, and participant perceived pros and cons of each type of activity, effectively prepare preservice special education teachers to respond to bullying situations?

- What are participants' perceptions on aspects of the three types of application activities considered to be most and least beneficial? 


\section{Chapter 3}

\section{Research Design}

The study employed an alternating treatments design across participants utilizing descriptive and nonparametric statistics as well as measures of social validity. Data was analyzed to make interferences regarding the efficacy of the following types of application activities for preparing preservice teachers to respond and prevent bullying: case study/automated feedback, role play/peer discussion, and virtual simulation/instructor feedback. Table 1 displays the counter-balanced order within which participants were engaged in the three types of application activities.

Table 1

The Administration of Three Interventions Balanced Across Three Scenarios and Three Groups of Participants.

Alternating order of Interventions during each week for each group of participants

\section{Application Activity/Intervention}

\begin{tabular}{lccc}
\hline $\begin{array}{l}\text { Group A } \\
\text { Scenario Type }\end{array}$ & 1st & 2nd & 3rd \\
$\begin{array}{l}\text { Week 1 Prevention } \\
\text { Week 2 Response }\end{array}$ & $\begin{array}{c}\text { Case Study } \\
\text { Virtual Simulation } \\
\text { Week 3 Referral }\end{array}$ & $\begin{array}{c}\text { Virtual Simulation } \\
\text { Role Play } \\
\text { Case Study }\end{array}$ & $\begin{array}{c}\text { Role Play } \\
\text { Case Study } \\
\text { Virtual Simulation }\end{array}$ \\
\hline $\begin{array}{l}\text { Group B } \\
\text { Scenario Type }\end{array}$ & 1 st & 2 nd & 3rd \\
Week 1 Prevention & Virtual Simulation & Role Play & Case Study \\
Week 2 Response & Role Play & Case Study & Virtual Simulation \\
Week 3 Referral & Case Study & Virtual Simulation & Role Play \\
\hline Group C & 1 st & 2nd & 3rd \\
Scenario Type & & & \\
Week 1 Prevention & Role Play & Case Study & Virtual Simulation \\
Week 2 Response & Case Study & Virtual Simulation & Role Play \\
Week 3 Referral & Virtual Simulation & Role Play & Case Study \\
\hline
\end{tabular}




\section{Procedures}

All of the students who volunteered for this study became part of a convenience sample. The original intent was to recruit twelve volunteers, however, only nine students volunteered to participate. All nine participants took part in a formal training to introduce bullying as an issue in public schools. During the training, materials and themes adapted from the OBPP as well as The American Institutes for Research (2013), Creating a Safe and Respectful Environment in Our Nations Classroom were used to define all options from which participants could choose when reacting to bullying situations.

Participants participated in three types of learning scenarios (prevention, response, and referral). Learning scenarios were designed to address interaction in bullying situations and reflection through the following types of application activities: Case study, role play, and virtual simulation, thus totaling nine sessions over the course of a semester (see Appendices A,B, and C for scenario descriptions).

During the case study intervention, participants were asked to read an interactive case study created in Qualtrics, an online survey tool. The case study gave participants choices as to what they would do in specific bullying situations. The choices were general and applicable to all types of intervention. For example, in all given situations a participant could choose to respond immediately utilizing gesture, respond immediately with a verbal directive, ignore the behavior completely, or ignore the behavior in the moment with the intention of addressing it at a later time. If a participant chose to address an issue at a later time, he or she then had the choice of addressing only the student who was bullying, addressing only the target, addressing both the bully and the target (but not at the same time), or referring the incident to a school counselor or 
administrator. The computerized case study was designed to give participants feedback regarding choices made. The feedback explained the rationale for what is considered to be the most appropriate response to a given behavior. Participants were asked to respond and then explain the reason for their responses, before they received the feedback with rationale describing what is considered the most appropriate response. This allowed participants to reflect upon their original response to determine if the feedback would shape future responses to similar situations. The steps for completing the case study/automated feedback activity were as follows:

1. Read through the given case situation.

2. When prompted, choose how you would respond to the given situation and then explain why.

3. Submit your response.

4. Read through the feedback that will appear immediately after you have submitted your response.

5. Decide if you would respond differently if faced with the same situation after reading the feedback. (Mark "yes" or "no" for each of the three behaviors)

6. Explain why you would or would not change your original response after reading the feedback.

7. Submit.

During the role play intervention, each participant had one opportunity to play the part of teacher and respond to a bullying situation being played out by other participants who were considered the actors. Participants playing the part of teacher had some idea of the type of bullying scenario in which they were participating. For example, they knew whether the session's scenario was to be a counseling scenario, an opportunity to respond to bullying 
behaviors, or an opportunity to prevent an occurrence of bullying, but they did not know the specifics of the scenario until they were in role. Upon arrival to begin participation in the role play scenarios, those participants who played the role of bully, target, and/or bystander in the given situation were given a scripted scenario. They were given time to practice the scenario before the participant who played the role of teacher was admitted into the classroom. As soon as the participant who played the part of teacher entered the classroom, participants began role play. After the participant who played the bully had created three opportunities for the participant who played the part of teacher to respond appropriately to the given behaviors, role-play was suspended by the participant who played the part of bully. Once out of role, participants immediately completed the first part an After Action Summary (AAS). Those participants who played the parts of bully, target, or bystander completed the AAS to describe what they would have done if they had been playing the part of the teacher. After participants completed the first part of the AAS (detailing the choices they made or would have made during the role play and their reasons for making those decisions), they participated in peer discussion. Peer discussion guidelines, which are outlined in Appendix D, were handed out and explained to participants during the initial whole group formal training session. The participant who played the part of teacher was expected to lead peer discussion. He or she was instructed to use the information provided in the peer discussion guidelines to describe: (a) the type of scenario, (b) his/her response and rationale for that response, (c) other possible responses from peers, and (d) the rationale(s) for any other responses peers may have chosen. Following peer discussion, participants completed the second part of their AAS and determined whether or not they would make the same decisions in similar situations. Because role play and peer discussion activities were student activities and did not require the direct supervision of an instructor, the sessions 
were video recorded and reviewed in order to assess treatment integrity. Video recordings were viewed by the researcher and analyzed using a treatment integrity checklist with items such as: (a) script was used as written; (b) participants stayed in role for the duration of all three bullying behaviors to occur; (c) the participant playing the part of teacher led the peer discussion; (d) all participants were actively involved in discussion; and (e) peer discussion guidelines were used to guide the discussion. The complete treatment fidelity checklist can be found in Appendix E. A second researcher viewed $25 \%$ of the role play videos to reduce the threat of observer bias or misperception. The steps for completing the role play/peer feedback activities were as follows:

1. Participants' roles defined

2. The participant playing the role of teacher waits while other participants read and practice role-play.

3. As soon as participants say they are ready, the participant playing the role of teacher walks into the classroom, "Good afternoon class. Today..." Role play begins immediately.

4. During role play there are three opportunities for response to bullying behaviors.

5. Once all behaviors have been acted out and there has been opportunity for response, the participant playing the part bully suspends role play.

6. The participant playing the role of teacher completes the first part of AAS.

7. Peer discussion begins (see guidelines in Appendix D)

8. Directly following peer discussion, the second part of the AAS is completed.

During virtual simulation, students interacted with live avatars in an interactive, online classroom. Avatars, in TeachLive ${ }^{\mathrm{TM}}$, are computerized or digital figures that represent students in a classroom environment. Avatars represented middle school students in bullying situations. Just 
as they did in role play, participants knew the type of scenario in which they were going to participate, but they did not know exactly what was going to happen during sessions. For example, participants knew in advance if they were participating in a scenario that required counseling, but they did not know who needed counseling, why counseling was necessary, or what type of counseling was needed until they were actively participating in the session. Participants completed the first part of their AASs immediately after completing the simulation activity. Next they participated in an instructor feedback session and then completed the second part of their AASs. All simulated activities were recorded. The instructor, (who was also the researcher), viewed the videos and completed a treatment integrity checklist on $100 \%$ of the sessions. In order to control for the threat of bias or misperception, $25 \%$ of the recordings were viewed by a second researcher. (The procedure for calculation is described in the experimental control section.) All participants were scheduled for three TeachLive ${ }^{\mathrm{TM}}$ sessions. During the first session, prior to beginning the actual scenario, participants were given an extra three minutes to familiarize themselves with the student avatars and the TeachLive ${ }^{\mathrm{TM}}$ lab. The steps for completing the virtual simulation/instructor feedback sessions were as follows:

1. Upon entering the TeachLive ${ }^{\mathrm{TM}}$ lab, participants will read a short disclosure describing the purpose of the session.

2. Participant will begin with, "Good morning class."

3. After 5-7 minutes the session will end.

4. Participants will complete the first part of the AAS.

5. After all participants have completed the sessions, the instructor will hold an instructor feedback session. (Participants should NOT discuss the session before receiving feedback.) 
6. Complete the second part of AAS.

\section{Experimental Controls}

An alternating treatments design was best suitable for this type of study because it allowed for comparison of effectiveness of one or more treatments or intervention strategies on a single dependent variable within a relatively short period (Alberto \& Troutman, 2006; Kazdin, 2011), which, in the case of this research, was an analysis of effectiveness across methods of delivering instruction on the appropriateness of participant responses to bullying situations. In alternating treatment designs, because differing interventions can be compared in the same phase, within a short period of time it can be determined if two or more interventions have a different impact (Kazdin, 2011). In the case of this study, the impact was on participant responses to bullying situations. Alternating methods of treatment, or intervention, employed in this design, eliminated the threat of positive or negative responses to intervention based upon the order in which interventions were delivered to participants. Participants, described in the following section, were recruited as volunteers for this study. They were randomly placed into groups, and their groups were systematically but also randomly assigned an order by which they would participate in application activities, therefore eliminating threat of multiple treatment interference.

One method of gathering data was AASs, found in Appendices F and G. AASs were completed by all participants during Role Play and Virtual Simulation activities and then evaluated by the researcher. In order to control for possible observer bias or misperception, a second evaluator was recruited to grade a minimum of $25 \%$ of the AASs collected from participants for every session. In order to measure inter-rater reliability, Cohen's Kappa was calculated. This type of calculation took into account any agreement that may have occurred due 
to chance. In order to ensure strong inter-rater reliability, kappa must be recorded with an acceptable agreement where $k>.7$ (Kazdin, 2011). As described by Kazdin (2011) kappa was calculated using the following formula:

$$
k=\frac{\mathrm{P}_{\mathrm{o}}-\mathrm{P}_{\mathrm{c}}}{1-\mathrm{P}_{\mathrm{c}}}
$$

where $\mathrm{P}_{\mathrm{o}}=$ proportion of agreements between observers (agreements on occurrences and nonoccurrences/total number of agreements and disagreements), and $\mathrm{P}_{\mathrm{c}}=$ Proportion of expected agreements based upon chance (occurrences for observer $1 *$ occurrences for observer $2+$ nonoccurrences for observer $1 *$ nonoccurrences for observer 2 , the sum of which is divided by the total number of intervals squared).

In addition to grading AASs, a treatment integrity checklist was completed for the role play sessions and the virtual simulation sessions. An original checklist was completed for $100 \%$ of both instructional methods, and after viewing video recordings, another checklist was completed by a second researcher for $25 \%$ of the role play sessions and $25 \%$ of the virtual simulation sessions. Kappa was then calculated as described above.

Inter-rater reliability for grading of AASs was calculated as follows: $\mathrm{P}_{\mathrm{o}}=.88$, and $\mathrm{P}_{\mathrm{c}}=$ .20 where $k=.85$, indicating an acceptable kappa $>.70$. Inter-rater reliability during Role Play activities was calculated as follows: $\mathrm{P}_{\mathrm{o}}=.94$, and $\mathrm{P}_{\mathrm{c}}=.22$ where $k=.92$, indicating an acceptable kappa > .70. Inter-rater reliability during Virtual Simulation activities was calculated as follows: $\mathrm{P}_{\mathrm{o}}=.97$, and $\mathrm{P}_{\mathrm{c}}=.24$ where $k=.96$, indicating an acceptable kappa $>.70$.

After participating in all nine sessions of this study, participants completed a social validity questionnaire (described in the data collection and analysis sections; also, see Appendix J) with questions rated on a Likert scale and open-ended responses. As a means of controlling for 
bias and increasing the likelihood that responses were accurately represented, all open-ended response questions were coded and compared for common theme by two evaluators.

\section{Sampling and Description of Participants}

Nine participants were recruited for this study. However, one of the nine participants did not complete the study. The study reports findings from two groups of three participants and one group of two participants. Participants were randomly placed in groups and groups were randomly assigned to a systematic order by which they would participate in application activities. The counter-balanced order within which participants were participating in application activities was not adversely affected by the absence of the ninth participant. All participants were still able to complete all activities in the order of which they had been scheduled.

Participants were enrolled in SPED 304, Special Education in Contemporary Society, offered during the Spring 2014 semester, at West Virginia University (WVU). Students enrolled in this course are typically freshman. Therefore, as a part of the selection criteria, it was stated that students must be at least 18 years of age. Because participants were recruited from an already intact group of students who were enrolled in a special education course at the university, all students enrolled in the course received a mass email describing the nature of the study and asking for volunteers. All students who signed up as volunteers and also signed a consent form had to be available to meet for a one hour training session prior to starting participation in application activities.

The majority of participants (67\%) were from 18-21 years old. Two participants reported being between the ages of 22-30 years old, and one participant reported being over 31 years old. Of the eight participants who completed the study, five were female and three were male. All participants were enrolled in programs offered through the College of Education and Human 
Services at WVU. Participants reported majoring in the following fields of study: Child Development and Family Studies, Physical Education (PE) and Athletic Coaching, PE and Disability Studies, Speech and Language/ Child Development and Family, English Education, Youth and Family/Communication, Special Education, Secondary Education, and Elementary Education. Three participants reported having prior training related to bullying, two of which were within the last 2-5 years and one within the last year. None of the participants reported having experience dealing with bullying situations as an adult in a professional role.

\section{Description of Setting}

The study took place in Allen Hall on the Evansdale Campus at West Virginia University. Because participants did not meet regularly throughout the semester, reserving computer labs and classrooms was a matter of taking what was available on the days that participants met. Participants were undergraduate students with various scheduling needs; accommodating their schedules was important in assuring they were available for the duration of the study. The study required access to three different learning environments.

The first setting was a computer lab. Participants needed to have access to a computer to complete the case study/automated feedback sessions. The second setting was a typical classroom with desks or tables for students who are playing the part of target, bully, and bystander and space to move freely for the participant playing the part of teacher. The space needed to be large enough to accommodate at least 4 students. The third setting was the TeachLive ${ }^{\mathrm{TM}}$ Lab, also in Allan Hall at West Virginia University. In the lab, participants interacted with virtual avatars playing the part of students in a simulated classroom. Within the TeachLive $^{\mathrm{TM}} \mathrm{Lab}$, there was a large screen that displayed the virtual classroom. In addition there was space in front of the large screen where participants could stand and walk around as they 
were interacting with avatars. Participants had to stand in the designated space because there was a camera utilizing Skype for TeachLive ${ }^{\mathrm{TM}}$ actors to see and hear the participant who was playing the part of teacher. TeachLive ${ }^{\mathrm{TM}}$ actors responded to participants based upon a list of objectives that were sent to them by the researcher. The objectives form provided by TeachLive ${ }^{\mathrm{TM}}$ included a description of each of the three target behaviors that have been outlined in Appendix C, Virtual Simulation/Instructor Feedback Scenarios. Participants were not permitted to view other participants' TeachLive ${ }^{\mathrm{TM}}$ sessions. Doing so would have been a threat to the integrity of the study as they would have been given some insight into what happened during their own sessions.

\section{Data Collection}

Data analyzed throughout this study were taken from AAS completed by participants during each session. Case studies were designed so that students must read and respond appropriately to given situations. Students were prompted to navigate through the case studies based upon their own responses to given case scenarios. There was no opportunity for deviation from the intended design or purpose of the case study. The AAS was embedded into the case study design. Participants chose how they would respond to target behaviors and described reasons for those responses as they were reading through the case study. After recording their original responses, participants were given automated feedback. Finally, participants were asked to indicate whether or not they would choose to change their original responses to bullying behaviors and why. A final document with an embedded AAS was printed by the researcher at the end of the session. Role-play and virtual simulation activities were video recorded in order to check for treatment integrity as described previously. In addition to AASs, participants also completed a social validity questionnaire. The social validity questionnaire provided opportunity for reporting quantitative and qualitative data, which was used to analyze the effectiveness of 
each method of delivery, the perceived impact of differences in instructional methods for preservice education, and participant perspective related to learning activities and feedback.

\section{Instrumentation}

The following instruments were used to collect data that were analyzed as a means of answering the research questions outlined in this study. Data collected for each of the research questions were categorized into measures of individual analysis and/or measures of group analysis.

1. A demographic/prior experience questionnaire was completed prior to participation in the study. A few areas of interest this questionnaire was used to examine include: age of participants, how long they have been in college, their career goals, whether they have had any other training on response and prevention of bullying, whether or not they have experience dealing with bullying behaviors, and if so the extent of that experience. This document included six multiple-choice items related to gender and preparedness, and four fill in the blank responses outlining course of study prior experience related to bullying in a professional role. This instrument was developed by the researcher in order to describe participants' levels of experience prior to participation in the study. (see Appendix H)

2. A 10 question multiple choice pre-test was administered to participants at the beginning of the initial training session. This document was utilized to determine participants' prior knowledge in relation to response and prevention of bullying situations. All questions were multiple choice and analyzed participants knowledge of bullying and bullying prevention prior to participating in this study. The document assessed participants' knowledge of bullying in terms of definition, policy, and effectively designed prevention programs. The instrument was created by the researcher. Questions were derived as a 
result of a thorough review of literature related to bullying and bullying prevention programs such as OBPP. (see Appendix I)

3. After Action Summaries were used in two parts. The first part of the AAS asked participants to record their responses to each of the three bullying behaviors that were presented in the scenarios and their reasons for making those choices. Immediately following each session, participants used the AAS to reflect upon their original responses. They participated in a feedback session and then completed the second part of the AAS. On the second part of the AAS, they reflected upon whether or not they would now, after receiving feedback, chose to respond differently to the same bullying behaviors. The AAS documents were created by the researcher and used to collect data related to accuracy of response and participants perceptions related to each type of possible response. (see Appendices F and G)

4. A social validity questionnaire utilizing a Likert-type rating scale and open ended questions was created by the researcher to distribute to participants after they had completed all sessions. Likert type questions on a scale of 1 to 5 were used to collect data on participants' perceptions related to perceived preparedness in response to bullying as a result of participating in this study, effectiveness of each of the three types of application activities for preparing to accurately respond to bullying situations, and the relationship between order of participation in application activities and the effectiveness of those activities for preparing to respond in bullying situations. Six open ended response questions were used to collect data on participants' perceptions related to activities that participants considered least and most beneficial, a description of the roles each 
participant played, pros and cons of each type of activity, and explanations. (see Appendix J )

5. Treatment fidelity checklists were completed by observers to calculate percentage of treatment integrity for role play/peer discussion and virtual simulation/instructor feedback sessions. An eight point checklist was created and used by two researchers during the review of video recordings of role play sessions to determine if participants' completed all of the necessary steps required to take part in an effective role play experience. A nine point checklist was used by two researchers to document if the avatars acted out each of the three target behaviors and provided opportunity for participants to respond to those behaviors, if the participants stayed in role for the duration of the three bullying behaviors to occur, and if the instructor feedback session allowed opportunity for active and appropriate discussion (see Appendix E for both checklists)

\section{Data Analysis}

Data collected throughout the duration of this study were analyzed during grading procedures in order to make inferences about the changes observed in participant reactions to bullying situations. Participants' responses to bullying behaviors were recorded and graded on AASs, then analyzed to determine percentage of correct answers for individual and group analysis. AAS were used to assess how each of the three methods of delivering instruction influenced the accuracy of participants responding in regards to response to bullying situations, if there was a relationship between order of participation in learning scenarios and their effectiveness, and differences in participant responses before and after receiving feedback.

In terms of accuracy, participants were given feedback to describe what is considered to be the most appropriate response to each behavior. Appropriate responses were derived from 
prior literature and information gathered from existing bullying prevention programs, as well as the researchers own experiences in the field. Bullying response and prevention is a concept that is subjective in nature. Every situation requires individual consideration in terms of correct and/or incorrect responses, or responses that are appropriate, more appropriate, or not appropriate. Because of the subjective nature, participants were asked to determine whether or not they would consider changing their original responses to bullying behaviors after participating in feedback sessions. Data collected were used to make inferences related to individual performance and group performance.

Individual performance analysis. To determine how the three methods of delivery influenced accuracy of participant responses during participation in bullying scenarios, the number of accurate responses were demonstrated visually on line graphs. Graphed data were analyzed utilizing descriptive statistics and nonparametric methods of analysis. Descriptive statistics, such as comparisons of level, or rather averages, of data point values within datasets during each stage of intervention were calculated to make inferences or conclusions about the effectiveness of each intervention on accuracy of participant responses. Two nonparametric methods of analysis, celeration line and c-statistic, were used to determine differences among the three datasets by presenting an analysis of trend.

A celeration line was used to measure observe whether each participant's accuracy of responding across all three types of training displayed an accelerating, decelerating, or stationary trend (Nourbakhsh \& Ottenbacher, 1994). Table 2 provides a detailed explanation of steps used to calculate a celeration line. Directions for measuring celeration found in White (2012) described steps for using a celeration finder to determine the value (x) by which the slope of the 
line is changing, expressed as a decimal value. A value slope of 1.0 is a flat trend representing no slope, and a value of -1.2 , for example, represents a trend with a decreasing slope of $20 \%$.

In addition, trend lines were computed along with R-squared values, used to predict the likelihood of continued increase or decrease in trend over time per participant for each application activity. When evaluating R-squared values, the closer to 1.0 , the better the predictive value of trend over time. R-squared values do not represent causal relationships. For example, they do not suggest that there is an increase in performance because of intervention, but rather, they indicate the level of probability for prediction of future outcomes (Wallace, 2004). Measurement of level for each intervention was determined by calculating the mean of data points within the three intervention conditions. Interventions with the two lowest levels, or mean, were compared to the intervention with the highest level, or mean, for each participant utilizing calculations for C-statistic. C statistic is a parametric analysis used with small data sets. According to Nourbakhsh and Ottenbacher (1994), C statistic can be applied to data sets with as little as 8 observations and it can be applied to data that demonstrate serial dependency. The procedure for calculating C-statistic as outlined in Table 2 produces a $z$ score (Nourbakhsh \& Ottenbacher, 1994). As described by Gravetter and Wallnau (2000), the $z$-score specifies the exact location of a given value within a distribution; positive $z$ scores represent data above the mean, and negative $z$-scores represent data below the mean. In order to achieve a confidence interval of $p<.05, z$ values must be less than -1.96 , and greater than 1.96 . A normal probability table for $z$-scores is used to determine the probability that other $z$-scores will be less than the $z$ score in question. 
Table 2

Steps for Computing Statistical Differences among Datasets

\begin{tabular}{|c|c|}
\hline Calculating for Celeration Line & Calculating for C Statistic \\
\hline $\begin{array}{l}\text { 1. Data for each of the nine sessions were } \\
\text { plotted on a graph displaying the } \\
\text { percentage of correct responses for } \\
\text { each session. Data are represented in } \\
\text { the counterbalanced order in which } \\
\text { participants participated in each } \\
\text { activity. } \\
\text { 2. The nine response percentages graphed } \\
\text { were divided in half. (four percentages } \\
\text { on each side of the data calculated for } \\
\text { responses of activity five, which is } \\
\text { where the vertical line was drawn) } \\
\text { 3. The median value of participants' } \\
\text { correct responses on each side of the } \\
\text { vertical line was calculated and marked } \\
\text { on the graph. } \\
\text { The median values were connected by } \\
\text { drawing a straight line. This is the } \\
\text { celeration line. }\end{array}$ & $\begin{array}{l}\text { 1. Each score in each of the three phases } \\
\text { was subtracted from the score adjacent } \\
\text { or next on the graph. } \\
\text { 2. Each value obtained in step } 1 \text { for } \\
\text { correct responses was squared and the } \\
\text { sum of the values obtained. } \\
\text { 3. Mean was calculated for each phase. } \\
\text { 4. The mean-difference score was then } \\
\text { calculated by subtracting each raw } \\
\text { score from the mean value, squaring the } \\
\text { results, and then taking the sum of } \\
\text { squared mean differences. } \\
\text { 5. The value obtained in step } 4 \text { was } \\
\text { multiplied by } 2 \text {. } \\
\text { 6. The C score formula: C= } 1 \text {-[value } \\
\text { obtained in step } 2 / \text { value obtained in } \\
\text { step } 5] \text { This is the } \mathrm{z} \text { value. } \\
\text { 7. Results of the C-statistic will be applied } \\
\text { by utilizing a probability table for } \mathrm{z}- \\
\text { score. } \\
\text { 8. The probability as it reads on the table } \\
\text { was subtracted by } 1 \text { to determine } \\
\text { statistical significance. } \\
\text { 9. In order to report significance, } p<0.05 \text {. }\end{array}$ \\
\hline
\end{tabular}

Note. This table was modified to fit the needs of this study. It was based on a table created by Nourbakhsh and Ottenbacher (1994).

Group performance analysis. Accuracy of responding was evaluated before and after the feedback phases to determine effectiveness of each type of application activity during preand post-feedback conditions. The Cochran's Q test was used to compare accuracy in responding for each intervention during the pre-feedback stage. The McNemar test was used to determine if there were differences on a dichotomous dependent variable, meaning that it was used to 
compare correct and incorrect responses during pre- and post-feedback conditions (Laerd Statistics, 2013). The Cochran's Q test is often described as an extension of the McNemar test. They each compare data of two conditions. For the purpose of this study, they were used to evaluate correct or incorrect pre-feedback responses (Cochrans Q test) across three interventions and to compare accuracy (correct and incorrect) during pre-and post- feedback conditions for each of the three interventions (McNemar test).

The chi-square test was used to determine differences in proportions of correct and incorrect responses during the pre- and post-feedback stages. Chi-square is intended to evaluate the relationships among variables within a contingency tale, and it can be obtained by classifying data into categories determined by a nominal or ordinal measurement (Gravetter \& Wallnau, 2000). For the purpose of this study nominal categories consisted or pre- and post-feedback conditions across three types of feedback: automatic, peer, and instructor. This study analyzed the differences in proportions of correct and incorrect responses across the three types of treatments, or rather feedback components.

Visual representations of data collected from the AAS instruments were also analyzed to determine if inferences could be made about the relationship between order of participation in learning activities and the effect it could have on accuracy of responses. General statements describing the results of this visual analysis and descriptive statistics in the form of a table to support the findings were reported. AASs were analyzed to examine differences in participant responses pre- and post-instructor feedback. Open-ended responses to reflection questions on the AASs were analyzed and coded for theme. Pattern coding, described in Miles and Huberman (1994), was used for this study. As stated by the authors, pattern coding provides more opportunity for inference and for explanation. Coding in general pulls together large amounts of 
material, therefore creating opportunity for analysis (Miles \& Huberman, 1994). For this study, two researchers compared results of coding to make inferences related to differences in participant responses before and after receiving feedback. After coding and chunking participant responses, analyzing and reanalyzing for theme, both researchers agreed upon the data being analyzed and the themes that emerged. In addition, descriptive statistics were utilized to calculate the percentage of participants during each session type who decided they would respond differently after responding inaccurately to a bullying situation and those who despite feedback would stand by their inaccurate response(s).

Data from the social validity questionnaire, described previously, were analyzed to determine the aspects of learning activities participants report as most beneficial versus those activities participants report as least beneficial. Data from the social validity questionnaire was also used to identify any differences between types of application activities such as various delivery tools, type of feedback, and participant perceived pros and cons of each type of activity for effectively preparing preservice teachers to respond in bullying situations. Responses to these types of questions were recorded from likert-type questions and as open-ended questions. Mean responses from the likert scale were calculated, while pattern coding, described by Miles and Huberman (1994), was used by two researchers to analyze responses to open-ended questions were and code for theme. Likert scale responses allowed for inferences to be made related to aspects of application activities participants' perceived as least and/or most effective in preparing them for bullying situations, perceived pros and cons of each type of application activity for preparing participants to respond in bullying situations, and participants' perceptions related to order of which they participated in application activities. 


\section{Chapter 4}

\section{Results}

This study was designed to investigate the effectiveness of three types of application activities in preparing preservice special education teachers for response and prevention of bullying behaviors. Of equal interest were the social validity aspects of each type of activity to describe participants' perceptions of preparedness to face bullying situations in the actual classroom as a result of participating in the study. Participants were asked to determine what aspects of each type of activity were most and least beneficial in preparing them to respond to or prevent bullying behaviors. The results of this study are organized around the following research questions: (a) How will each of the three types of application activities influence the accuracy of participant responding in regard to their responses to bullying situations?; (b) Across the three types of application activities, what are the differences in participant responses between both pre- and post-instructor feedback?; and (c) What are participants' perceptions related to counterbalanced order, pros and cons of each type of application activity, and aspects of application activities considered most and least beneficial? Specifically, What are participants' perceptions regarding the relationship between order of participation in application activities for each scenario and accuracy of responding?; What are participants' perceptions related to differences in the three types of application activities, such as various participation tools, type of feedback, and participant perceived pros and cons of each type of activity, effectively prepare preservice special education teachers to respond to bullying situations?; and What are participants' perceptions on aspects of the three types application activities considered to be most and least beneficial? Data collected from AASs and a Social Validity Questionnaire were analyzed to answer the research questions. 


\section{Question 1: Effectiveness of Each Activity Type on the Accuracy of Participant Responses}

In order to answer question one, participant responses during each session were analyzed individually. In addition, participant responses from all three sessions were combined by activity type to determine overall percentage of accuracy during each type of application activity. Individual analyses for each participant included determination of celeration, which allows for a measure of acceleration and deceleration over time and represents an overall change in rate of performance across all activities and all sessions. Results of this measurement are described as slope. It is important to understand that a flat celeration line, consisting of no slope, is assigned a value of 1 . Therefore, a negative slope with a deceleration of 1.4 is actually a decrease of 0.4 , and similarly, a positive slope of 1.4 is actually an increase of 0.4 . Data for each participant were also analyzed for trend. R-squared values have been assigned to trend lines. They are calculated to indicate the accuracy of (a) the trend line in representing the current dataset, and (b) a prediction of ongoing performance, or the extension of the trend line beyond the current dataset. An R-squared score of .5 represents a moderate probability for the accuracy and predictive effect of a trend line, and an R-squared value of 1.0 suggests there is an almost definite probability of the same.

Whole group comparisons of mean $(M)$ were calculated to make inferences about participant performance during each type of application activity. In addition, visual and quantitative analysis of the data (see Figures 1-16) was utilized as one determinate of participants' accuracy in responding to bullying behaviors during each type of application activity.

Results of analysis for Participant A1. Analyses of A1's data included celeration, level, trend, and C-statistic. Figures 1 and 2 show results of data collected from Participant A1 
across all treatments. Figure 1 incorporates a celeration line, indicating any change in the rate of the participant's overall performance. The celeration line for Participant A1 is flat, indicating no slope. Therefore, no cumulative acceleration or deceleration in accuracy of responding over time was indicated for this participant (i.e., slope $=1$ ).

Represented in Figure 2 are trend and level for each activity type. The data suggest an increasing trend in performance during the Case Study condition, a flat (or maintaining) trend during Virtual Simulation, and a decreasing trend during Role Play. Trend lines were analyzed by computing R-squared values. An R-squared value of 0.75 was derived from data collected during Role Play/Peer Discussion activities, indicating a high likelihood of accuracy and predictive effect. This suggests that, over time, participation in Role Play/Peer Discussion activities would be likely to yield a decrease in accurate responses to bullying behaviors from this participant. An R-squared value of 0.52 was derived from data collected during the Case Study condition, indicating a moderate likelihood that the participant's performance would continue to increase in accuracy during this condition.

Based on the assessment of level, the treatments for Participant A1 seemed to produce the following effect on performance, in order from most to least effective: Role Play, Virtual Simulation, and Case Study ( $M=77.78,66.67$, and 44.44, respectively). Levels calculated for this participant suggest that Role Play activities produced the most positive effect on performance. A representation of level for each of the three activities (see Figure 2) was utilized as a tool for determining how the analysis of statistical significance between performances across the three experimental conditions would be systematically conducted. The activity dataset with the highest level was statistically compared to each of the other two datasets using the steps for calculating the C-statistic, as described in Table 2. 
The C-statistic for Participant Al was first calculated to indicate any statistically significant change in performance (using a 0.05 confidence interval) within the Case Study condition, yielding a z score of 0.25 indicating a $59.8 \%$ probability that other scores in a normal distribution fall below 0.25 , and a $p$ value of 0.40 , which indicates no significance. Calculation across Case Study and Role Play datasets provided a z score of 0.47 , signifying a $68.1 \%$ probability that other scores in a normal distribution would fall below 0.47 , and $p=0.32$, indicating no significance in change across the datasets The C-statistic could not be calculated for the Virtual Simulation condition because there was no change over time.

Further calculations provided a z score of 0.89 across Virtual Simulation and Role Play datasets, signifying an $81.3 \%$ probability that other scores in a similar distribution would fall below 0.89 , and where $p=.19$, which indicates no significant change across data sets. 


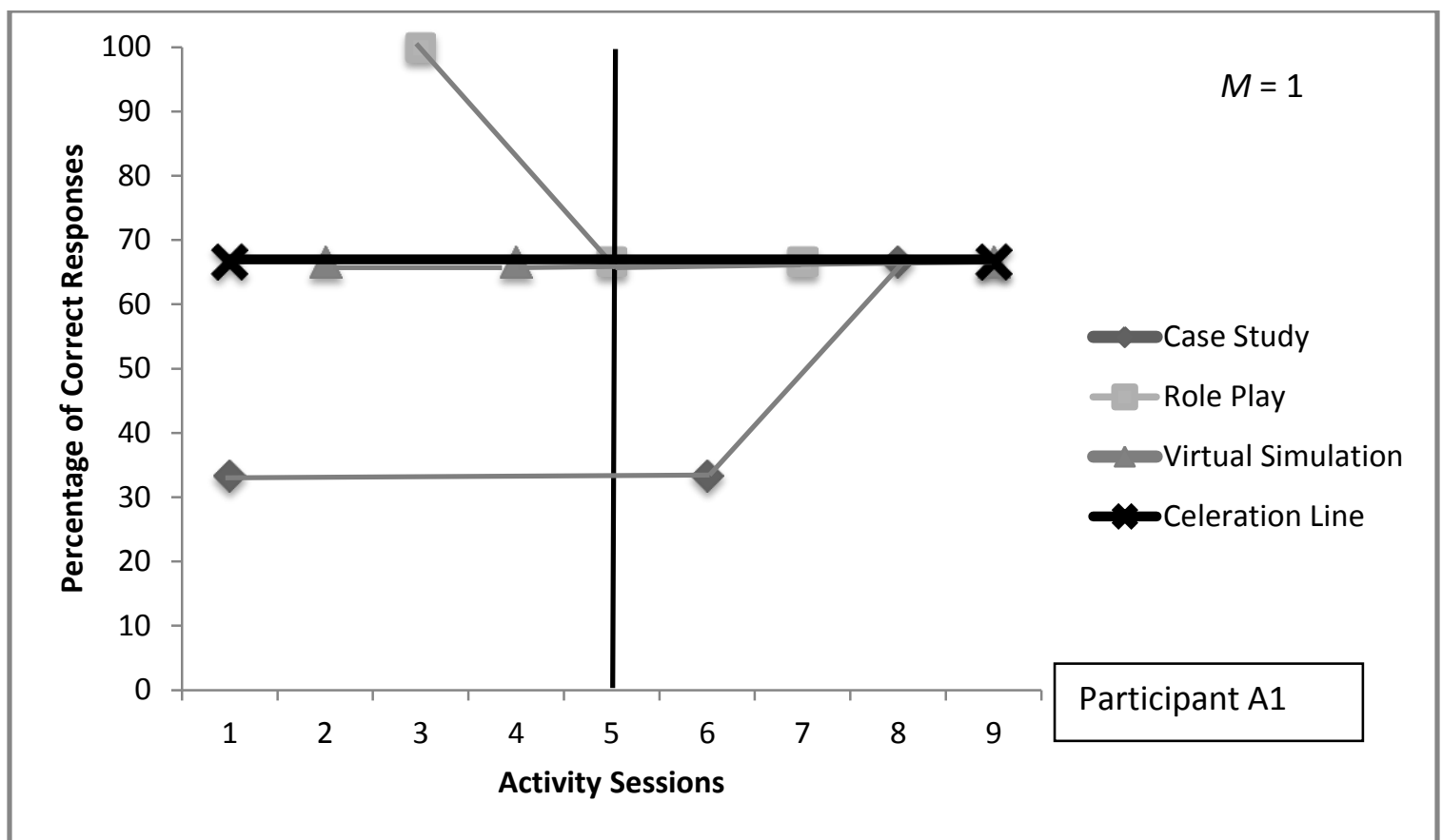

Figure 1. Participant A1: Celeration line indicating change in rate of performance over time, across all conditions.

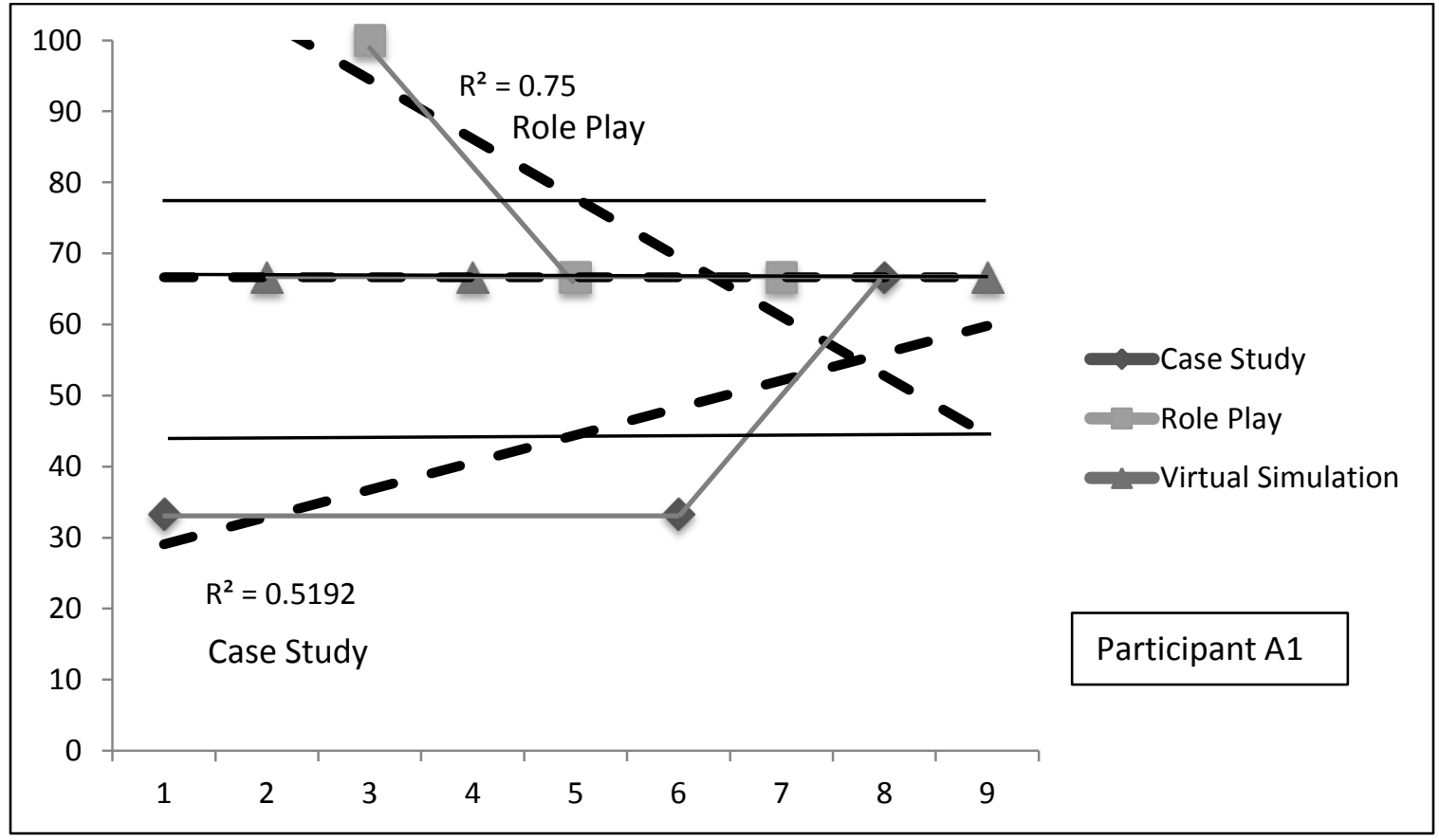

Figure 2. Participant A1: Trend, level, and $\mathrm{R}^{2}$ values across experimental conditions. 
Results of analysis for Participant A3. Figures 3 and 4 show the data collected for Participant A3 across all treatments. The celeration line for Participant A3 was estimated to have a positive slope of 1.4 , or $+40 \%$, revealing acceleration in accuracy of responding over the duration of the study for this participant.

Figure 4 includes trend and level for each activity type. The data suggest an increasing trend in performance during each of the three conditions. Once again, trend lines were analyzed by computing R-squared values, which were very low for both the Case Study and Virtual Simulation conditions $\left(\mathrm{R}^{2}=0.06\right)$ but highly accurate/predictive for Role Play $\left(\mathrm{R}^{2}=1.0\right)$.

Based on the assessment of level, the treatments for Participant A3 seem to produce the following effect on performance, in order from most to least effective: Virtual Simulation, Role Play, and Case Study ( $M=88.89,66.67$, and 44.44, respectively). Levels calculated for this participant suggest that Virtual Simulation activities produced the most positive effect on performance. A visual representation of level for each of the three activities (see Figure 4) was again utilized for determining how the $\mathrm{C}$-statistic analysis would take place.

C-statistic calculations for Participant A3 within the Case Study condition yielded a z score of 0.49 , indicating a $31.2 \%$ probability that other scores in a normal distribution fall below 0.49 , and a $p$ value of 0.69 , indicating no significant change in performance during the intervention. Calculations across Case Study and Virtual Simulation provided a z score of 0.0, signifying a $50 \%$ probability that other scores would fall below the 0.50 , and where $p=0.50$, thus showing no significant change across datasets. The C-statistic was also calculated for the Role Play intervention, providing a $\mathrm{z}$ score of 0.50 , signifying a $69.2 \%$ probability that other scores in a normal distribution fall below 0.50 , and $p=.31$ (no significance). A final calculation across 
Role Play and Virtual Simulation yielded a z score of 0.59 , indicating a $65.5 \%$ probability that other scores in a similar distribution would fall below 0.59 , and $p=.34$, indicating that no significant change occurred across the datasets. 


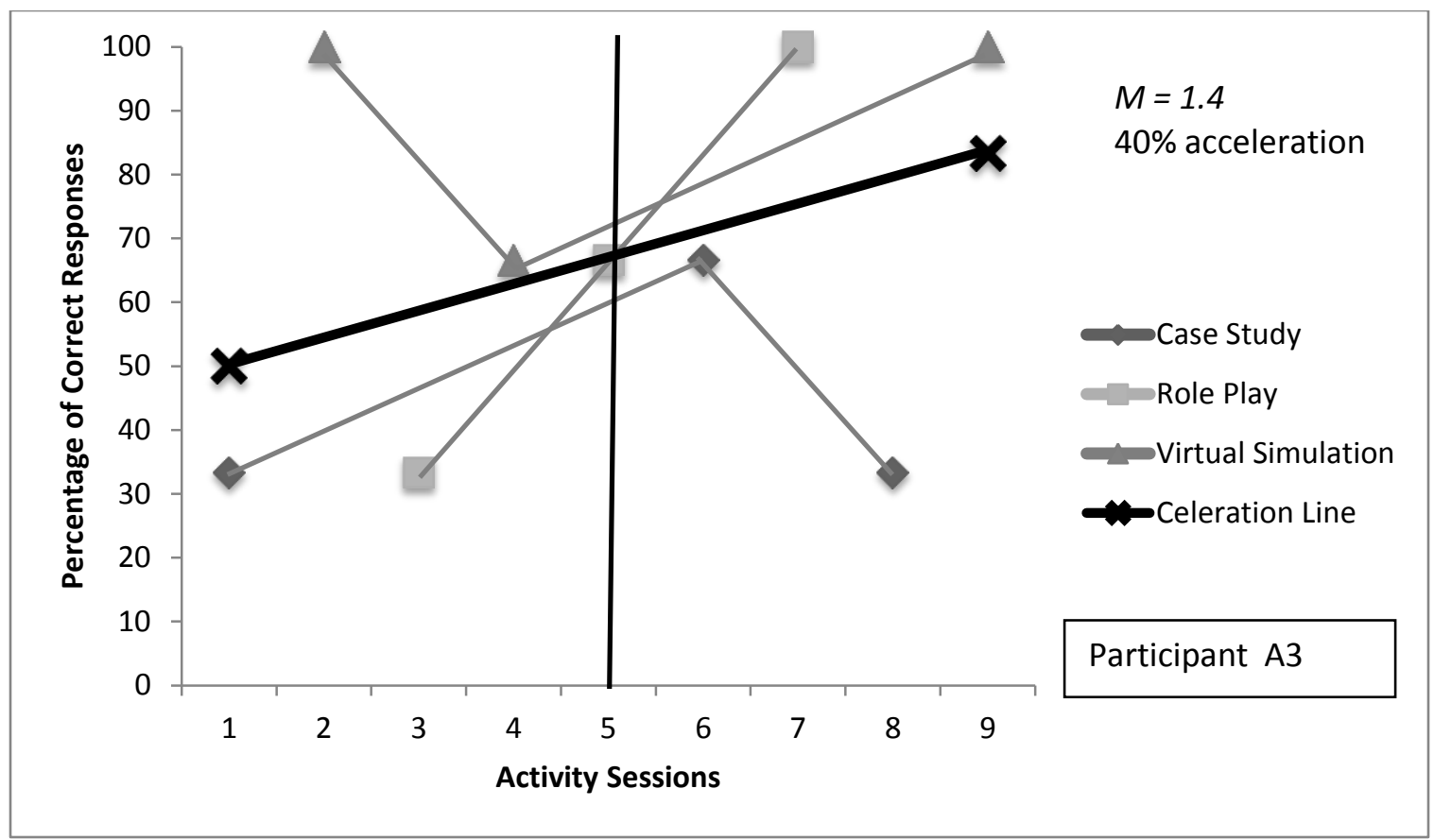

Figure 3. Participant A3: Celeration line indicating change in rate of performance over time, across all conditions.

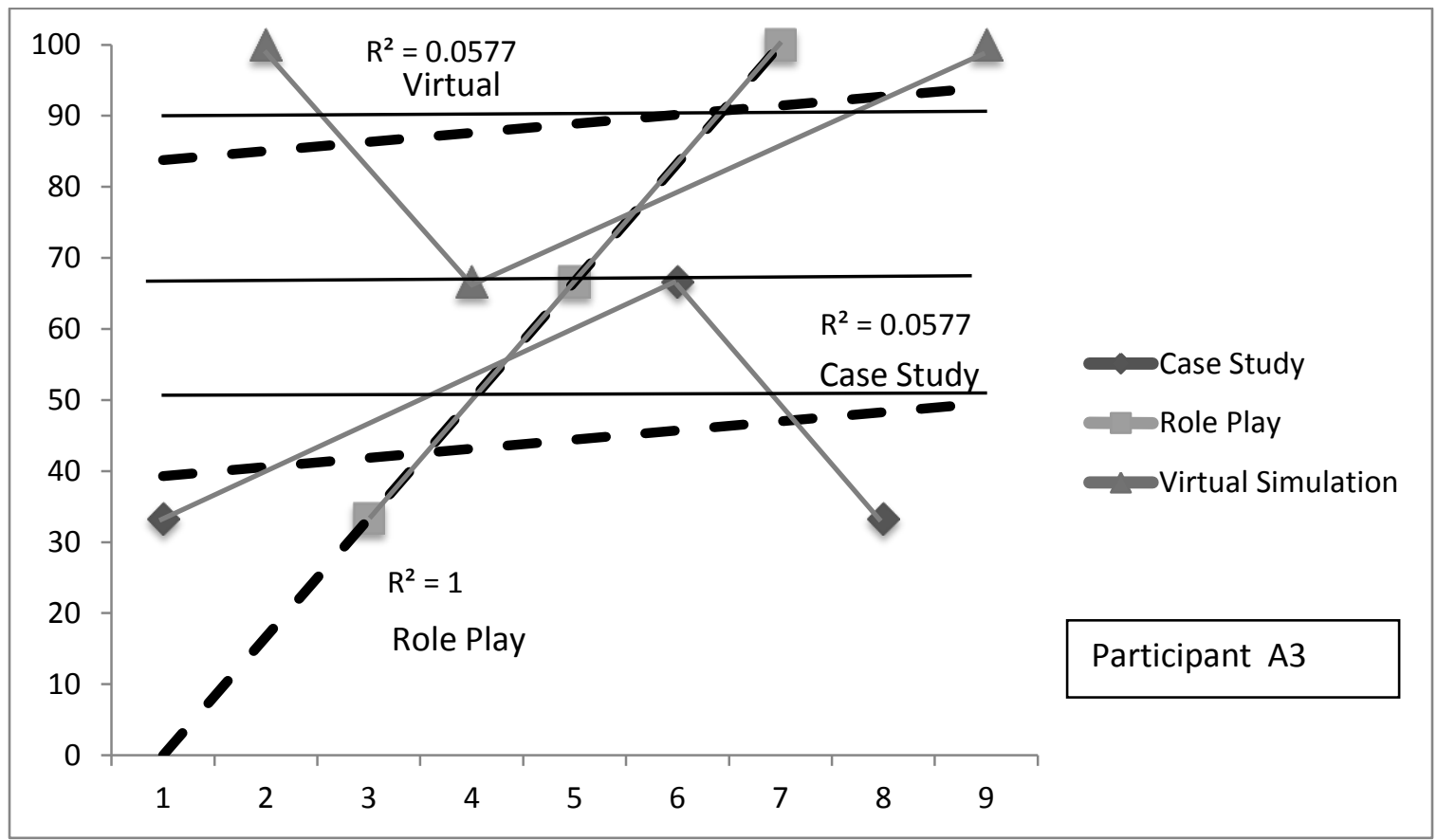

Figure 4. Participant A3: Trend, level, and $\mathrm{R}^{2}$ values across experimental conditions. 
Results of analysis for Participant B1. Figures 5 and 6 show results of data collected for Participant B1 across all treatments. The celeration line for Participant B1 was estimated to have a negative slope of -1.15 , or $-15 \%$, revealing deceleration in accuracy of responding over the duration of this study for this participant.

Figure 6, includes trend and level for each activity type. The data suggest a flat (or maintaining) trend during the Case Study condition, a decreasing trend during the Virtual Simulation condition, and a decreasing trend during the Role Play condition. Trend lines were analyzed by computing R-squared values, which were very low during the Virtual Simulation $\left(\mathrm{R}^{2}=0.05\right)$ and during the Role Play condition $\left(\mathrm{R}^{2}=0.08\right)$.

Based on the assessment of level, the treatments for Participant B1 seem to produce the following effect on performance, in order from most to least effective: Case Study, Virtual Simulation, Role Play $(M=88.89,66.67$, and 55.55, respectively). Levels calculated for this participant suggest that Case Study activities produced the most positive effect on performance. A visual representation of level for each of the three activities (see Figure 6) was utilized for determining how the $\mathrm{C}$-statistic analysis would take place.

C-statistic calculations for Participant B1 within the Role Play condition yielded a z score of -0.39 , indicating a $34.8 \%$ probability that other scores in a normal distribution fall below 0.39 , and a $p$ value of 0.65 , indicating no significance change in performance during the intervention. Calculations across Role Play and Case Study provided a z score of -0.17 , signifying a $43.2 \%$ probability that other scores would fall below -0.39 , and where $p=0.57$, thus showing no significant change across datasets. C-statistic was also calculated for the Virtual Simulation condition, providing a z score of -0.49 , signifying a $31.2 \%$ probability that other scores in a normal distribution would fall below -0.49 , and where $p=.67$ (no significance). A 
final calculation of across Virtual Simulation and Case Study conditions yielded a z score of .36 , indicating a $35.9 \%$ probability that other scores would fall below -0.36 where $p=0.64$, indicating that no significant change occurred across datasets. 


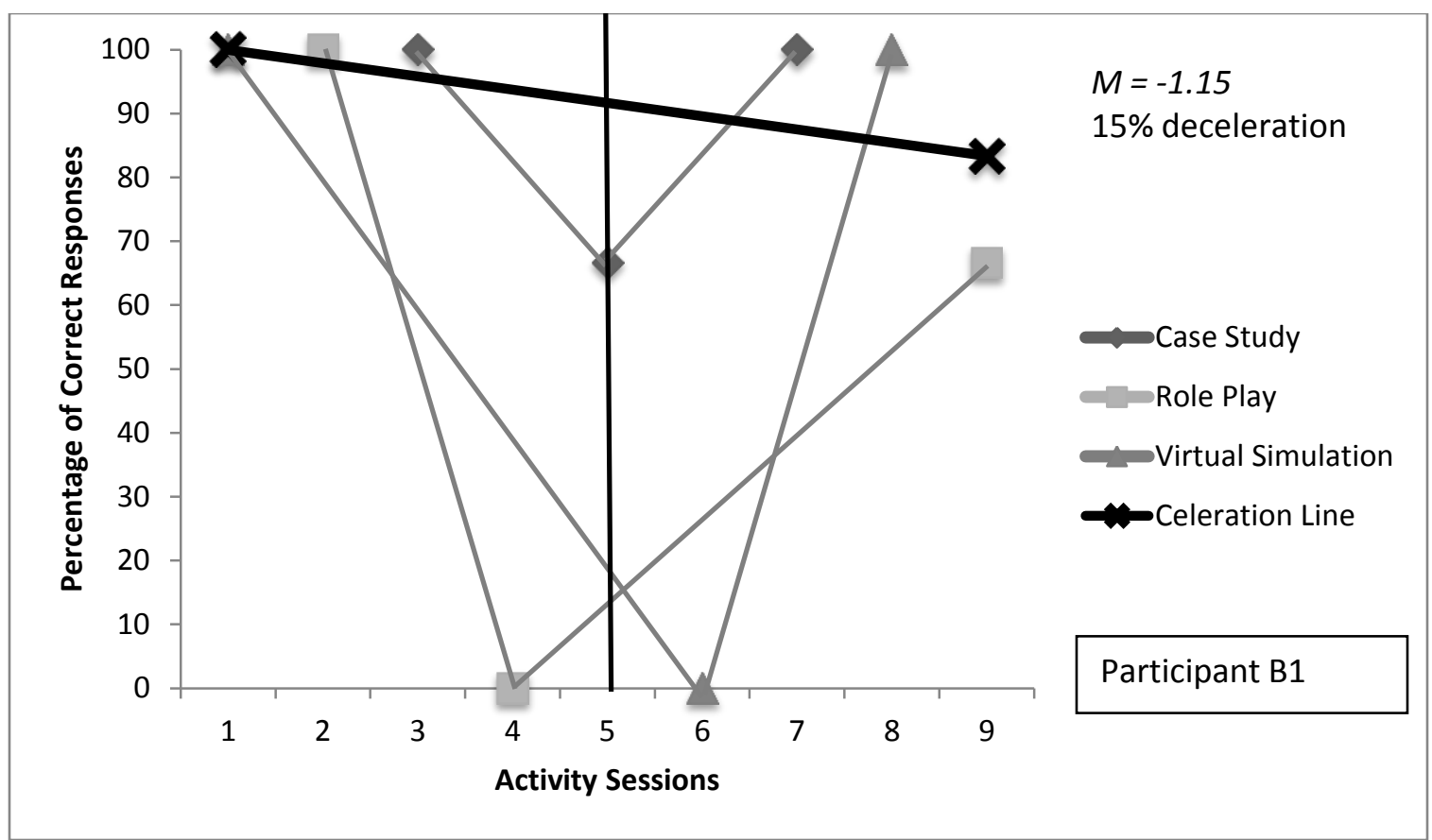

Figure 5. Participant B1: Celeration line indicating change in rate of performance over time, across all conditions.

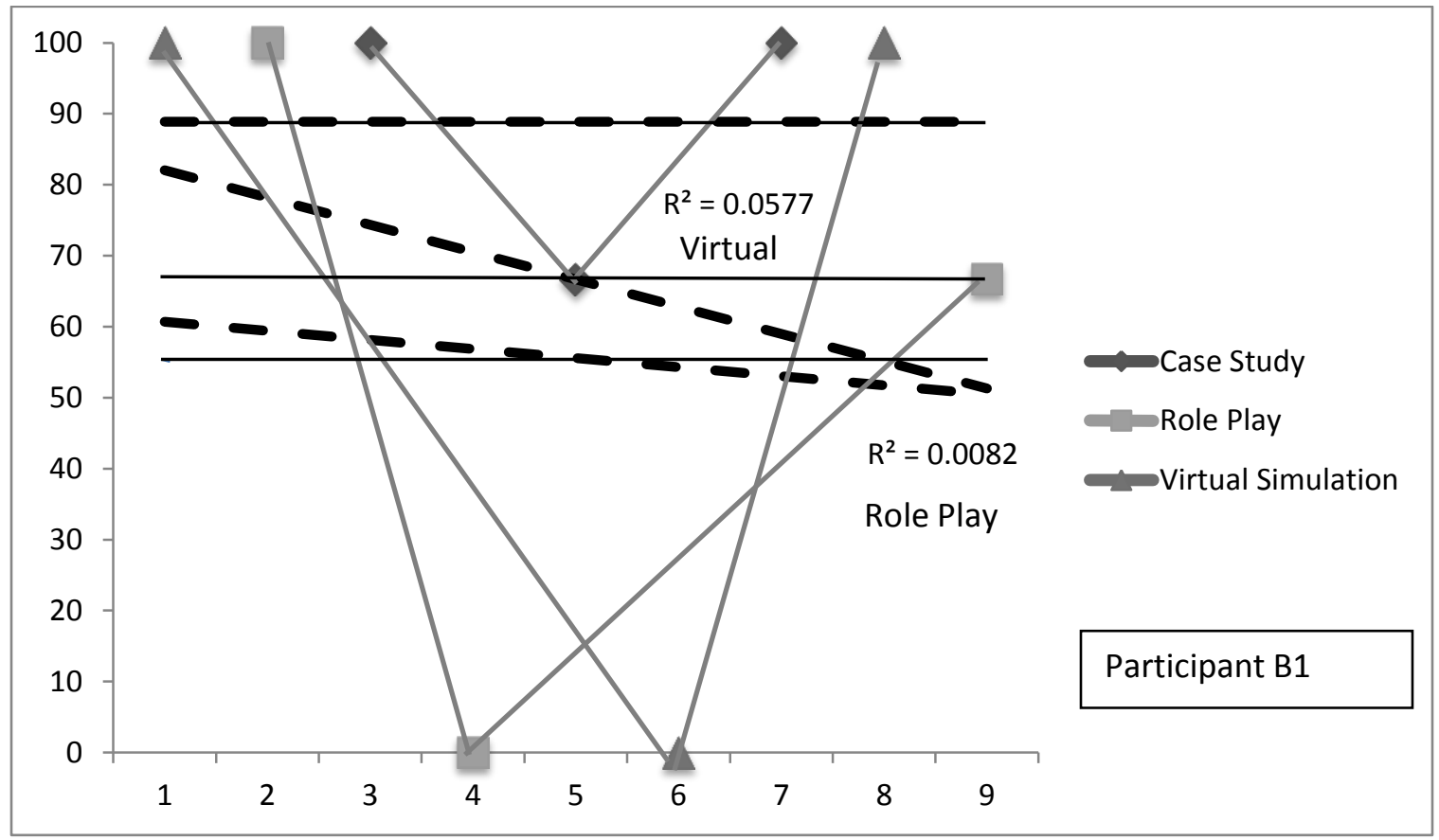

Figure 6. Participant B1: Trend, level, and $\mathrm{R}^{2}$ values across experimental conditions. 
Results of analysis for Participant B2. Figures 7 and 8 show results of data collected from Participant B2 across all treatments. The celeration line for Participant B2 was estimated to have a negative slope of -1.4 , or $+40 \%$, revealing deceleration in accuracy of responding over the duration of the study for this participant.

Figure 8 includes trend and level for each activity type. The data suggest a decreasing trend in performance during each of the three conditions. Once again, trend lines were analyzed by computing R-squared values, which were very low for Virtual Simulation $\left(R^{2}=0.06\right)$ and Role Play $\left(R^{2}=0.08\right)$ but highly accurate/predictive for Case Study $\left(R^{2}=0.75\right)$.

Based on the assessment of level, the treatments for Participant B2 seem to produce the following effect on performance, in order from most to least effective: Virtual Simulation, Role Play, and Case Study $(M=77.78,66.67$, and 44.44 , respectively). Levels calculated for this participant suggest that Virtual Simulation activities produced the most positive effect on performance. A visual representation of level for each of the three activities (see Figure 8) was again utilized for determining how the $\mathrm{C}$-statistic analysis would take place.

C-statistic calculations for Participant B2 within the Case Study condition yielded a z score of 0.25 , indicating a $59.8 \%$ probability that other scores in a normal distribution fall below 0.25 , and a $p$ value of 0.40 , indicating no significant change in performance during the intervention. Calculation across Case Study and Virtual Simulation provided a z score of -0.34 , signifying a $36.6 \%$ probability that other scores would fall below the -0.34 , and where $p=0.63$, thus showing no significant change across datasets. C-statistic was also calculated for the Role Play intervention, providing a $\mathrm{z}$ score of -0.25 , signifying a $40.1 \%$ probability that other scores in a normal distribution would fall below -0.25 , and $p=0.59$ (no significance). Calculations across Role Play and Virtual Simulation provided a z score of -0.45 , signifying a $32.6 \%$ probability of 
other scores falling below -0.45 , and $p=0.67$, indicating that no significant change occurred across the data sets.

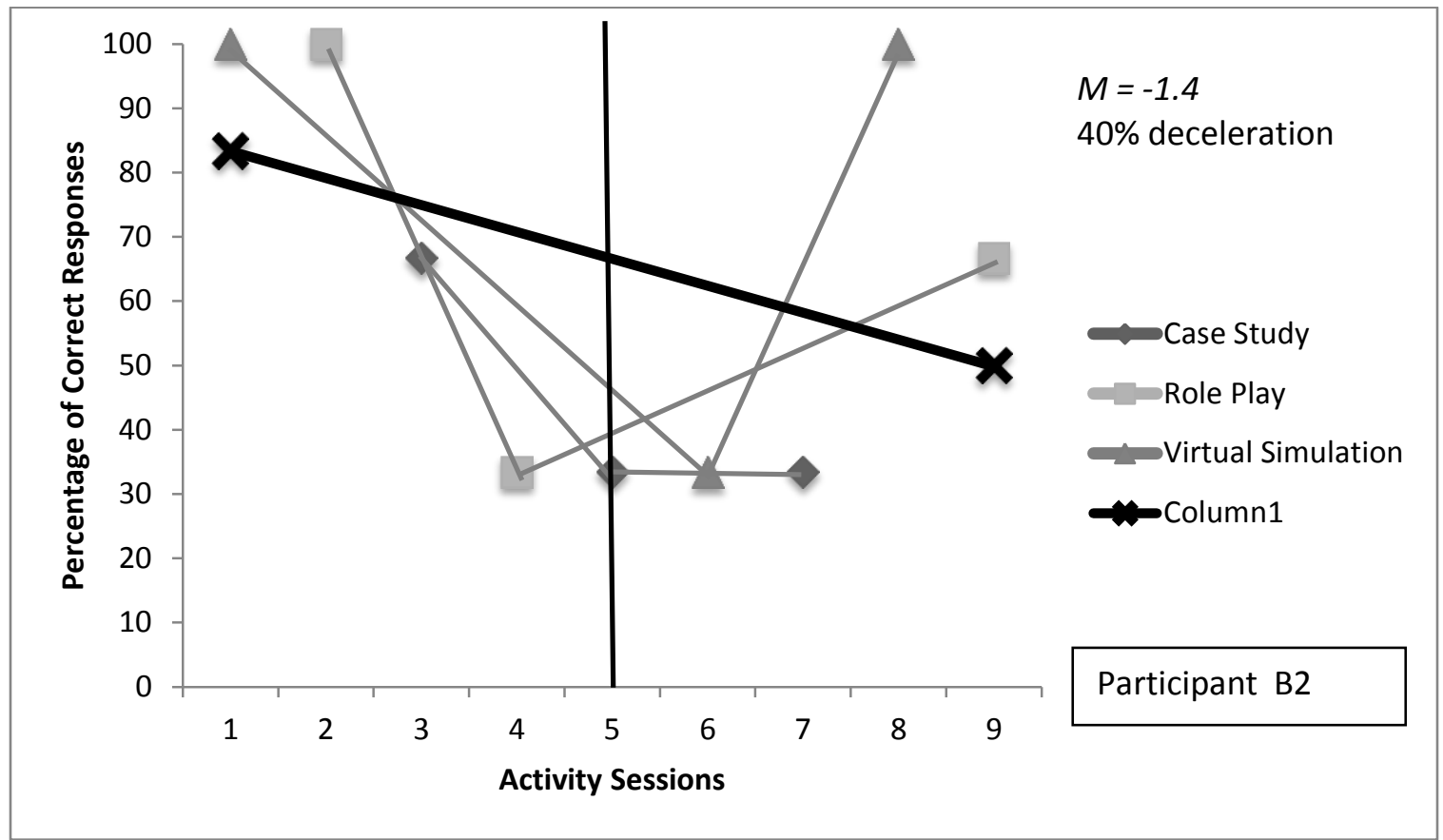

Figure 7. Participant B2: Celeration line indicating change in rate of performance over time, across all conditions.

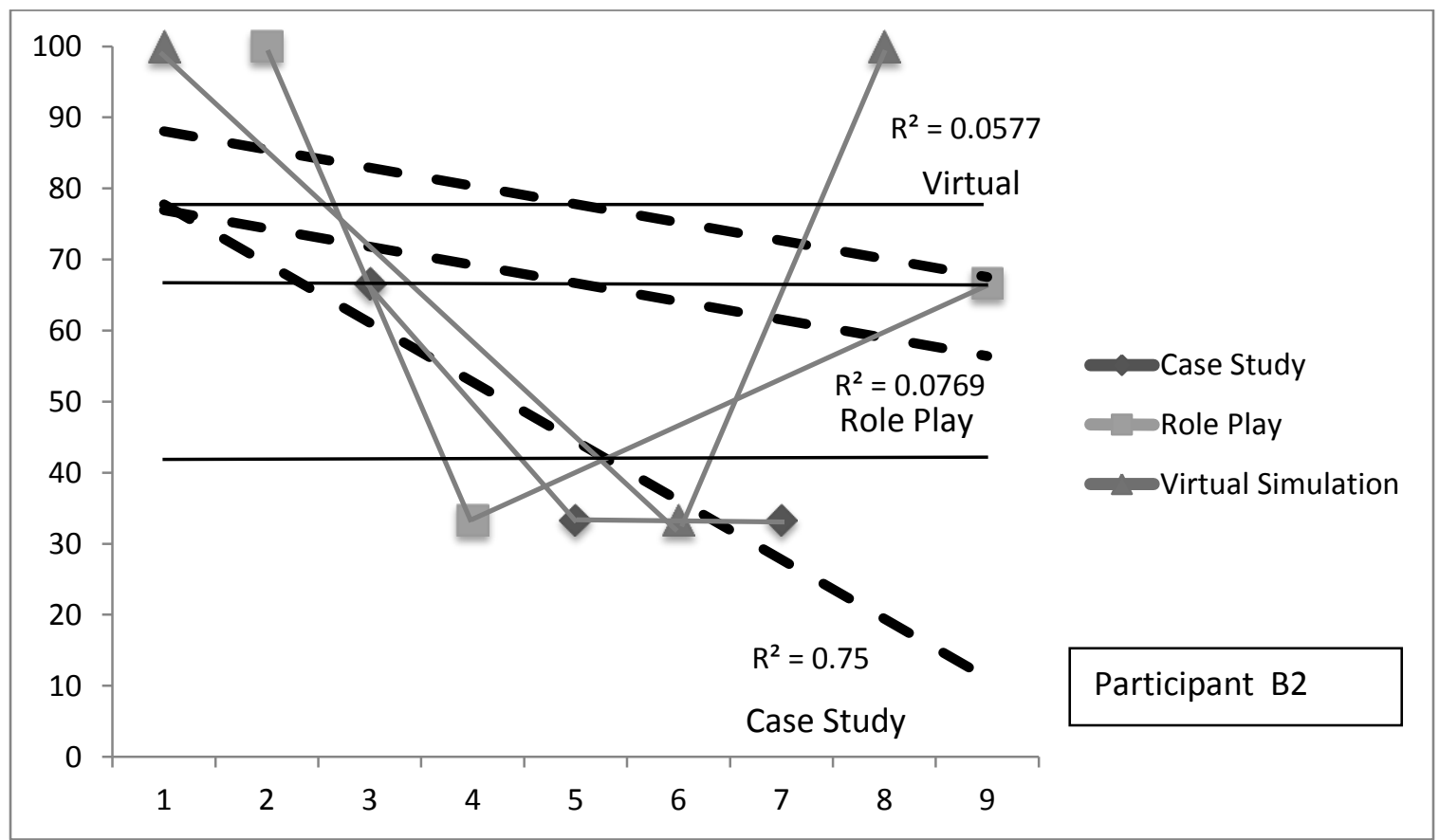

Figure 8. Participant B2: Trend, level, and $\mathrm{R}^{2}$ values across experimental conditions. 
Results of analysis for Participant B3. Figure 9 and 10 show results of data collected for Participant B3 across all treatments. The celeration line for Participant B3 is flat, indicating no slope. Therefore, no cumulative acceleration or deceleration in accuracy of responding over time was indicated for this participant (i.e., slope $=1$ ).

Figure 10, includes trend and level for each activity type. The data suggest an increasing trend in performance during the Virtual Simulation condition, a decreasing trend during the Role Play condition, and flat (or maintaining) trend during the Case Study condition. Once again, trend lines were analyzed by computing R-squared values, which were very low for both the Role Play and Virtual Simulation conditions $\left(\mathrm{R}^{2}=0.06\right)$ but not assessed for the Case Study condition, because there was not an increase or a decrease in performance.

Based on the assessment of level, the treatments for Participant B3 seem to produce the following effect on performance, in order from most to least effective: Role Play and Virtual Simulation both with the same mean, then Case Study ( $M=77.78,77.78,55.56$, respectively). Levels calculated for this participant suggest that Role Play and Virtual Simulation activities produced the most positive effect on performance. A visual representation of level for each of the three activities (see Figure 10) was again utilized for determining how the $\mathrm{C}=$ statistic analysis would take place.

C-statistic calculations for Participant B3 within the Case Study condition, yielded a z score of -0.5 , indicating a $30.9 \%$ probability that other scores in a normal distribution fall below -0.5 , and a $p$ value of 0.69 , indicating no significant change in performance during the intervention. Calculation across Case Study to Role Play and Virtual Simulation provided a z score of 0.5 , signifying a $69.2 \%$ probability that other scores would fall below the 0.5 , and $p=$ 0.30 , indicating that no significant change occurred across datasets. 


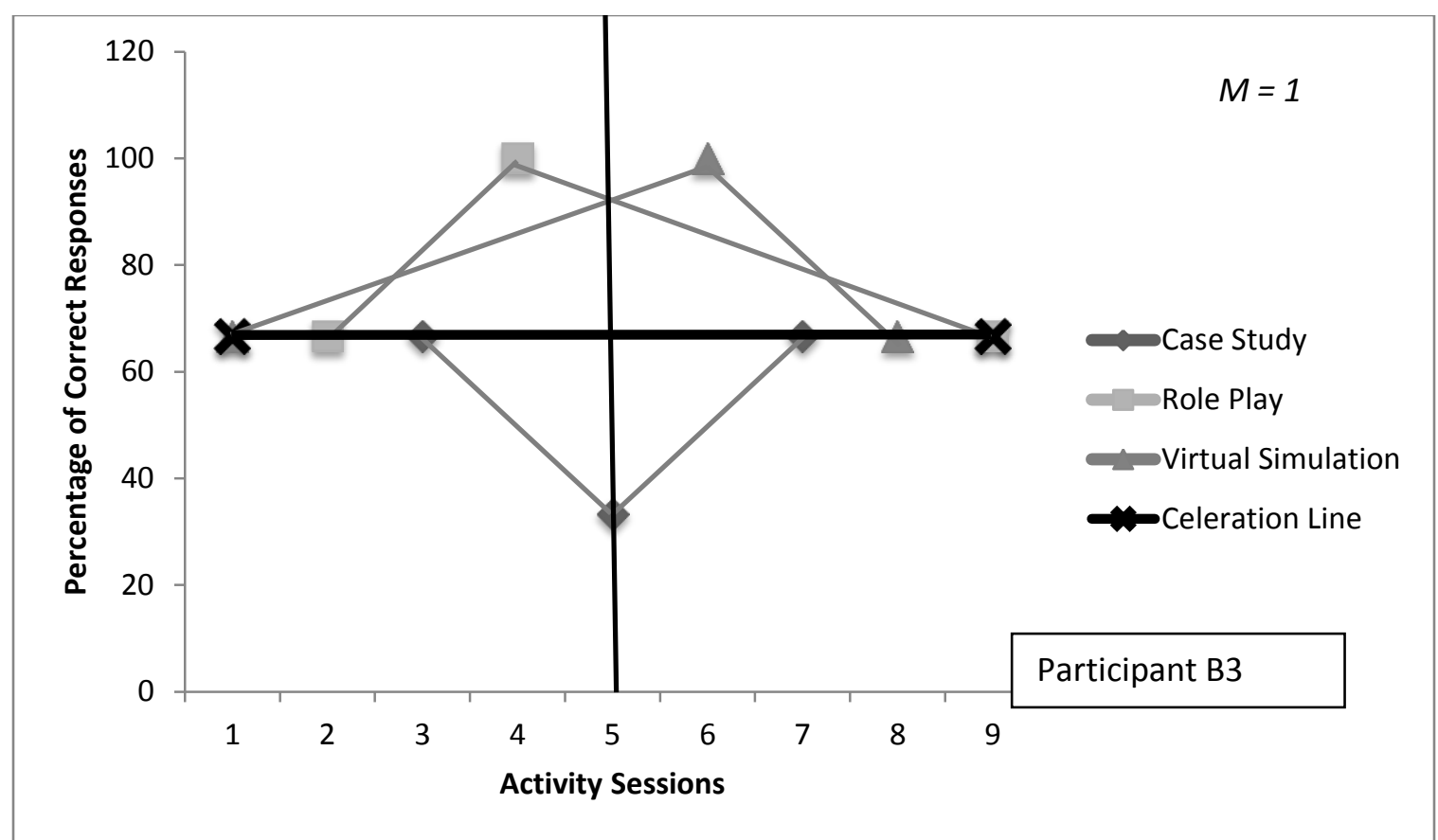

Figure 9. Participant B3: Celeration line indicating change in rate of performance over time, across all conditions.

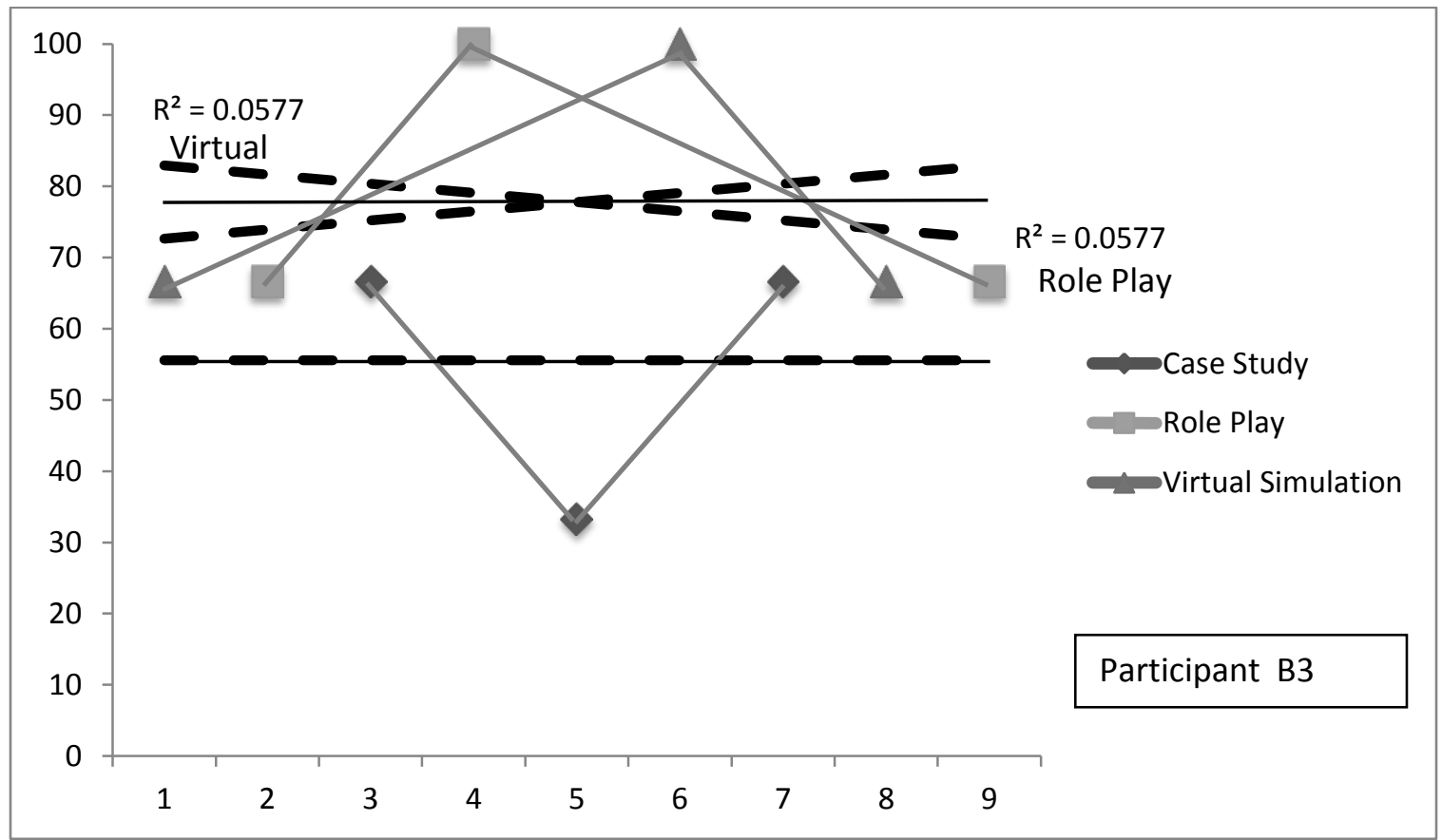

Figure 10. Participant B3: Trend, level, and $\mathrm{R}^{2}$ values across experimental conditions. 
Results of analysis for Participant C1. Figures 11 and 12 show the data collected for Participant C1 across all treatments. The celeration line for Participant $\mathrm{C} 1$ was estimated to have a negative slope of 1.2 , indicating a $-20 \%$ deceleration of responding over the duration of the study for this participant.

Figure 12 includes trend and level for each activity type. The data suggest an increasing trend in performance during the Virtual Simulation condition, a decreasing trend during Case Study, and a decreasing trend during Role Play. Once again, trend lines were analyzed by computing R-squared values, which were low for Case Study $\left(\mathrm{R}^{2}=0.08\right)$ and Virtual Simulation $\left(\mathrm{R}^{2}=0.3\right)$ but highly accurate/predictive for Role Play $\left(\mathrm{R}^{2}=0.92\right)$.

Based on the assessment of level, the treatments for Participant $\mathrm{C} 1$ seem to produce the following effect on performance, in order from most to least effective: Case Study and Virtual Simulation with the same mean, then Role Play $(M=66.67,66.67,44.44$, respectively). Levels calculated for this participant suggest that Role Play or Case Study activities produced the most positive effect on performance. A visual representation of level for each of the three activities (see Figure 12) was again utilized for determining how the C-statistic analysis would take place.

C-statistic calculations for Participant $\mathrm{Cl}$ within the Role Play condition yielded a z score of 0.25 , indicating a $59.8 \%$ probability that other scores in a normal distribution fall below 0.25 , and a $p$ value of 0.40 , indicating no significant change in performance during the intervention. Calculations across Role Play and Virtual Simulation provided a z score of -0.05, signifying a $48 \%$ probability that other scores would fall below -0.05 , and $p=0.52$ (no significance). Further calculations across Role Play and Case Study provided a z score of -0.5 , signifying a $30.8 \%$ probability that other scores would fall below -0.5 , and $p=.69$ (no significance). A final calculation across Case Study and Virtual Simulation provided a z score of -0.25 , signifying a 
$40 \%$ probability that other scores would fall below -0.25 , and $p=0.60$, showing that no significant change occurred across the datasets.

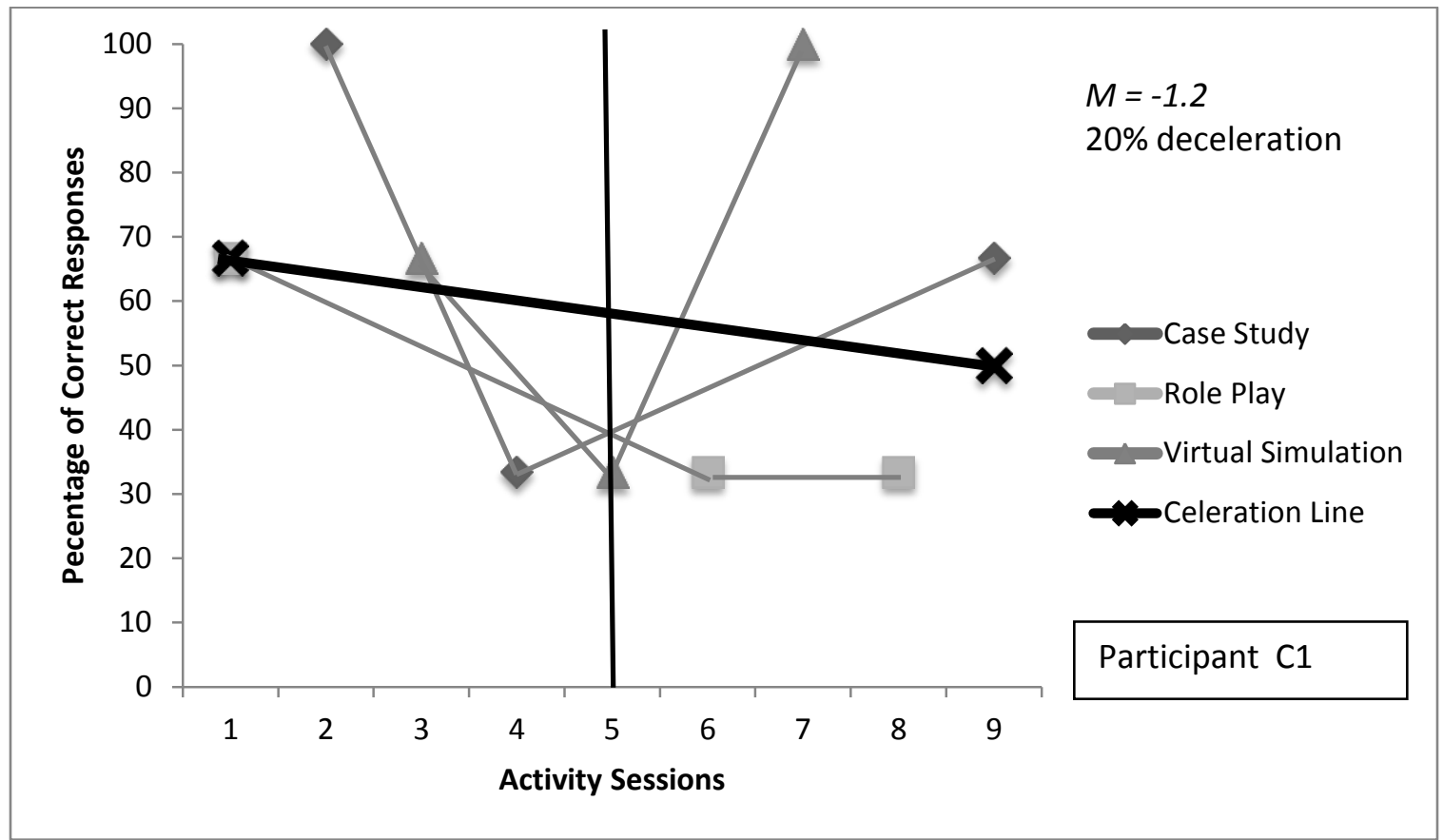

Figure 11. Participant C1: Celeration line indicating change in rate of performance over time, across all conditions.

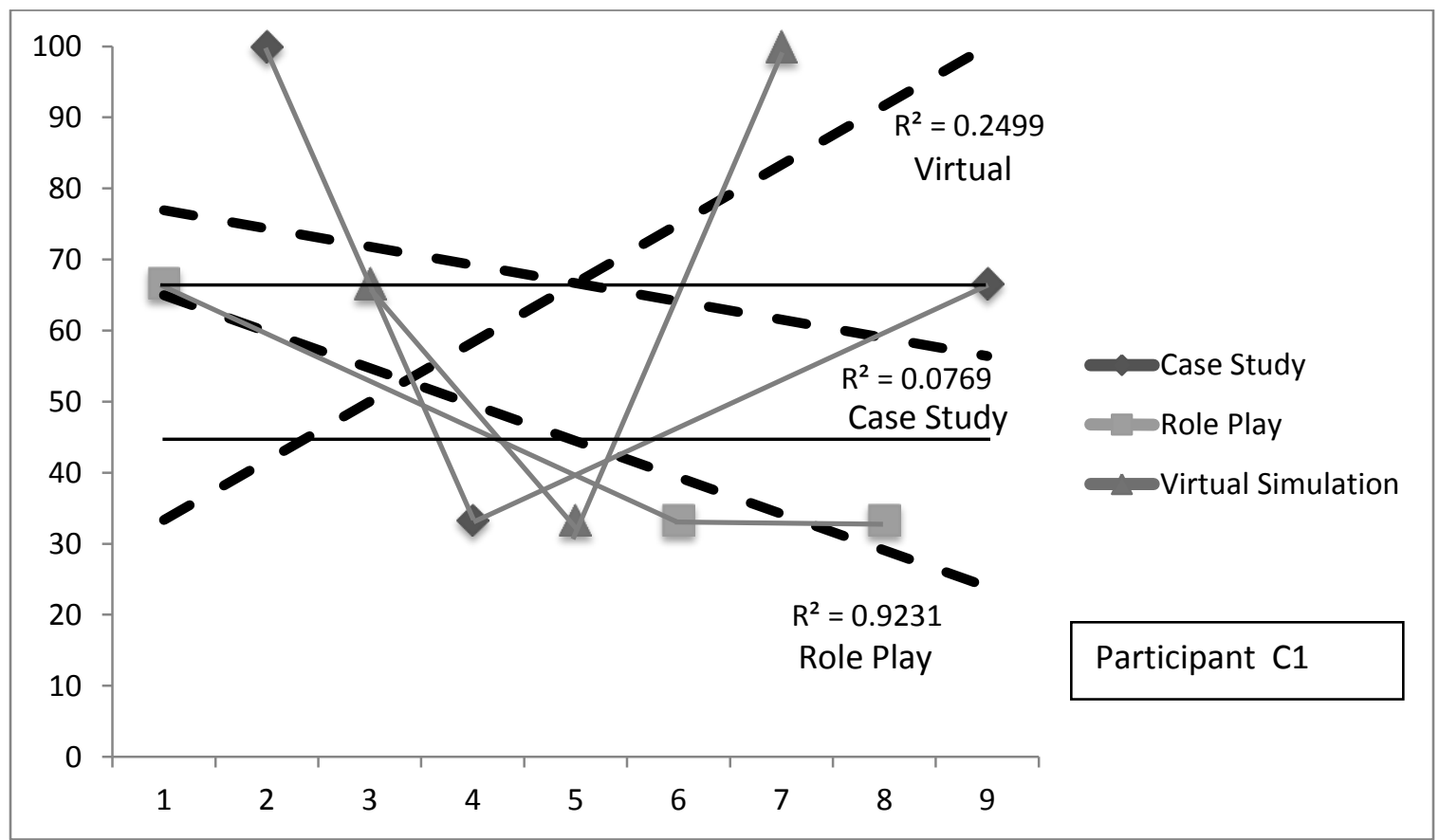

Figure 12. Participant $\mathrm{C} 1$ : Trend, level, and $\mathrm{R}^{2}$ values across experimental conditions. 
Results of analysis for Participant C2. Figures 13 and 14 show the data collected for Participant C2 across all treatments. The celeration line for Participant was estimated to have a positive slope of 1.4 , or $+40 \%$, revealing acceleration in accuracy of responding over the duration of the study for this participant.

Figure 14 includes trend and level for each activity type. The data suggest an increasing trend in performance during the Case Study and Role Play conditions, and a decreasing trend during the Virtual Simulation condition. Once again, trend lines were analyzed by computing Rsquared values, which was low for the Role Play condition $\left(\mathrm{R}^{2}=0.06\right)$ but highly accurate/predictive for the Virtual Simulation condition $\left(\mathrm{R}^{2}=0.75\right)$ and the Case Study condition $\left(\mathrm{R}^{2}=0.92\right)$

Based on the assessment of level, the treatments for Participant C2 seem to produce the following effect on performance, in order from most to least effective: Virtual Simulation, then Role Play and Case Study with the same mean. $(M=77.78,44.44,44.44$, respectively). Levels calculated for this participant suggest that Virtual Simulation produced the most positive effect on performance. A visual representation of level for each of the three activities (see Figure 14) was again utilized for determining how the $\mathrm{C}$-statistic would take place.

The C-statistic calculations for Participant C2 within the Case Study condition yielded a z score of 0.25 , indicating a $59.8 \%$ probability that other scores in a normal distribution fall below 0.25 , and a $p$ value of 0.40 , indicating no significant change in performance during intervention. Calculation across Case Study and Virtual Simulation provided a z score of 0.47 , signifying a $68.1 \%$ probability that other scores would fall below 0.47 , and $p=0.32$ (no significance). Calculations within the Role Play condition yielded a z score of -0.5 , indicating a $31 \%$ probability that other scores with a normal distribution would fall below -0.5 , and $p=.69$ (no 
significance). A final calculation across Role Play and Virtual Simulation provided a z score of 0.05 , indicating a $48 \%$ probability that other scores would fall below -.05 , and $p=.52$, indicating that no significant change occurred across datasets. 


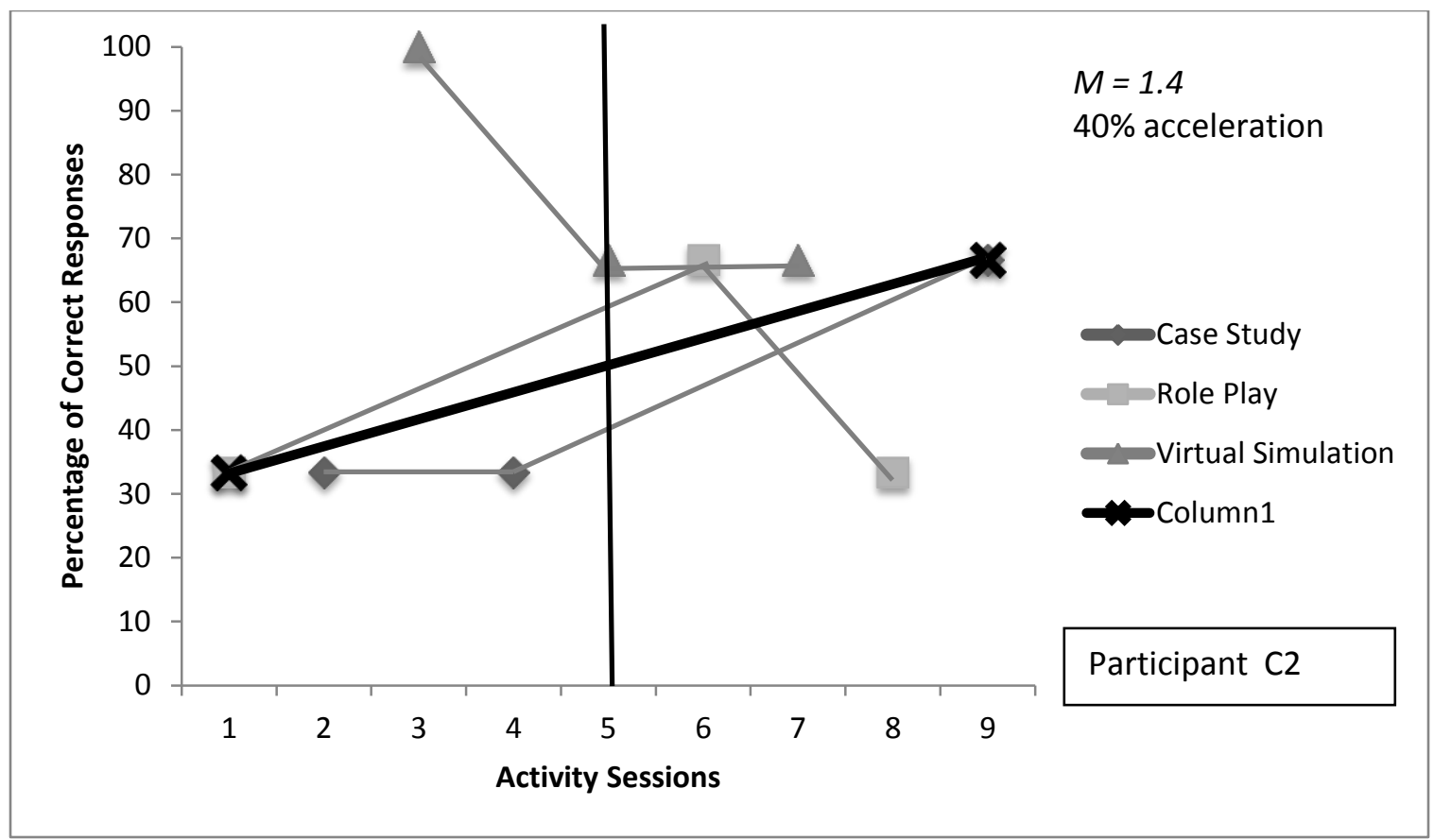

Figure 13. Participant $\mathrm{C} 2$ : Celeration line indicating change in rate of performance over time, across all conditions.

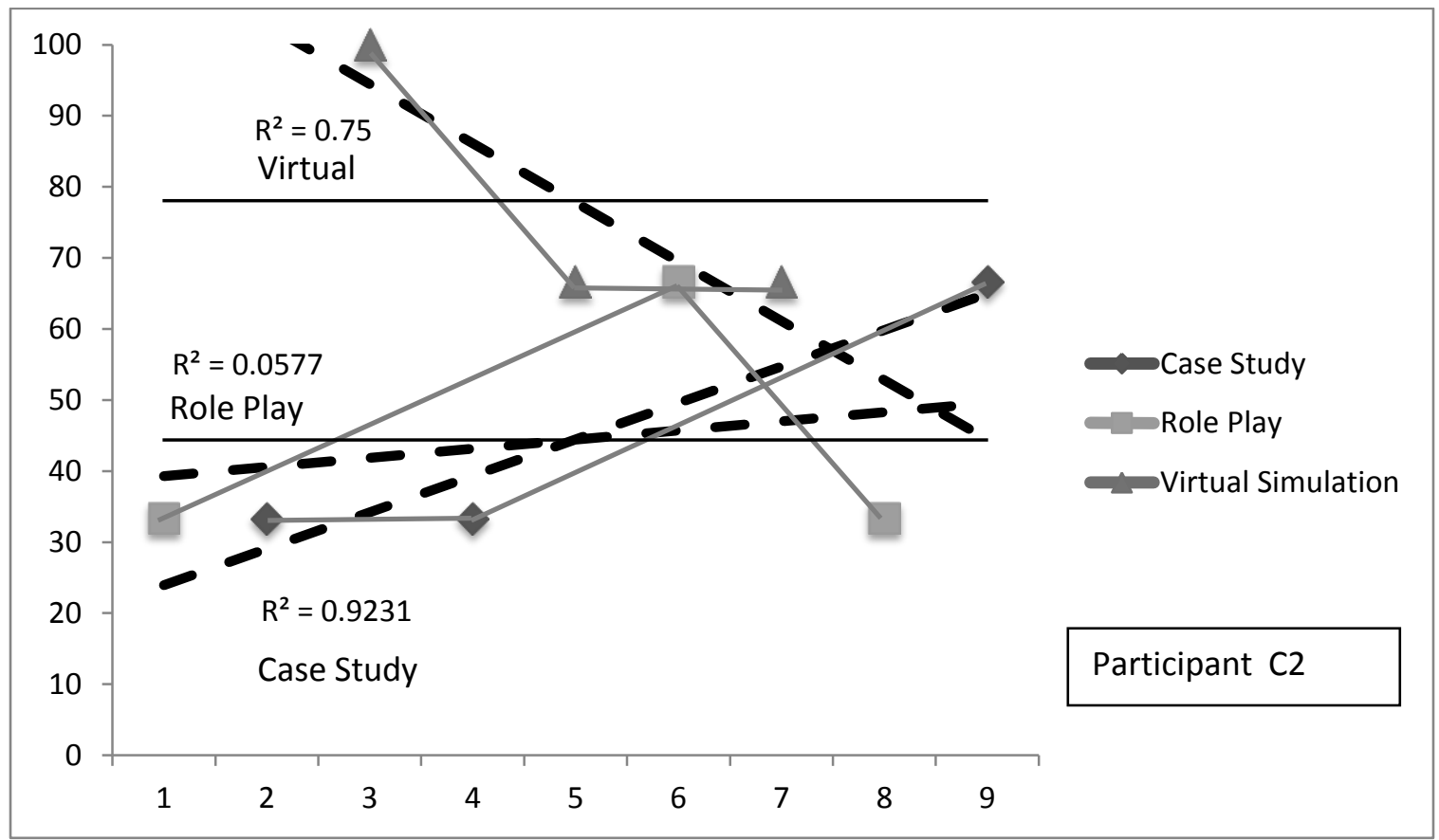

Figure 14. Participant C2: Trend, level, and $\mathrm{R}^{2}$ values across experimental conditions. 
Results of analysis for Participant C3. Figures 15 and 16 show the data collected for Participant C3 across all treatments. The celeration line for Participant was estimated to have negative slope of 1.2 , or $-20 \%$, revealing deceleration in accuracy of responding over the duration of the study for this participant.

Figure 16 includes trend and level for each activity type. The data suggest an increasing trend in performance during the Case Study condition, and decreasing trends during Virtual Simulation and Role Play conditions. Once again, trend lines were analyzed by computing Rsquared values, which were highly accurate/predictive for Virtual Simulation $\left(R^{2}=0.75\right)$ and Role Play $\left(\mathrm{R}^{2}=0.94\right)$ but low for Case Study $\left(\mathrm{R}^{2}=0.3\right)$.

Based on the assessment of level, the treatments for Participant C3 seem to produce the following effect on performance, in order from most to least effective: Virtual Simulation, Role Play, and Case Study $(M=77.78,66.67$, and 55.56, respectively). Levels calculated for this participant suggest that Virtual Simulation activities produced the most positive effect on performance. A visual representation of level for each of the three activities (see Figure 16) was again utilized for determining how the C-statistic analysis would take place.

C-statistic calculations for Participant C3 within the Case Study condition yielded a z score of -0.39 , indicating a $34.8 \%$ probability that other scores in a normal distribution fall below -0.39 , and $p$ value of 0.65 , indicating no significant change in performance during intervention. Calculation across Case Study and Virtual Simulation provided a z score of -.17, indicating a $43.3 \%$ probability that other scores would fall below -.17 , and a $p=0.57$ (no significance). Cstatistic calculated within the Role Play condition yielded a z score of 0.5 , indicating a $69.2 \%$ probability that other scores would fall below 0.5 , and a $p=.31$ (no significance). A final calculation across Role Play and Virtual Simulation provided a z score of -.24, signifying a 
$40.5 \%$ probability that other scores would fall below -.24 , and a $p=.59$, indicating that no significant change occurred across the datasets.

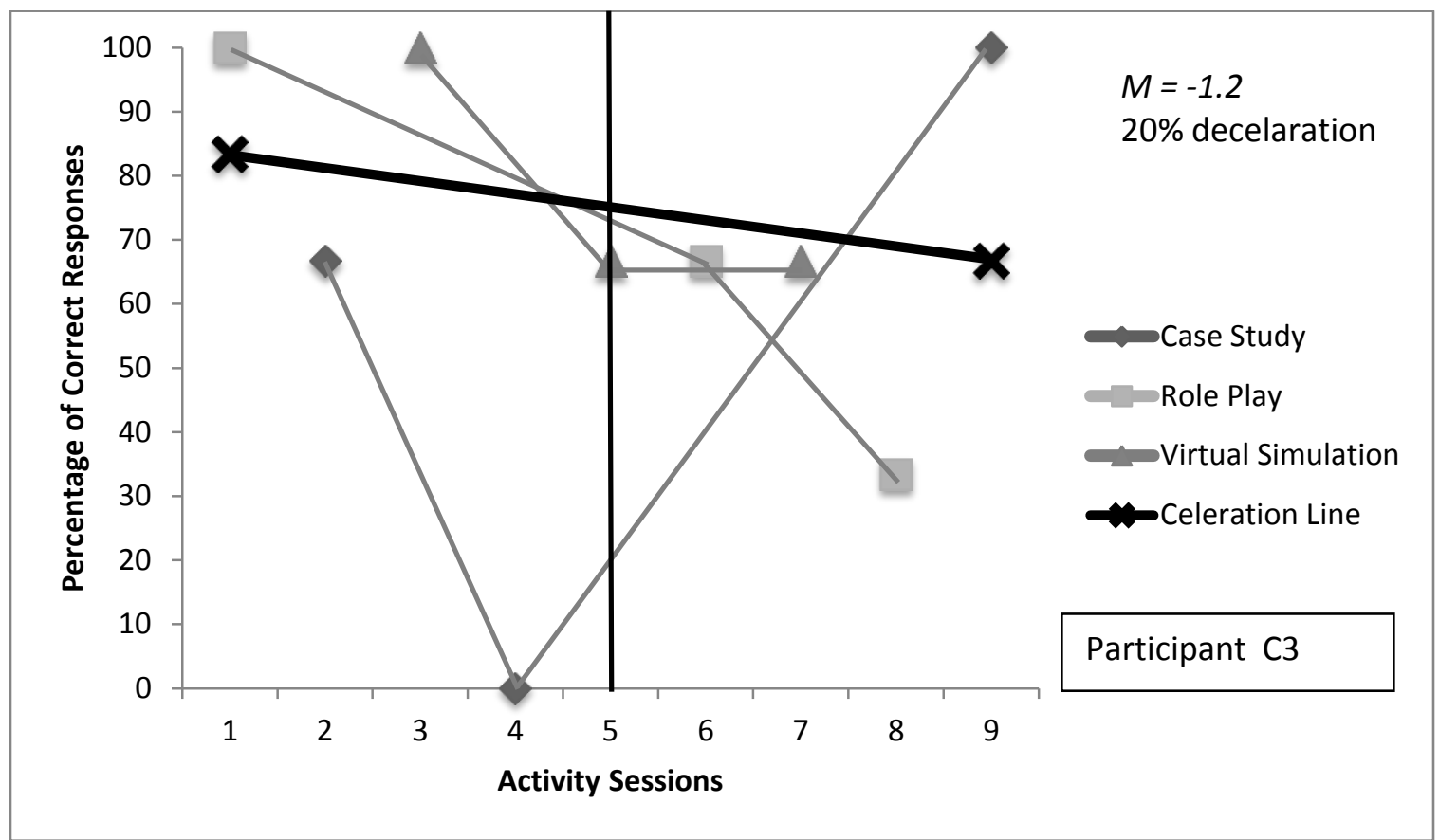

Figure 15. Participant C3: Celeration line indicating change in rate of performance over time, across all conditions.

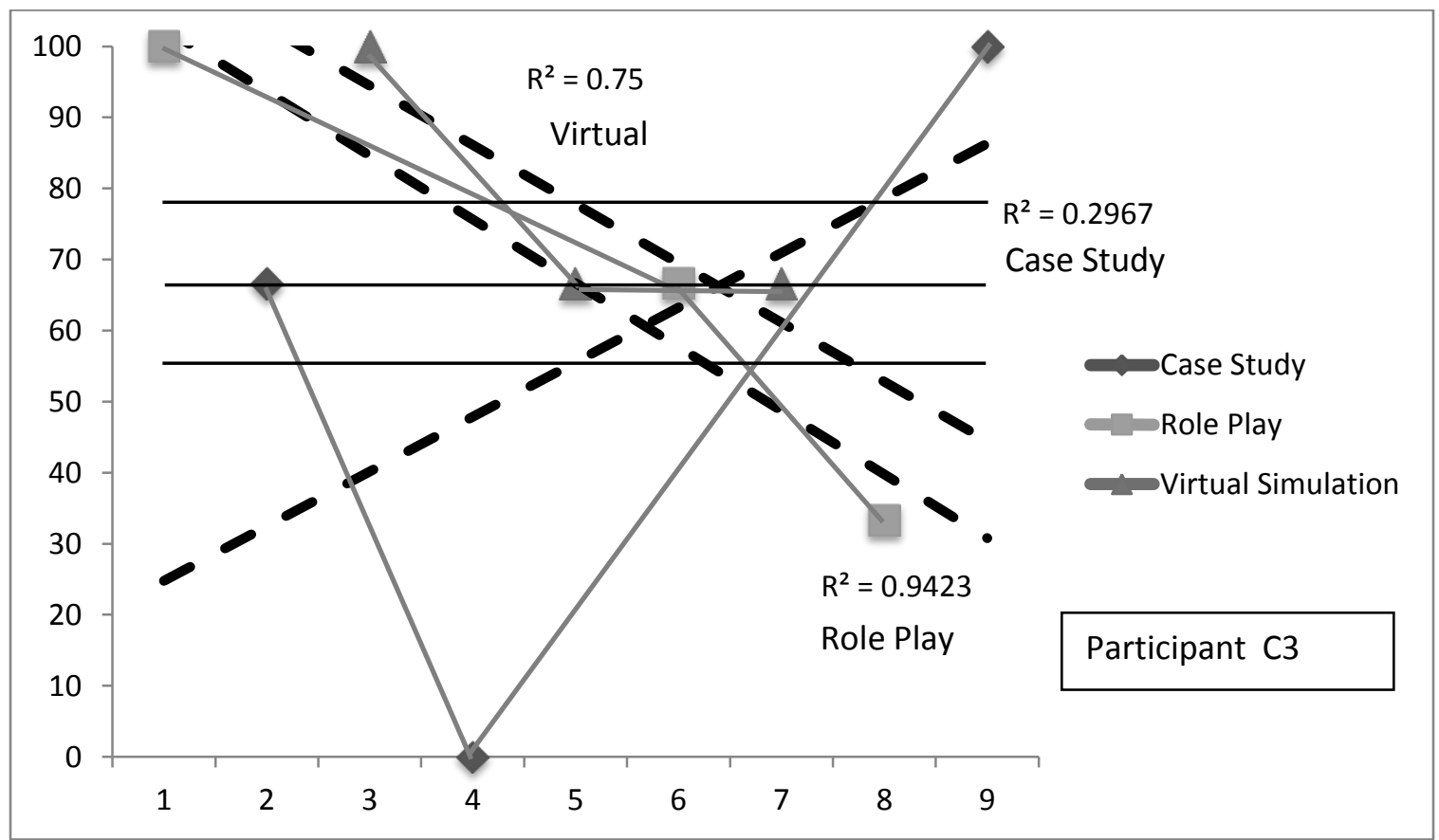

Figure 16. Participant C3: Trend, level, and $\mathrm{R}^{2}$ values across experimental conditions. 
Results of group analysis. Descriptive analyses of mean were calculated to demonstrate total performance of all participants across each activity type. For participation in Case Study/Automated Feedback activities, $12.5 \%$, or one out of eight participants, responded each week with accuracy of $66.67 \%$ or higher to bullying behaviors. For Role Play/Peer Discussion activities, $62.5 \%$, or five out of eight participants, responded each week with accuracy of $66.67 \%$ or higher to bullying behaviors. For Virtual Simulation/Instructor Feedback activities, 87.5\%, or seven out of eight participants responded each week with accuracy of $66.67 \%$ or higher to bullying behaviors.

Participants' combined percentages of accurate responses for each type of application activity are represented in Table 3, which can be found under the subheading for Research Question 2. Participants' percentages of accuracy in responding to Case Study/Automated Feedback activities ranged from $44.44 \%-88.89 \%$. The total percentage of accurate responses for all participants during Case Study/Automated Feedback activities was 55.56\%. Participants' percentages of accuracy in responding to Role Play/Peer Discussion activities ranged from $44.44 \%-77.78 \%$. The total percentage of accurate responses for all participants during Role Play/Peer Discussion activities was 58.33\%. Participants' percentages of accuracy in responding to Virtual Simulation/Instructor feedback activities ranged from $66.67 \%-88.89 \%$. The total percentage of accurate responses for all participants during Virtual Simulation/Instructor Feedback was $75 \%$. The mean values described suggest that overall participants responded most accurately when utilizing the TeachLive ${ }^{\mathrm{TM}}$ lab for Virtual Simulation/Instructor Feedback activities.

\section{Question 2: Differences in Participant Responses between both Pre- and Post-Instructor}

\section{Feedback}


Data from AAS were compiled to determine the relationship between participation in feedback activities and participants' choices when asking whether or not they would change their response types if presented with similar instances of bullying in the future. Several measurement tools were used to analyze participant responses during pre- and post-feedback. A Chi-squared analysis compared grouped differences in proportions of correct responses for both pre- and post-feedback conditions. Cochran's Q test was used to compare pre-feedback accuracy in responding across the three experimental conditions (Case Study, Role Play, and Virtual Simulation). Additionally, the McNemar test was used to independently compare pre- and postfeedback accuracy in responding for each of the three experimental conditions. Table 3, provides a visual representation of participant responses during each experimental condition. In a final attempt to understand participants' reasons for choosing specific responses, AAS were examined to identify the themes within participant descriptions of their decision making processes.

Results of Chi-squared test. Proportions of correct and incorrect responses during preand post-feedback conditions were compared across the three types of feedback (Automated Feedback, Peer Discussion, and Instructor Feedback). Results of this test yielded no significance $\left[x^{2}(2, N=324)=0.75, p=0.69\right]$. Although correct responses increased with each type of feedback, no one type of feedback produced a significantly different proportion of correct responding as compared to pre-feedback performance.

Results of Cochran's $\mathbf{Q}$ test. This test was used as a means of comparing accuracy of responding during pre-feedback and was calculated across the three experimental conditions (Case Study, Role Play, and Virtual Simulation). Results of this test indicated a significantly higher number of accurate responses during Virtual Simulation activities $(p=0.041)$, as compared with participant responses in the other two pre-feedback conditions. A significant 
number of accurate responses to TeachLivE activities were recorded for participants prior to participating in feedback.

Results of the McNemar test. This test was used to compare accuracy of responding during pre- and post-feedback for each of three conditions or activity types. The test indicated positive results for each of the three conditions. Post-feedback accuracy in responding during the Role Play condition was found to be significantly better $(p=0.0001)$ than that during prefeedback. Responding during the Case Study condition was also found to be significantly more accurate $(p=.0001)$ during the post-feedback phase, as was post-feedback responding during the Virtual Simulation condition $(p=.001)$. Accuracy of responding for all three conditions was significantly improved from pre- to post-feedback.

Table 3.

Breakdown of Accurate Responses Pre- and Post-Feedback

\begin{tabular}{lcccc}
\hline $\begin{array}{l}\text { Activity } \\
\text { Type of Feedback }\end{array}$ & $\begin{array}{c}\text { Correct } \\
\text { Out of } \mathbf{7 2}\end{array}$ & $\begin{array}{c}\text { \% of Accurate } \\
\text { Responses }\end{array}$ & $\begin{array}{c}\text { Correct } \\
\text { Out of } \mathbf{7 2}\end{array}$ & $\begin{array}{c}\text { \% of Accurate } \\
\text { Responses }\end{array}$ \\
\hline $\begin{array}{l}\text { Case Study } \\
\text { Automated } \\
\text { Feedback }\end{array}$ & 40 & $\mathbf{5 5 . 6 0 \%}$ & 58 & $\mathbf{8 0 . 6 0 \%}$ \\
$\begin{array}{l}\text { Virtual } \\
\text { Simulation } \\
\text { Instructor } \\
\text { Feedback }\end{array}$ & 54 & $\mathbf{7 5 \%}$ & 66 & $\mathbf{9 1 . 7 0 \%}$ \\
$\begin{array}{l}\text { Role Play } \\
\text { Peer Discussion }\end{array}$ & & & & \\
\hline
\end{tabular}

Participants' reasons for choosing specific responses. In addition to analyzing changes in responses attributed to specific types of feedback, participants also reported reasons for choosing specific responses. This was a qualitative measure assessed by determining themes within the context of participants' explanations found on AASs for all Role Play and Virtual 
Simulation sessions and printed responses from all Case Study sessions. Participants were asked to explain reasons for responding to bullying behaviors. This occurred both before and after reading or participating in feedback. Explanations for each of the four response options (Respond by Gesture, Respond by Verbal Directive, Ignore Completely, and Ignore in the Moment, but with Intentions of Addressing the Behavior at a Later Time) were analyzed and categorized by theme in order to make inferences regarding participants' reasons for choosing specific response options.

When analyzing participant responses for why they chose to respond by gesture, three themes emerged: awareness, uncertainty, and least disruptive response. See Table 4 for a list of participant comments related to the three themes. 
Table 4.

Themes to Describe Reasons Participants Chose to Respond by Gesture

\begin{tabular}{|c|c|c|c|}
\hline & $\begin{array}{l}\text { Number of } \\
\text { Related } \\
\text { Responses }\end{array}$ & $\begin{array}{l}\text { Percentage of } \\
\text { Comments } \\
\text { Related to } \\
\text { Theme }\end{array}$ & Participants' Comments \\
\hline awareness & 9 & $47 \%$ & $\begin{array}{l}\text { A1: "to let them know I am aware of what is going on" } \\
\text { A1: "to assure the boy I am watching and is aware of his } \\
\text { actions" } \\
\text { A1: "it will allow bullies to know I am aware of the } \\
\text { situation" } \\
\text { A3: "to let them know that I may know something" } \\
\text { A3: "to show that I noticed the behavior,..." } \\
\text { B1: "not to interrupt the class, but be aware" } \\
\text { B1: "let the student know I am aware of his actions" } \\
\text { C1: "to let the student know that I am aware" } \\
\text { C3: "at this point I do not have enough information to say } \\
\text { something, but I feel like the [bullies] should know that I } \\
\text { am aware" }\end{array}$ \\
\hline uncertainty & 4 & $21 \%$ & $\begin{array}{l}\text { A1: "because I am not sure of the situation...to give them } \\
\text { a chance to settle down" } \\
\text { A3: "because I do not understand the situation yet" } \\
\text { A3: "at this point, I do not have enough information to say } \\
\text { something, ..." } \\
\text { C2: "trying to find out [whats going on]" }\end{array}$ \\
\hline $\begin{array}{l}\text { least } \\
\text { disruptive } \\
\text { response }\end{array}$ & 6 & $32 \%$ & $\begin{array}{l}\text { A1: "not to interrupt the class, but be aware" } \\
\text { B1: "didn't want to escalate [the situation] unnecessarily" } \\
\text { B3: "not disruptive but gets the point across" } \\
\text { B3: "a gesture would be less disruptive and obvious" } \\
\text { C1: "least amount of distraction" } \\
\text { C3: "try to revert their attention back to their work ..." }\end{array}$ \\
\hline
\end{tabular}

When analyzing participant responses in terms of why they chose to respond by verbal directive, four themes emerged: respect, physical bullying, redirection, and seriousness of the problem. See Table 5 for a list of participant comments related to the four themes. 
Table 5.

Themes to Describe Reasons Participants Chose to Respond by Verbal Directive

\begin{tabular}{|c|c|c|c|}
\hline & $\begin{array}{l}\text { Number of } \\
\text { Related } \\
\text { Responses }\end{array}$ & $\begin{array}{l}\text { Percentage of } \\
\text { Comments } \\
\text { Related to } \\
\text { Theme }\end{array}$ & Participants' Comments \\
\hline respect & 6 & $24 \%$ & $\begin{array}{l}\text { A1: "I wanted to teach her respect" } \\
\text { A1: "to teach about respect" } \\
\text { A3: "necessary because students were talking and being } \\
\text { disrespectful" } \\
\text { B1: "reminded about respect" } \\
\text { B2: "not respecting others in the classroom" } \\
\text { C2: "disrespectful, shouldn't be tolerated" }\end{array}$ \\
\hline $\begin{array}{l}\text { physical } \\
\text { bullying }\end{array}$ & 4 & $16 \%$ & $\begin{array}{l}\text { A1: "no one should be allowed to put their hands on } \\
\text { anyone..." } \\
\text { A2: "it was physical contact and inappropriate" } \\
\text { "it's physical" } \\
\text { A3: "the bullying is physical at this point, so a simple } \\
\text { gesture is not enough" } \\
\text { B3: "Inappropriate behavior, students should not lay } \\
\text { hands on each other or invade personal space" }\end{array}$ \\
\hline redirection & 7 & $28 \%$ & $\begin{array}{l}\text { A1: "to get the class back on track" } \\
\text { A3: "to keep the class on track" } \\
\text { B1: "to stop the crying, and then handle after class" } \\
\text { B1: "to refocus" } \\
\text { B2: "to avoid the topic as a whole and revert attention } \\
\text { back to [the lesson]" } \\
\text { B2: "because it was distracting to the class" } \\
\text { B3: "redirect attention" }\end{array}$ \\
\hline $\begin{array}{l}\text { seriousness } \\
\text { of the } \\
\text { problem }\end{array}$ & 8 & $32 \%$ & $\begin{array}{l}\text { A1: "serious matter that needs to be handled as soon as } \\
\text { possible" } \\
\text { A2: "she ended up crying you need to address it } \\
\text { immediately" } \\
\text { A3: "one student was crying and I felt like the issue had } \\
\text { already gone too far and needed addressed immediately" } \\
\text { A3: "completely unacceptable" } \\
\text { A3: "behaviors getting out of hand and needs more than a } \\
\text { gesture to show that I am serious" } \\
\text { B1: "because the situation is out of hand" } \\
\text { B1: "bullying is at a point where it needs to be stopped. } \\
\text { Just gesturing is not enough" } \\
\text { C3: "becoming a serious issue; it needs to be resolved" }\end{array}$ \\
\hline
\end{tabular}


When analyzing participant responses in terms of why they chose to completely ignore a situation, the following two themes emerged: not considered disruptive and unaware. See Table 6 for a list of participant comments related to the two themes.

Table 6.

Themes to Describe Reasons Participants Chose to Respond by Ignoring the Behavior Completely

\begin{tabular}{|c|c|c|c|}
\hline & $\begin{array}{l}\text { Number of } \\
\text { Related } \\
\text { Responses }\end{array}$ & $\begin{array}{l}\text { Percentage of } \\
\text { Comments } \\
\text { Related to } \\
\text { Theme }\end{array}$ & Participants' Comments \\
\hline $\begin{array}{l}\text { not } \\
\text { considered } \\
\text { disruptive }\end{array}$ & 6 & $46 \%$ & $\begin{array}{l}\text { A1: "it wasn't anything I took for a problem," } \\
\text { A2: "it didn't seem like anything" } \\
\text { B1: "not disruptive to the classroom" } \\
\text { B3: "it didn't start any conflict" } \\
\text { C2: "not sure if it was a problem" } \\
\text { C3: "didn't seem like a big deal" }\end{array}$ \\
\hline unaware & 7 & $54 \%$ & $\begin{array}{l}\text { A1: "I really did not notice so I just ignored it" } \\
\text { A3: "I didn't even notice" } \\
\text { B1"didn't realize [the behavior] occurred" } \\
\text { B1: "I don't think I heard it" } \\
\text { B2: "didn't see it" } \\
\text { B2: "it was very subtle, I was unaware" } \\
\text { C3: "wasn't sure what was going on" }\end{array}$ \\
\hline
\end{tabular}

When analyzing participant responses in terms of why they chose to ignore a situation in the moment, with the intention of returning to behavior at a later time, the following three themes emerged: gather information, seek assistance, and finish the class. See Table 7 for a list of participant comments related to the three themes. 
Table 7 .

Themes to Describe Reasons Participants Chose to Respond by Ignoring in the Moment, With the Intention of Addressing the Behavior at a Later Time

\begin{tabular}{|c|c|c|c|}
\hline & $\begin{array}{l}\text { Number of } \\
\text { Responses }\end{array}$ & $\begin{array}{l}\text { Percentage of } \\
\text { Comments } \\
\text { Related to } \\
\text { Theme }\end{array}$ & Participants' Comments \\
\hline $\begin{array}{l}\text { gather } \\
\text { information }\end{array}$ & 7 & $41 \%$ & $\begin{array}{l}\text { A3: "because I am not completely aware of which } \\
\text { students are doing the bullying. I would pay close } \\
\text { attention to the situation" } \\
\text { A3: "I do not have enough information or reliable facts... } \\
\text { I am going to do what I can to gather more information } \\
\text { and take care of the issue" } \\
\text { B1: "don't have enough to go on at this point" } \\
\text { B1: "still don't have enough information to take action" } \\
\text { B2: "not enough information, need to understand more" } \\
\text { B2: "get info" } \\
\text { B3: "gain more insight about the situation" }\end{array}$ \\
\hline $\begin{array}{l}\text { seek } \\
\text { assistance }\end{array}$ & 5 & $29 \%$ & $\begin{array}{l}\text { B1: "It's a difficult line between deciding to handle it } \\
\text { myself as a teacher or refer to a counselor, but if there is a } \\
\text { counselor...it would be good to talk to them" } \\
\text { B2: "The bully needs to go to a higher power because the } \\
\text { situation cannot be controlled in my hands" } \\
\text { C1: "I should address a counselor since I was not there } \\
\text { when the bullying occurred" } \\
\text { C3: "no proof of whats going on, must confront a } \\
\text { counselor" } \\
\text { C3: "I would not confront the students, but I would } \\
\text { immediately inform a counselor or my supervisor about } \\
\text { the issue so Jessica will be safe"" }\end{array}$ \\
\hline $\begin{array}{l}\text { finish the } \\
\text { class }\end{array}$ & 5 & $29 \%$ & $\begin{array}{l}\text { A1: "wait until class is over to handle the situation" } \\
\text { A1: "because students are doing work, ... ignore til after } \\
\text { class..." } \\
\text { A3: "wait until class is over" } \\
\text { B3: "calling the situation out at that time will draw too } \\
\text { much attention to it"" } \\
\text { C3: "probably not best to make a scene" }\end{array}$ \\
\hline
\end{tabular}


Question 3: What are participants' perceptions related to Counter-Balanced Order, Pros and Cons of Each Type of Application Activity, and Aspects of Application Activities Considered Most and Least Beneficial?

This research question is answered in three parts. All data for each part of research question 3 were collected from participants' written responses to a Social Validity Questionnaire which can be found in Appendix J. The questionnaire included Likert type responses and openended responses. Participants were given the opportunity to rate each activity individually and describe a rationale or explanation of how or why they would prefer one type of activity or sequence of activities over another.

Question 3, Part 1: Participants' perceptions regarding the relationship between order of participation in application activities and accuracy of responding.

Participants' perceptions regarding the relationship between counter-balanced orders by which participants participated in application activities and the effectiveness of those activities to prepare for responding accurately to bullying behaviors were collected by analyzing item 5 of the Social Validity Questionnaire (see Appendix J). Item 5 includes two types of questions (one Likert type question and one open ended question).

The first type of question for item 5 utilized a Likert scale of 1-5, with 1 indicating no relationship between counter-balanced order and the effectiveness of preparing participants for response to bullying and 5 indicating a high possibility of relationship. The mean score for this rating was 3.75, which suggested participants believed there was a relationship between order of participation in each of the three types of application activities and effectiveness. Item 5 also asked participants to indicate which order they thought was most effective in preparing them to respond to bullying behaviors and to explain why they thought it was most effective order. At 
least one participant responded to the open ended question by suggesting that each of the three orders in which they completed application activities were "equal" in terms of preparing them for bullying situations. Two participants preferred the following order: Case Study, Virtual Simulation, and Role Play. Written comments suggested that Case Study was useful in preparing them for what to expect in the other activities. Another participant preferred the following order: Role Play, Case Study, and Virtual Simulation. This participant suggested the other activities helped to prepare for TeachLive. Two more participants preferred Case Study, Role Play, and then TeachLive. In response to item 6 of the social validity questionnaire one of the two participants described a rationale for choosing this order by suggesting Case Study, "slightly prepares you for what you are going to do during the other activities," and Role Play, "helps to prepare for TeachLive, while Virtual Simulation, "really helps prepare for real life situations [and/or] for [a] future career."

Question 3, Part 2: Participants' perceptions related to differences in the three types of application activities and the effect differences have on preparing preservice special education teachers to respond to bullying situations.

This question was answered by analyzing information collected from item 6 of the Social Validity Questionnaire. Participants were asked to report pros and cons of each type of application activity for preparing to respond to or prevent bullying behaviors. Several themes emerged from the collected data. Themes outlining participant responses to positive and negative differences in each type of application activity are represented in Table 8. 
Table 8 .

Themes to Describe Differences in Application Activities

\begin{tabular}{lll}
\hline & Pros & Cons \\
\hline $\begin{array}{l}\text { Case } \\
\text { Study/Automated } \\
\text { Feedback }\end{array}$ & $\begin{array}{l}\text { Structured/Controlled } \\
\text { Instant Feedback }\end{array}$ & Not Interactive \\
$\begin{array}{l}\text { Role Play/Peer } \\
\text { Feedback }\end{array}$ & $\begin{array}{l}\text { Interactive } \\
\text { An Opportunity to Observe } \\
\text { Peers }\end{array}$ & $\begin{array}{l}\text { Difficult to Stay in Role } \\
\text { Not Taken Seriously }\end{array}$ \\
$\begin{array}{l}\text { Virtual } \\
\text { Simulation/Instructor } \\
\text { Feedback }\end{array}$ & $\begin{array}{l}\text { Realistic } \\
\text { Good Practice } \\
\text { Prepares you for the Future }\end{array}$ & \\
& & Nothing Negative \\
\hline
\end{tabular}

Participants preferred learning activities that seemed to be structured or controlled, and they appreciated timely feedback, interactivity with peers, and realistic practice to prepare for the future. Participants suggested Case Study activities were a good learning tool because they provided immediate feedback. However, they preferred activities that were more interactive. Virtual Simulation activities were more preferential than Role Play activities. Participants reported difficulty staying in role and remaining serious for the duration of role play activities. Question 3, Part 3: Participants' perceptions on aspects of the three types of application activities perceived as most and least beneficial.

Item 1 of the Social Validity Questionnaire ask participants to rate, on a Likert scale, how prepared they are to respond to bullying behaviors as a result of participating in the study with 1 being least prepared and being more prepared. Calculation of mean suggest participants do feel more prepared to respond to bullying behaviors as a result of participating in this study $(M=$ 4.75). Items 2, 3, and 4 of the Social Validity Questionnaire were used to analyze participants' perceptions in regards to aspects of application activities that were thought to be most and least 
beneficial. Participants responded to the three questions on a Likert scale, with 1 indicating the least effectiveness and 5 indicating the most. Results of the ratings have been displayed in Table 9. Participants rated Virtual Simulation activities as the most beneficial $(M=4.75)$, with Case Study activities ranked as second $(M=4.375)$. Participants rated the Role Play activities as least beneficial of the three $(M=4.0)$. Also on Table 5, is participants' responses collected from items 7 and 8 of Social Validity Questionnaire describing aspects of each type of Application Activity that they considered to be most and least beneficial. 
Table 9.

Effectiveness Ratings for each type of Application Activity

\begin{tabular}{|c|c|c|c|}
\hline \multirow[t]{2}{*}{ Application Activity } & \multirow{2}{*}{$\begin{array}{l}\text { Effectiveness } \\
\text { Rating }\end{array}$} & \multicolumn{2}{|l|}{ Participant Comments: } \\
\hline & & Most Beneficial & Least Beneficial \\
\hline $\begin{array}{l}\text { Case Study/Automated } \\
\text { Feedback }\end{array}$ & 4.375 & -"a learning lesson" & $\begin{array}{l}\text {-"hard to fully } \\
\text { understand...by just reading } \\
\text { about it" } \\
\text {-"not interactive" }\end{array}$ \\
\hline Role Play/Peer Discussion & 4.0 & $\begin{array}{l}\text {-"real life scenarios that } \\
\text { you can participate in" }\end{array}$ & $\begin{array}{l}\text {-"it's not real" } \\
\text {-"hard to learn something } \\
\text { while playing a role" } \\
\text {-"it was hard to get in } \\
\text { role....it distracted me from } \\
\text { learning" } \\
\text {-"needed more structure" } \\
\text {-"felt like [my group] didn't } \\
\text { take it serious" } \\
\text {-"limited to how good peers } \\
\text { act" } \\
\text {-"couldn't really get a feel } \\
\text { for the situation" }\end{array}$ \\
\hline $\begin{array}{l}\text { Virtual } \\
\text { Simulation/Instructor } \\
\text { Feedback }\end{array}$ & 4.75 & $\begin{array}{l}\text {-"real life scenarios that } \\
\text { you can participate in" } \\
\text {-"time to react" } \\
\text {-"more realistic... have to } \\
\text { be ready....helps prepare } \\
\text { you for that" } \\
\text {-"put yourself in a realistic } \\
\text { situation" } \\
\text {-"most real" } \\
\text {-"helped me to get a } \\
\text { better understanding of } \\
\text { teaching" } \\
\text {-"valuable experience" }\end{array}$ & $\begin{array}{l}\text { None of the Participants } \\
\text { described Virtual Simulation } \\
\text { activities as least beneficial. }\end{array}$ \\
\hline
\end{tabular}




\section{Chapter 5}

\section{Discussion}

\section{Summary of Purpose}

The purpose for conducting this research was to examine methods of preparing preservice special education teachers to respond to or prevent bullying. Application activities were designed in a way that participants were actively involved in bullying scenarios and required each individual to make immediate choices for responding to behaviors. A single subject alternating treatments approach was utilized for this study because it would allow for a detailed analysis of each type of application activity and the evaluation of potential effects each activity may or may not have on participants' accuracy in responding. The approach to this study provided opportunity for qualitative and quantitative analysis. Although one aspect of this research was to examine the effectiveness of each type of application activity on the accuracy of responding in bullying situations in order to determine which activity proved best in addressing bullying, data analyzed to determine accuracy of responses during pre- and post-feedback also provided valuable data.

Qualitative measures described in this study were designed to provide insight into activities that would be preferred by preservice teachers. It was the intent of this research to find theme among participant responses to determine what aspects of the activities provided the most opportunity for learning as perceived by the preservice teachers. It was important to understand which of the activities were perceived to be most and least beneficial, as well as what aspects of the activities were thought to be most useful to them as learners.

\section{Accuracy in Responding}


Correct and incorrect responses to bullying behaviors were documented on AASs. Participant perceptions of each activity are an important component to describing effectiveness. An increase in accurate responses was utilized to report significance allowing for a more comprehensive examination of each type of activity.

Individual participant analysis of accuracy in responding during each type of learning activity did not lead to concrete results suggesting that any one type of intervention was more or less significant than another. Participants' accuracy of responding varied from activity to activity. For most participants there was not any indication of progress over the duration of this study. Although there was variability of performance the result of individual analyses did reveal that individual participants each responded more accurately to specific activities than others. Specifically, some of the participants performed better during role play activities, while others performed better during virtual simulation. Additionally, it can be inferred from the results, that each participant is most likely going to benefit from a different combination of activities. For example, based upon calculations of C-statistic and evaluation of $\mathrm{z}$ score, accuracy of responses by Participant $\mathrm{Al}$ suggested that a combination of Virtual Simulation activities followed by Role Play activities would yield an $81.3 \%$ chance that in a normal distribution others would perform with less accuracy in responding to bullying behaviors. This does not suggest statistical significance, but it is preferential when compared to calculations of $68.1 \%$ probability during Case Study followed by Role Play intervention. This finding suggests that an effective instructional plan for preparing Participant A1 for response and prevention of bullying behaviors would likely begin with participation in virtual simulation activities followed by participation in role play activities. 
Overall acceleration or deceleration in performance throughout the duration of participation in this study was assessed by calculating for celeration. Visual inspection of celeration revealed that four out of eight participants were decelerating or decreasing in accuracy of responding over the duration of the study, and the other four out of eight participants were maintaining or increasing in accuracy of responding over the duration of this study. Visual inspection of level or mean calculated for each activity for each participant suggested that participants responded more accurately during virtual simulation activities than any other activity. Visual inspection of level was analyzed to make comparisons related to participation in specific combinations of activities.

There was no evidence that participants responded better to any one combination of activities. It seems likely that this finding could possibly be attributed to specific learning styles of each participant although learning styles was not a measured variable in this study. There were several variables present in each activity that could have been considered preferential to learning. Some participants reported being apprehensive about participating in role play activities. It was noted by one participant that learning, while acting, was not possible. Perhaps this participant was nervous about acting and could not move beyond the feeling of discomfort in order to learn from the experience. Another participant had suggested it was difficult to read and learn from the case study activities because of the lack of interaction, while another participant commented about how reading the case study activities helped him prepare for everything else. There appeared to be a dichotomous explanation of the task - helpful or tedious. Once again, it is possible that participants' learning styles may have contributed to the accuracy or lack of accuracy when responding to bullying behaviors during each of the three activity types. 
Directly prior to beginning their first Virtual Simulation sessions, participants' questions for the instructor and statements to one another provided information that would suggest elements of uncertainty and to some extent intimidation. During initial interactions with avatars prior to beginning their first Virtual Simulation sessions, most participants seemed uncomfortable; still, all of the participants by the end of the study reported feeling as if virtual simulation was most beneficial to them as learners. Of the themes found during analysis of participant described pros and cons of each type of application activity, and participants perceptions describing aspects of activities that were most and least beneficial, the most common theme was that virtual simulation seemed realistic. All respondents felt as if their participation in the TeachLivE ${ }^{\mathrm{TM}}$ lab was very similar to what they would experience in a real classroom. Group comparisons indicated higher percentages of accuracy during Virtual simulation activities than any other activity. In addition, evidence of significance from the Cochran's Q test, as it revealed significantly higher accuracy in response to bullying behaviors even before participation in feedback, is evidence to support the participants' perceptions of virtual learning as most beneficial to them in preparing for how to respond to bullying behaviors.

The results of this study strongly support virtual simulation as an effective means of preparing preservice teachers for response and prevention of bullying behaviors. The virtual simulation activity utilized for this study was TeachLivE ${ }^{\text {TM }}$. The TeachLivE ${ }^{\text {TM }}$ lab is expensive, and therefore, only available at select institutions. Another virtual simulation platform that can be utilized in a similar respect is Second Life (www.secondlife.com). Second Life does come at a price, but it is not as costly as TeachLivE ${ }^{\mathrm{TM}}$. A virtual classroom created in Second Life can be designed to function very similarly to that of the TeachLivETM lab. Skype (www.skype.com) or 
Oovoo (www.oovoo.com) are websites available free of charge. These websites could also be used as platforms for creating activities similar to the ones designed for this study.

\section{Pre- and Post-Feedback}

Feedback was an important component of this research during the design phase; however, the full implication for the power of feedback was unexpected. Results of the Chi Squared test described in relation to pre- and post-feedback did not suggest that any one type of feedback was more effective than the other. Yet, results of pre- and post-feedback did represent significant findings suggesting that feedback is an essential component in a systematic process to prepare preservice special education teachers for responding to bullying behaviors. In fact, results described for feedback during each of the three types of application activities represent the most significant of statistical findings reported in this study. The only true assumptions that can be made from this research would suggest that feedback or discussion, of any type, is an essential component in the process of preparing preservice teachers for the critical decision making they are likely to face when confronted with bullying situations

Although participants were never asked which type of feedback they thought was most beneficial or desirable, a few assumptions can be considered. Results of the McNemar test, which yielded the largest significance of any other measurement recorded for the purposes of this study, reported the highest levels of significance after participating in peer discussion $(p=$ $0.0001)$ and automated feedback $(p=0.0001)$. Therefore, it seems likely that participants might have preferred either peer discussion or automated feedback as opposed to instructor feedback. That being said, it should still be noted that feedback from instructor feedback also yielded statistical significance $(p=0.001)$. 
Participants' accuracy of responses after participating in feedback was significantly improved across all three types of application activities. This is a substantial finding that should be addressed in future literature. The current study does not suggest that any one type of feedback was more effective than the other, but it does provide rationale for designing learning activities for preservice teachers that include a feedback component.

Participants reported reasons for choosing responses during both the pre- and postfeedback phases. Participants' comments suggest they gesture in order to let students know that although they may not necessarily know exactly what is going on when a behavior occurs, they are aware of the behavior. Gesture seemed like the most likely response in many instances because it was perceived as the best way to respond without disrupting the lesson. Participants' comments suggest that use verbal directive if a behavior is perceived to be disrespectful, physical in nature, or serious then it should be addressed verbally and right away. Another theme for verbal directive was redirection. By addressing the behavior right away, it was possible to redirect attention away from the bullying behavior. Participants' comments suggest they ignore a situation completely when the behavior, although not ideal, did not warrant a response, and in some instances should be completely overlooked, possibly because the behavior was never perceived to be a bullying behavior from the start. Another reason the participants completely ignored behaviors was because they did not realize the behavior had occurred. Participants comments related to ignoring the behavior only to address it at a later time suggested that participants needed to gather more facts before responding to a situation, they needed to consider seeking assistance before responding, or they didn't want to disrupt the classroom instruction.

\section{Participants' Perceptions}


Participants' perceptions related to this study were categorized into three parts: counterbalanced order, pros and cons of each type of Application Activity, and aspects of Application Activities that participants perceived as least and most beneficial. Participant's responses to the Social Validity Questionnaire are indicative of positive relationships among participation in application activities and accuracy in responding. Most participants $(M=3.75)$ chose a preferred order of participation in application activities that they thought to be more effective than others, but there was not any one order that was preferred by the majority of participants. Each participant had their own reasons as to why they preferred one order over another. Most participants reported that they thought Role Play and Case Study activities were useful in preparing them for the TeachLive sessions.

Participants were asked to list the pros and cons of each type of application activity in preparing them to respond to bullying behaviors. Theme determined to describe Case Study activities as a result of analyzing pros reported by participants suggest that Case Study activities are structured, controlled, and offer instant feedback. Cons reported described Case Study as not interactive. It seems likely that because participants did not feel as if they were actively involved in the Case Study activities, Case Study was not ranked as most effective. Themes describing Role Play as a result of analyzing pros reported by participants suggest that Role Play activities are interactive, and they provide an opportunity to observe how their peers would react in a bullying situation. Cons reported by participants describe Role Play activities as, difficult in terms of staying in role and lacking in seriousness. Therefore, it seems likely that because participants had difficulty staying in role and because during role play participants had to depend upon others in their group taking the activity seriously, Role Play was not ranked as most effective. Participants' perceptions of Virtual Simulation activities were very positive. In fact, 
participants did not report any negative aspects related to Virtual Simulation activities. They reported thinking that the TeachLive lab was more realistic, it was good practice, and it would prepare them for the future. It was, therefore, ranked as most effective by participants.

Aspects of activities that placed it in the category of most beneficial were centered on the theme of being realistic life scenarios that allow for participation and interactivity. Aspects of activities that placed it in the category of being least beneficial was in part due to the idea that it was not real, not interactive, or it was difficult understand or take seriously.

\section{Social Validity}

Examining participants' perceptions in regards to participation in this study was essential in determining the impact of applications activities in terms of preparing preservice teachers for field placement situations and future careers where eventually they will take on the responsibilities that come with being the teacher in a classroom full of students (i.e., real people with a variety of academic, social, and emotional needs). On the Social Validity Questionnaire (see Appendix J), participants rated participation in this study as highly effective (4.75 out of 5) in preparing them for their future careers. Bullying is a societal issue that affects an entire community of learners. Participation in the application activities associated with this study helped a small group of preservice to teachers to feel more prepared or confident in their ability to handle bullying situations.

All of the participants in this study discussed the need for instruction to teach them how to appropriately address bullying in the classroom. After the initial training session, many of the participants discussed acts of bullying they had read about in the news or heard about on television. It was clear from their conversations that they viewed bullying as an issue of relevance in the field and their own communities. Further, participant responses on the 
demographic questionnaire corroborated this because five out of the nine participants who began this study indicated that they are very likely to encounter bullying issues in their future careers, three of the nine participants indicated that they are somewhat likely, and only one participant indicated being not likely to encounter bullying in his or her future career. Additionally, seven of the nine participants reported thinking they are only somewhat prepared to handle bullying situations they might encounter.

Although inspection of individual participant responses to bullying behaviors revealed little to no significance in terms of accuracy of responding across the duration of this study, the overall accuracy rates of all participants did improve during the post-feedback phase. It is likely that further participation overtime would have yielded more positive results for individual participants which can be assessed by examining the R-squared values and trend associated with research question one. For example, before ever participating in feedback the trend line for Participant C2 during Case Study activities increased with an R-squared value of 0.9231 which suggests a high likelihood or prediction of similar trend if collection of data were to be extended over a longer period of time. What this means is that there is a high possibility for continued success in accuracy of responding, especially given the considerable improvement in accuracy of responding participants reported after receiving feedback. Visual inspection of graphs for Participants A1, A3, B3, C1, C2, and C3, all show at least one type of application activity with a slightly positive to moderate trend line, each of which indicates at least a minimal increase in performance over time. It seems likely that if participants were to continue participating in application activities and meaningful feedback, then results would likely yield positive results.

\section{Implications for Practice}


Although there is a growing commitment in our communities to address bullying, policies to define and describe best practices in addressing bullying are still limited (Gorly, Neilsen-Hewitt, \& Sweller, 2013). As bullying continues to gain nationwide awareness and destruction in our communities and schools, it is imperative that strategies, supports, and training be developed which are preventative rather than reactive. It is also imperative that said strategies and supports be disseminated across state, local, and national school districts.

The design of this study included feedback as a major component of preparing preservice teachers for responding to bullying behaviors. Shantz (2000) described feedback as organized talking that is significant to preservice teachers as they are developing ways of organizing and internalizing their own thought about classroom teaching. The author suggested that providing opportunity for feedback is one means of assisting preservice teachers through the process of internalization. Teacher education programs already take advantage of feedback by providing preservice teachers with college supervisors and on-site supervisors during field experiences. Feedback will likely become a major factor for the future of preparing preservice teachers to respond appropriately to bullying behaviors.

A thorough search of keywords and phrases such as; bullying preparation and preservice teachers, preservice teachers and content delivery, methods of instruction and preservice teachers, instructional methods of preparing preservice teachers for bullying, etc., found that there is a shortage of literature available to suggest best instructional methods for preparing preservice teachers to respond in bullying situations. As bullying continues to gain nationwide interest, instructional methods for preparing teachers and preservice teachers to respond to bullying situations will likely elicit interest among university instructors and professional development leaders nationwide. 
Acknowledgement of bullying is a critical issue in the field of education and special education is the foundation for creating safe school environments. Bullying has been described as a pervasive problem with the highest of prevalence rates among students with disabilities, and still there is a gap between research and practice as very few studies address individualized intervention strategies for students with disabilities (Rose, Monda-Amaya \& Espelage, 2011). Recognizing the limited amount of research available to address bullying intervention strategies for students with disabilities, and understanding the implications of bullying for all parties involved (bully, target, bystander, teacher, administrator, and parent) will likely spark interest among stakeholders to continue research efforts, design and analyze the effectiveness of strategies for responding and preventing bullying behaviors in school and community, and eventually prompt enough awareness that institutions of higher learning will consider including a bullying component to the requirements for completion of teacher education programs. As state, local, and federal legislation continue to address bullying as a part of policy, and teacher professional development, it will be noted that the timing and the focus of this research will be relative to stakeholders.

\section{Limitations}

This study was limited to a small sample size. Although a small sample size does not allow for inferences to the general population to be made, the study has created implementation guidelines and expected outcomes for comparison in regard to future studies of larger scope. The alternating treatments design comes with advantages in that it allows for simultaneous collection of data across more than one treatment effect. Although measures of comparison have been described to account for accuracy of described effect among methods of instruction, the likelihood of multiple-treatment interference cannot be ignored. 
The study was designed to eliminate threat of treatment interference based upon the order by which participants completed application activities. It was limited in that there is still possibility that effect of various interventions could have attributed to the sequence or counter balance order by which instructional methods appeared to prove effective for individual participants. A study of larger proportion over time would allow for analysis of replication.

Another limitation to this study was duration. The duration of this study did not provide opportunity for collecting large sets of data points. In a study of longer duration over time, collection of more data may have revealed statistical significance among individual participants, and likewise it may have revealed statistical significance associated with order of participation in application activities. Once again, collection of more data overtime would allow for the possibility of replication.

Furthermore, there is literature available that addresses response to bullying behaviors by categorizing responses as direct and indirect, or punitive and constructive (Marshall et al., 2009). The number of data points available for analysis during this study was a limitation. The limited number of data points collected from participants made it very difficult to determine significance for individual participants. Therefore a study that is carried out over a longer period of time and provides opportunity for collection of more data points, may elicit more desired results. Restructuring the types of response options described in this study to fit the model described by Marshall et al. (2009) may be one way of collecting a larger number of data points that can be organized to make better comparisons and inferences about the types of choices participants make.

In terms of external validity, it should be noted that this study was comprised of a convenience sample. All participants were recruited as volunteers from two sections of the same 
course that was offered at West Virginia University. Lack of participants' experiences with actual students and lack of opportunities to serve as student observers as they were mostly students in their first or second year of college, as well as the variations of disciplines participants were studying as some were planning to be teachers while others were planning to work in schools as occupational or speech therapists may be factors that limit the ability to generalize findings to a larger population of special education teachers.

\section{Future Research}

Results of this study indicated that participants responded with more accuracy during virtual simulation activities than any other activity. This study specifically utilized the TeachLive $^{\mathrm{TM}}$ lab at West Virginia University. Participation in the TeachLive ${ }^{\mathrm{TM}}$ lab provided realistic virtual simulated experiences by which participants were able to react to bullying behaviors. Andreasen and Haciomeroglu (2009) suggested virtual simulation will become a popular means of addressing critical issues as it creates opportunity for addressing difficult circumstance outside of the actual classroom. Participants of this study reported feeling as if they were immersed into a real classroom environment. Interaction with avatars as opposed to interaction with real students provides opportunity for growth and refined practice in a safe environment (Dieker, Hynes, Hughes \& Smith, 2008). Therefore, another study designed to address bullying behaviors in a virtual simulation lab, such as the TeachLive ${ }^{\mathrm{TM}}$ lab used for this study, is a logical next step. It allows for trial and error, but without the threat of making decisions that could cause harm or discomfort for actual students.

Another study should address levels of confidence. It would be of value to study virtual simulation as a means of increasing confidence among teachers and their likelihood of intervening in bullying situations. In order to understand specifically how confidence might 
correlate to effectively addressing bullying behaviors. Unfortunately, research has suggested that often teachers do not respond to bullying because they are uncertain in their ability to make the appropriate choices. In other words, they lack confidence. Goryl et al. (2013) discussed general behavior management issues and lack of confidence that teachers expressed in their ability to appropriately manage bullying. The concept of virtual simulation as a means of improving confidence among preservice and in-service teachers is worthy of further investigation.

Although the results of this study supported participation in feedback as a means of preparing preservice teachers to respond appropriately when faced with bullying behaviors, it has not provided any evidence to describe which types of feedback are most effective. Before combining any one type of feedback with an instructional activity such as those designed for this study, future research should address various types of feedback in preparing teachers for critical decision making. We can say feedback substantially impacted the participants in this study, because the results of the McNemur test suggest statistical significance between accurate and inaccurate choices participants made before and after participating in feedback activities. Determining which type of feedback has the biggest impact on participant choices, or which type of feedback participants perceive as most effective when faced with difficult situations would be the next logical step to improving the design of future research. Choosing to focus on activities to include one type of feedback, would strengthen the design of a study similar to this one by taking away unnecessary variables.

As stated by Bauman and Del Rio (2006), the next logical step to addressing reduction of bullying behaviors as a critical issue in our nation's schools is to equip teachers with the appropriate knowledge, skills, and tools to strategically intervene in bullying situations, and to do so by including training in teacher preparation programs. Convincing institutes of higher 
education that there is a dire need to implement these types of activities into their programs curriculum or programs requirements for completion may require a larger scale study outlining need for intervention. Surveying special education teachers, who in many instances may also be college students working on permit as they complete the requirements of their special education programs, and surveying students in public schools who are receiving special education services is one means of collecting enough information to define instruction targeted to address specific areas of need. Among other topics of relevance, a survey will assist in determining where and when training to address bullying should occur, during preservice training or as a part of professional development opportunities for practicing teachers.

In sum, bullying has become a nationwide issue of relevance. With limited literature specifically addressing bullying in special education, future research is needed. There is a plethora of resources available to address bullying and bullying prevention. Resource are available to address programs in schools, but there was very little research to suggest how institutions of higher education might incorporate bullying prevention and response into programs of study, which seems to be the likely path for reaching out to the largest population of teachers. If new teachers enter their discipline with these skills it will speed up the process of disseminating information to the field as a whole.

\section{Conclusion}

The results of this study provide support for participation in activities designed to prepare preservice special education teachers to respond in bullying situations. Concrete data derived from calculating the number of correct and incorrect responses participants recorded for each type of application activity, as well as before and after participating in feedback, combined with the results of themes described by participants when answering questions related to the 
effectiveness of each type of intervention suggested that Virtual Simulation is the most effective means of preparing preservice teachers to respond to or prevent bullying. Additionally, it is evident from the results of this study that feedback is a crucial component to success. This study is an initial attempt to acknowledge bullying as an issue that should be addressed in teacher education programs. It provides a foundation for where to begin in terms of developing programs or curriculum that will address bullying, especially among special education preservice teachers. 


\section{References}

Alberto P.A., \& Troutman A.C. (2006). Applied behavior analysis for teachers. Upper Saddle River, New Jersey: Pearson Education.

American Institutes for Research (2013). Creating a safe and respectful environment in our nation's classrooms. Retrieved from http://safesupportivelearning.ed.gov/sites/default/ files/sssta/20121108_20120928ClsrmMod1HandoutsFINAL1.pdf

Andreasen, J. B. and Haciomeroglu, E. S. (2009). Teacher training in virtual environments. Paper presented at the annual meeting of the North American Chapter of the International Group for the Psychology of Mathematics Education, OMNI Hotel, Atlanta, GA Online <PDF>. 2013-05-24 from http://citation.allacademic.com/meta/p369 936_index.html

Bauman, S., \& Del Rio, A. (2006). Preservice teachers' responses to bullying scenarios: Comparing physical, verbal, and relational bullying. Journal of Educational Psychology, 98(1), 219-231. doi:10.1037/0022-0663.98.1.219

Bell, A., \& Morris, G. (2009). Engaging professional learning in online environments. Australasian Journal Of Educational Technology, 25(5), 700-713.

Blake, J. J., Lund, E. M., Zhou, Q., Kwok, O., \& Benz, M. R. (2012). National prevalence rates of bully victimization among students with disabilities in the United States. School Psychology Quarterly, 27(4), 210-222.

Bowllan, N.M. (2011). Implementation and evaluation of a comprehensive, school-wide bullying prevention program in an urban/suburban middle school. Journal of School Health, 81(4), $167-173$. 
Burden, R., Tinnerman, L., Lunce, L., \& Runshe, D. (2010). Video case studies: Preparing teachers for inclusion. Teaching Exceptional Children Plus, 6(4) Retrieved from http://search.ebscohost.com.www.libproxy.wvu.edu/login.aspx?direct=true $\& d b=e r i c \& A$ $\underline{\mathrm{N}=\mathrm{EJ} 907031 \& \text { site }=\text { ehost-live }}$

Clapper, T.C. (2010). Role play and simulation. Education Digest, 75(8), 39-43.

Council for Exceptional Children (2013). CEC Initial Preparation Standards with Elaborations. Retrieved from http://www.cec.sped.org/ /media/Files/Standards/Profess ional\%20Preparation $\% 20$ Standards/Initial\%20Preparation $\% 20$ Standards $\% 20$ with $\% 20$ Ela borations.pdf

Coyle, H.E. (2008). School culture benchmarks: Bridges and barriers to successful bullying prevention program implementation. Journal of School Violence, 7(2), 105-122.

Dieker, L., Hynes, M., Hughes, C., \& Smith, E. (2008). Implications of mixed reality and simulation technologies on special education and teacher preparation. Focus on Exceptional Children, 40(6), 1-20.

Duong, J., \& Bradshaw, C. P. (2013). Using the extended parallel process model to examine teachers' likelihood of intervening in bullying. Journal of School Health, 83(6), 422-429. doi:10.1111/josh.12046

Estell, D. B., Farmer, T. W., Irvin, M. J., Crowther, A., Akos, P., \& Boudah, D. J. (2009). Students with exceptionalities and the peer group context of bullying and victimization in late elementary school. Journal of Child and Family Studies, 18(2), 136-150. Retrieved from http://search.ebscohost.com.www.libproxy.wvu.edu/login.aspx?direct=true\&db =eric\&AN=EJ851380\&site=ehost-live;http://dx.doi.org.www.libproxy.wvu.edu/10. $\underline{1007 / s 10826-008-9214-1}$ 
Floyd, D.M., \& Bodur, Y. (2008). Using case study analysis and case writing to structure clinical experiences in a teacher education program. The Educational Forum, 70(1), 48-60.

Goryl, O., Neilsen-Hewett, C., \& Sweller, N. (2013). Teacher education, teaching experience and bullying policies: Links with early childhood teachers' perceptions and attitudes to bullying. Australasian Journal of Early Childhood, 38(2), 32-40.

Gravetter, F.J., \& Wallnau, L.B. (2000). Statistics for the behavioral sciences. Belmont, California: Wadsworth.

Hixon, E. \& So, H.J. (2009). Technologies role in field experiences for preservice teacher training. Educational Techology and Society, 12(4), 294-304.

Hong, J.S. (2009). Feasibility of the olweus bullying prevention program in low-income schools. Journal of School Violence, 8, 81-97.

Inoue, Y. (2008). Concepts, applications, and research of virtual reality learning environments. International Journal Of Social Sciences, 2(1), 1-7.

Kahn, J. H., Jones, J. L., \& Wieland, A. L. (2012). Preservice teachers' coping styles and their responses to bullying. Psychology in the Schools, 49(8), 784-793. doi:10.1002/pits.21632

Kazdin, A.E. (2011). Single-case research designs: Methods for clinical and applied settings. NewYork, New York: Oxford University Press.

Laerd Statistics. (2013). Lund Research Ltd. McNemars test using SPSS. Retrieved from https://statistics.laerd.com/spss-tutorials/mcnemars-test-using-spss-statistics.php.

Marshall, M.L., Varjas, K., Meyers, J., Graybill, E.C., \& Skoczylas, R.B. (2009). Teacher responses to bullying: Self-reports from the front line. Journal of School Violence, 8, $136-158$. 
Miles, M.B., \& Huberman, A.M. (1994). Qualitative Data Analysis. Thousand Oaks, California: SAGE Publications.

National Center for Educational Statistics (2012). Indicators of school crime and safety: 2012. Retrieved from http://nces.ed.gov/programs/crimeindicators/crimeindicators2012/index.asp

Nourbakhsh, M.R., \& Ottenbacher, K.J. (1994). The statistical analysis of single-subject data: A comparative examination. Physical Therapy, 74(8), 768-776.

Olweus, D. \& Limber S. P. (2010). Bullying in school: Evaluation and dissemination of the olweus bulling prevention program. American Journal of Orthopsychiatry, 80(1), 124134. doi: 10.1111/j.1939-0025.2010.01015.x

Pacer's National Bullying Prevention Center (2013). Bullying and harassment of students with disabilities: Top 10 facts parents, educators and students need to know. Retrieved from http://www.pacer.org/bullying/resources/students-with-disabilities/

Poling, D.A., \& Hupp, J.M. (2009). Active learning through role playing. College Teaching, $57(4), 221-226$.

Raskauskas, J., \& Modell, S., (2011). Modifying anti-bullying programs to include students with disabilities. Teaching Exceptional Children, 44(1), 60-67.

Reiter, S., \& Lapidot-Lefter, N. (2007). Bullying among special education students with intellectual disabilities: Differences in social adjustment and social skills. Intellectual \& Developmental Disabilities, 45(3), 174-181. Retrieved from http://search.ebscohost.co m.www.libproxy.wvu.edu/login.aspx $?$ direct $=$ true $\& d b=a 9 h \& A N=25282357 \&$ site $=$ ehost$\underline{\text { live }}$ 
Rose, C.A., Espelage, D.L., \& Monda-Amaya, L. (2009). Bullying and victimization rates among students in general and special education: a comparative analysis. Educational Psychology, 29(7), 761-776.

Rose, C. A., Espelage, D. L., Aragon, S. R., \& Elliott, J. (2011). Bullying and victimization among students in special education and general education curricula. Exceptionality Education International, 21(3), 2-14. Retrieved from http://search.ebscohost.com.www. libproxy.wvu.edu/login.aspx?direct=true $\& d b=$ ehh $\& A N=73752048 \&$ site $=$ ehost-live

Rose, C. A., Monda-Amaya, L., \& Espelage, D. L. (2011). Bullying perpetration and victimization in special education: A review of the literature. Remedial \& Special Education, 32(2), 114-130. doi:10.1177/0741932510361247

Rose, C.A., Swearer, S., Espelage, D.L. (2012). Bullying and students with disabilities: The untold narrative. Focus on Exceptional Children, 45(2), 1-10.

Russell, C., \& Shepherd, J. (2010). Online role-play environments for higher education. British Journal of Educational Technology, 41(6), 992-1002. Retrieved from http://search.ebs cohost.com.www.libproxy.wvu.edu/login.aspx?direct=true \&db=eric \&AN=EJ901413\&sit e=ehost-live;http://dx.doi.org.www.libproxy.wvu.edu/10.1111/j.1467-8535.2009.01048.x

Savin-Baden, M., Gourlay, L., Tombs, C., Steils, N., Tombs, G., \& Mawer, M. (2010). Situating pedagogies, positions and practices in immersive virtual worlds. Retrieved from http://dx.doi.org/10.1080/001311881.2010.482732.

Sawchuk, S. (2011). Simulations helping novices hone skills. Education Week, 30(15), 1-18.

Shantz, D. (2000). Feedback, conversation and power in the field experience of preservice teachers. Journal of Instructional Psychology, 27(4), 288. 
Wallace, R. (2004). Graphing with excel: Linear regression in excel. Unpublished, National Science Foundation, NC State University, Raleigh, North Carolina. Retrieved from http://ncsu.edu/labwrite/res/gt/gt-reg-home-html.

White, O. R. (2012). The finder book for the standard celeration chart. University of Washington, Seattle, Washington.

Ysseldyke, J. E., \& Algozzine, B. (2006). Public policy, school reform, and special education. Thousand Oaks, CA: Corwin Press.

Zaretsky, E. (2009). Generation and application of virtual dynamic learning environments. Journal Of Systemics, Cybernetics \& Informatics, 7(2), 75-81 


\section{Appendix A}

\section{Case study/Automated Feedback Scenarios}

The following scenarios were created as three interactive surveys in Qualtrics (www.qualtrics.com). Participants were not able to view feedback until after they had chosen a response and explained their reasons for choosing the indicated response.

\section{Scenario One: Preventing Bullying Behaviors}

\section{Part I:}

Your school has just adopted a new bullying prevention and response initiative. Cyberbullying has become a major issue for students in your high school. A new school-wide policy that your faculty has agreed to adopt and your administration has agreed to enforce states that students at your school are not allowed to have cell phones out of their lockers unless it is before school, after school, or during their lunch period. In addition, security cameras have been placed in all of your computer labs. Teachers are being held accountable for walking around the computer lab while students are working to ensure students are not logged into their email or any other type of social networking site. During your morning homeroom, you learned that several students are sending vulgar text messages to Erin, a student who struggles with her weight. This is happening during her 3rd Block Math class. Erin has a very outgoing personality and usually associates with the "popular" kids at school. A few of her friends have confided in you that Erin is receiving these text messages from other students during the school day, but she does not want anyone to know. They do not want you to tell Erin you are aware of the situation. They hate to break Erin's trust in them, but they are worried about their friend.

\section{What can you do at this point to prevent this text messaging from happening again during the school day? Explain why you have chosen the response indicated.}

Respond immediately utilizing gesture

Respond immediately utilizing verbal directive

Ignore completely

Ignore, or choose not to respond immediately, with the intention of addressing the issue at a later time

Explain why you have chosen the response indicated: 


\section{If you chose Respond immediately utilizing gesture}

This is not a possible response. You do not know who is sending the text messages, so who or what would you gesture?

\section{If your chose Respond immediately utilizing verbal directive}

In terms of prevention, this is not considered the best, but it is a possible response. You would have to deliver your directive or message to the entire school or an entire group of students. It might be a good time to remind teachers that they should be enforcing the no cell phones rule during the school day, and it might be a good time to make a school-wide announcement reminding students that they should not have their cell phones out during the school day. The likelihood that a school-wide reminder will put an end to the cyberbullying that Erin is experiencing is not good, but it is a way of warning the perpetrator(s). This school-wide warning will allow the administration to take the perpetrators' phones from them if they are caught with it during the school day. Parents can also be asked to pick up confiscated phones, and in light of the cyberbullying issues that have been reported, administration can recommend parents check their child's text message history. It is important they understand that all parents/guardians with students whose phones are taken away during the school day are being given the same recommendations. It would, of course, be up to the parent whether or not they would want to share that information with the school. Even if parents find something in their child's text history and do not share the information, making them aware of this situation could help to prevent future cyberbullying.

\section{If you chose Ignore Completely}

This is not the best possible response as a teacher you are responsible for ensuring students receive a free and appropriate public education in a safe and secure learning environment. It is your duty to respond to these types of situations.

You should have chosen Ignore, or choose to not respond immediately, with the intention of addressing the issue at a later time

This is considered to be the best response in this situation. As the target, Erin has not identified herself yet, so at this point, you are simply investigating to determine if the story you were told is actually true. Now that you understand the best possible response would be to choose not to respond immediately, how would you plan to address the issue?

\footnotetext{
- Address the students who are suspected as being the bullies or doing the bullying

- Address the student who is being bullied

- $C$ Address both the bully and the target, but not at the same time.

- Address by sharing the issue with a counselor or and administrator
} 
If you chose Address the students who are suspected as being the bully

You can't. Right now, you don't know who to suspect.

If you chose Address the student who is being bullied,

You should consider that speaking directly to Erin at this time would be breaking the confidence of the girls who shared this information with you. If you feel that it is in Erin's best interest to confront her because of her own emotional well-being, then you should. However, Erin has a really strong personality and a lot of friends on her side, so it may not be necessary.

It is not possible to Address both, but not at the same time, because you do not know who is sending the messages.

If you chose to Address by referring the situation to a counselor or an administrator,

this is the best response; let the administrator be the one to issue a school-wide warning about cell phones. (If that is how they choose to handle the situation) The warning should go to all students as they are not allowed to have them out of their lockers during the school day and to teachers as they should be enforcing this rule. Once you have taken the situation to administration, it is up to them to determine whether or not Erin should be approached by a counselor to discuss the situation.

\section{Part II:}

The same day during your third block class you notice a student trying to hide his mobile phone in his lap, under his desk. He is looking down at the phone, and he is pushing buttons. You are not sure exactly what the student is doing, but you do know that he has his phone out.

What are you going to do?

» Respond immediately utilizing gesture

» Respond immediately utilizing verbal directive

» Ignore completely

» Ignore, or choose not to respond immediately, with the intention of addressing the issue at a later time 
Explain why you have chosen the response indicated.

If you chose Respond immediately utilizing gesture

Gesturing to the student to put his phone away is one way of responding to this situation. However, it is not the best response. Because of your schools cell phone policy, it is your duty to appropriately address this issue. Simply gesturing to the student to put his phone away gives him the impression that it is ok to have his phone in class as long as you don't see the phone.

\section{If you chose Ignore Completely}

By ignoring the fact that this student has a cell phone, you are setting precedence. Students will believe that you are not serious about the cell phone policy and eventually more students will start bringing mobile devices to your classroom.

If you chose Ignore, or choose to not respond immediately, with the intention of addressing the issue at a later time

You should understand that this is not a situation that should be ignored or put off for later. At the very least, you should gesture for the student to put his phone away.

If you chose Respond immediately utilizing verbal directive

This is the best response. Your school has adopted a bullying policy, and it has been made clear to students and teachers alike that cell phones will not be permitted during the school day. It is your responsibility to address the issue right away. Not allowing cell phones during the school day is your faculty's way of preventing cyberbullying. If you respond appropriately by either requiring the student to take his phone to his locker or by confiscating the phone (the adopted policy should outline the number of chances students receive before having their phones confiscated), then you are doing your part to prevent instances of cyberbullying via mobile phones in your school.

\section{Part III:}

You typically stand outside of the cafeteria during your lunch duty. The following day as you are standing outside of the cafeteria speaking to another teacher you notice Erin get up from her seat and run out of the cafeteria. Because of what you were told by Erin's friends the morning before you are concerned about what is wrong. You decide to follow her, from 
a distance, to see where she is going. She walks outside and sits on a bench by herself. You notice that she is crying.

What do you do?

» Respond immediately utilizing gesture

> Respond immediately utilizing verbal directive

\ Ignore completely

» Ignore, or choose not to respond immediately, with the intention of addressing the issue at a later time

Explain why you have chosen the response indicated.

\section{If you chose Respond immediately utilizing gesture}

This is not a situation that allows for gesture. You cannot gesture to a student who has walked away.

\section{If you chose Ignore Completely}

Ignoring this situation completely is unethical. Erin, a student who is typically very vibrant and outgoing, is sitting alone crying, and you have information to suggest she is being bullied. It is your responsibility to address the situation.

If you chose Ignore, or choose to not to respond immediately, with the intention of addressing the issue at a later time

You should not wait to speak to Erin. You have probable cause to believe she is being bullied and because she is crying you should be concerned with her emotional well-being. 
If you chose Respond immediately utilizing verbal directive

This is the best response. Erin is obviously distraught. Whether or not her sudden change in behavior is due to an instance of bullying, it is still the teacher's responsibility to be aware of her emotional well-being. Furthermore, because you have information that may tie her to bullying, she is considered at-risk. This situation is the perfect opportunity to approach Erin. It would be a good idea to ask her if she needs to talk about whatever has happened to upset her. If she does not want to talk to you, it would be a good idea to tell her to talk with some friends whom she feels she can trust, or to talk to the school counselor.

Now that you have responded to each behavior and read the feedback describing the most appropriate responses, do you still believe your original response was the best response or would you choose to respond differently if faced with a similar situation in the future?

Answer for each of the three behaviors.

For behavior 1, Erin's friends confide in you. After reading the feedback, do you still believe that your original response was the best response?

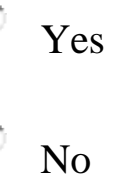

Explain

For behavior 2, you notice a student texting in class. After reading the feedback, do you still believe that your original response was the best response?

Yes

No

\section{Explain}


For behavior 3, Erin is crying. After reading the feedback, do you still believe that your original response was the best response?

Yes

No

Explain

Case study/Automated Feedback

Scenario Two: Responding to Bullying Behaviors

Part I:

You are a special education teacher in a high school. You recently learned from the parent of Jake, a high functioning student with Asperger Syndrome, that some kids are bullying her son in the locker room. This is said to be happening at the beginning of his physical education class, which is when students go to the locker room to change into their gym clothes. The parent did not know the names of the students supposedly bullying her son, and she didn't know exactly what they were doing to bully him. Her son had only confided in her enough to say the other boys were picking on him in the locker room. Because you are the special education teacher assigned as case manager for Jake, your principal calls you into the office and asks you to try to find out what is happening. The principal is hoping you can handle the situation on your own.

What will you do first?

Respond immediately utilizing gesture

Respond immediately utilizing verbal directive 
Ignore completely

Ignore, or choose not to respond immediately, with the intention of addressing the issue at a later time

Explain why you have chosen the response indicated:

\section{If you chose to Respond immediately utilizing gesture}

You cannot respond immediately by gesturing if you are not present when the bullying behavior occurs. You have not witnessed this behavior; therefore, it is not possible for you to respond by gesture.

\section{If you chose to Respond immediately utilizing verbal directive}

You cannot respond immediately if you are not present when the bullying behavior occurs. You have not witnessed this behavior; therefore, it is not possible for you to respond right away.

\section{If you chose to Ignore Completely}

Ignoring the situation completely at this point is NOT the best response. This student has the right to a free and appropriate public education in a safe and healthy learning environment. If you ignore this situation, the parent has grounds for a strong suit which can be filed against you and the school.

You should have chosen Ignore, or choose to not respond immediately, with the intention of addressing the issue at a later time

This is considered the best response in this situation. Before you can respond appropriately to this type of bullying behavior you must first collect all of the facts. It isn't possible for you to respond right away, because you have not witnessed the behavior. Your only option is to wait and gather information.

Now that you know you are going to have to speak with someone to find out what exactly is happening, how would you plan to further address the issue? 
Address the students who are suspected as being the bullies or doing the bullying

Address the student who is being bullied

Address both the bully and the target, but not at the same time.

Address by sharing the issue with a counselor or and administrator

If you chose to Address the students who are suspected to be doing the bullying

Depending upon the number of boys who are enrolled in Jake's physical education class, you may or may not be able to address the students who are suspected as being the bully. Therefore, this is not considered the best response.

If you chose to Address the student who is being bullied

Jake has already reached out for help. It's very difficult for a student with Asperger Syndrome to reach out in this way. If Jake will talk to you, try to get the names of the students who are bullying him. They need to be held responsible for their actions. Still, this is not considered the best response.

If you chose to Address by referring the situation to a counselor or an administrator

The administrator came to you in this situation. You should try to find out as much information as possible before referring the situation back to them again.

You should have chosen to Address both, but not at the same time

This IS the most appropriate response. Jake has already reached out for help. It was very difficult for him to tell his mom there was a problem. When he told her about this situation, he was looking for the issue to be resolved. Hake will only reach out to someone he truly trusts, which is a characteristic of his disability. If you are not that person, then you should consult that person and let that person do the talking for you. If Jake will talk to you, try to get the manes of the students who are bullying him. They need to be held responsible for their actions. Once you have identified the possible perpetrators, they should be interviewed to determine what is actually going on in the locker room. It might be a good idea to ask an administrator to be present during your conversation with the suspected bullies. 


\section{Part II:}

After speaking to Jake, you realized that the boys who were taking his materials in the locker room and throwing them around are also doing things to agitate him throughout the entire day. Now that you are aware of the situation and you know the names of the boys who are bullying him, you begin to notice things that you may have overlooked before. For example, during breakfast you noticed a student ask Jake several times if he plans to drink his second juice. Even after Jake had said yes and asked him to please stop asking, the boy continued to bother him about the juice.

\section{What do you do in this situation?}

» Respond immediately utilizing gesture

» Respond immediately utilizing verbal directive

» Ignore completely

» Ignore, or choose not to respond immediately, with the intention of addressing the issue at a later time

Explain why you have chosen the response indicated.

If you chose to Respond immediately utilizing gesture

This is a possible option, but it is not considered the best. Although gesturing can immediately stop the behavior from occurring, it might not be enough in this situation. In the cafeteria, there will be several bystanders. Everyone who witnesses this behavior needs to understand that it is not acceptable, and there is not risk of interrupting the learning process when you are in the cafeteria.

\section{If you chose to Ignore Completely}

Ignoring the situation completely at this point is not the best response. This student has the right to a free and appropriate public education in a safe and healthy learning environment 
free from harassment or bullying.

If you chose Ignore, or chose to not address the issue immediately, with with thie intention of addressing the issue at a later time.

It is NOT a good idea to ignore this situation for any period of time. If you were to allow the student to continually ask Jake even though you can see that it is very upsetting for Jake then you are encouraging bullying behavior. It is your responsibility to respond when you see this type of behavior.

You should have chosen to Respond immediately utilizing verbal directive

This is the best possible response. The student should be approached immediately. He should understand exactly what will happen the next time he is caught bullying, harassing, or antagonizing Jake. He should be directed to stop asking Jake for his juice and told that it is NOT ok to continuously harass or bully other students.

\section{Part III:}

You decide to observe Jakes physical education class this afternoon. You notice that most of the kids are in and out of the locker room pretty quickly. Jake is the last student to leave the locker room. When you ask him what was taking him so long, he cannot answer you. You can see that he is very frustrated with your questioning, so you decide to ask another student who you have known to be honest and helpful in the past. This student tells you the name of a student who was throwing Jake's gym shoes around the locker room. It is the same student who has been bothering Jake during breakfast by continuously asking him to give away his juice.

How will you respond now that you have gathered this information?

» Respond immediately utilizing gesture

» Respond immediately utilizing verbal directive

» Ignore completely

» Ignore, or choose not to respond immediately, with the intention of addressing the issue at a later time

Explain why you have chosen the response indicated. 


\section{If you chose to Respond immediately utilizing gesture}

Gesture is only appropriate if it is going to immediately eliminate a behavior without disrupting a learning process. Typically gesture is followed up with a verbal directive.

\section{If you chose to Respond immediately utilizing verbal directive}

You cannot respond immediately because you did not witness the behavior.

\section{If you chose to Ignore Completely}

Again, it is unethical to ignore this situation. You have a duty to ensure all students receive their education in a healthy and safe learning environment.

You should have chosen to Ignore, or chosen to not to respond immediately, with the intention of addressing the issue at a later time

This is the recommended response. It was unfortunate that you had to question a bystander. Typically, it is better to not involve anyone else in this type of situation, but because of Jake's disability, you are not able to get the information from him. Therefore, you didn't have a choice.

Now that you have this information, this situation must be addressed, so how do you plan to address the issue?

Address the students who are suspected as being the bullies or doing the bullying

Address the student who is being bullied

Address both the bully and the target, but not at the same time.

Address by sharing the issue with a counselor or and administrator

If you chose to Address the students who are suspected as being the bullying 
Ultimately this student does need to be addressed, but it is not the recommended response because you only have the word of a bystander.

\section{If you chose to Address the student who is being bullied}

This is not the best response at this time. Jake is already frustrated. It is important to be able to tell him that you have done everything you can to eliminate the bullying. Until you feel that the situation has been handled you should refrain from approaching Jake.

If you chose to Address both, but not at the same time

Eventually both students will need to be addressed. However, you may not be the best person to proceed with questioning at this point.

You should have chosen to Address by referring the situation to a counselor or an administrator

The most appropriate response to the issue described in this case study is to refer the incident to a counselor. The counselor will be able to speak to the student who is bullying Jake, attempt to get a confession from the student, and ensure he understands the seriousness of his behavior as well as the consequences to follow. Counselors are trained to handle these types of issues. Referring the incident to the counselor will ideally prevent future incidents of bullying.

Now that you have responded to each behavior and read the feedback describing the most appropriate responses, do you still believe your original response was the best response or would you choose to respond differently if faced with a similar situation in the future?

Answer for each of the three behaviors.

For behavior 1, Jake's parent reports bullying in the locker room. After reading the feedback, do you still believe that your original response was the best response?

Yes

No

Explain 
For behavior 2, Bully tries to get Jake to give up his juice. After reading the feedback, do you still believe that your original response was the best response?

Yes

No

Explain

For behavior 3, A bystander gives you the name of the locker room bully. After reading the feedback, do you still believe that your original response was the best response?

Yes

No

Explain

\section{Case study/Automated Feedback}

Scenario Three: Referring Bullying Behaviors to Counselors or Administrators

Part I:

The faculty at Independence Junior High have noticed that a particular student, Jessica, an inclusion student who typically participates in class discussion and makes good grades has slowly, over the course of a month, began to not only avoid participating in classroom activities and classroom discussion, but also started to earn lower grades on quizzes and 
tests. The student has been sitting alone during her lunch period texting on her mobile phone. Jessica was never considered to be one of the "popular" students at the school, but she does have friends. As her special education teacher, you have not witnessed any occurrence or heard rumor of why her friends are no longer speaking with her at lunch time, but you are suspicious.

During group work in math class, you over hear a group of students talking about plans to follow another student home after school. However, as you move closer to the table the group members quickly begin discussing their math assignment. Not only do you believe the students' behaviors to be suspicious, but you also notice one of the students continuously looking over at Jessica.

What do you do?

Respond immediately utilizing gesture

Respond immediately utilizing verbal directive

Ignore completely

C

Ignore, or choose not to respond immediately, with the intention of addressing the issue at a later time

Explain why you have chosen the response indicated:

\section{If you chose, Respond immediately utilizing gesture}

Although this is not the best answer, it can be considered a correct response. If you chose to respond by utilizing gesture, the students who are conspiring to bully understand that you are suspicious of something, but they most likely do not suspect that you have any real idea of what they are possibly planning to do. This can be considered a correct response as long as the teacher continues to watch and listen to the students, but it is not considered the most accurate response.

\section{If you chose, Respond immediately utilizing verbal directive}

You don't have enough information to give a verbal directive. All you have at this point in time is a hunch. It's best not to say anything yet, because if you do, it can be considered accusatory. There is no proof of wrong doing at this time. 


\section{If you chose, Ignore Completely}

Ignoring the situation completely at this point is NOT the best response. Although you do not have any proof that bullying has or will be occurring, you do have a responsibility to ensures students the right to learn in a healthy and safe learning environment. If you ignore your suspicion, you might be allowing these students to bully another student.

You should have chosen to Ignore, or choose not to respond immediately, with the intention of addressing the issue at a later time

This is considered to be the best response in this situation. Pretending to ignore the situation allows you to keep your eyes and ears open as you might accidentally overhear more throughout the course of your class.

Now that you've decided to ignore at the present and address the issue at a later time, how do you plan to address the issue?

Address the students who are suspected as being the bullies or doing the bullying

Address the student who is being bullied

Address both the bully and the target, but not at the same time.

Address by sharing the issue with a counselor or and administrator

If you chose to Address the students who are suspected as doing the bullying

You should NOT address these students as bullies, because all you have at this point in time is a hunch. It's best not to say anything yet, because if you do, it can be considered accusatory. There is no proof of wrong doing at this time.

\section{If you chose to Address the student who is being bullied}

It is NOT a good idea to address Jessica at this time. You are not certain that she is actually being bullied. Right now you only suspect that there is something going on.

If you chose to Address both, but not at the same time

It is NOT a good idea to address any of the students involved at this situation, yet. All you have at this point is a hunch with no real proof. 
You should have chosen to Address by referring the situation to a counselor or an administrator

This the best response for this situation. You cannot address the issue yourself, because at this time, you only suspect there is a problem. Addressing it any other way could be accusatory. Counselors and Administrators are trained to investigate or handle these types of scenarios.

\section{Part II:}

You've made your first decision. However, as you continue to walk around the class, you notice one of the students in the group that is suspected to be conspiring to follow Jessica home get up to throw away a piece of scrap paper. On her way back to her desk, she walks by Jessica's desk. You hear her ask, "Hey Jessica, do you plan to walk home after school today." Jessica answers by simply saying, "Yes."

Now part of your suspicion has been answered. You know the group was talking about Jessica.

What do you do now?

» Respond immediately utilizing gesture
» Respond immediately utilizing verbal directive
» Ignore completely
\ Ignore, or choose not to respond immediately, with the intention of addressing the issue at
a later time

Explain why you have chosen the response indicated. 


\section{If you chose, Respond immediately utilizing gesture}

Once again, this is NOT the best answer, but it can be considered a correct response. It would not do any harm to gesture the student back to her seat. Once again, the students will realize you're suspicious. However, it is very unlikely that they believe you know what is really going on. This can be considered a correct response only if the teacher continues to watch and listen to the students.

\section{If you chose, Respond immediately utilizing verbal directive}

The only verbal directive you could give at this time would be to tell the student to go back to her desk. This is NOT the best response. You still only have a hunch at this point. You had suspected the students were referring to Jessica and now it seems very likely that you were correct, but you still don't have enough information. It's best not to say anything yet, because if you do, it can be considered accusatory. There is still no proof of wrong doing at this time.

\section{If you chose, Ignore Completely}

Ignoring the situation completely at this point is NOT the best response. Although you do not have any proof that bullying has or will be occurring, you do have a responsibility to ensure students the right to learn in a healthy and safe learning environment. If you ignore your suspicion, you might be allowing these students to bully another student.

You should have chosen to Ignore, or choose not to respond immediately, with the intention of addressing the issue at a later time

This is still considered to be the best response in this situation. Pretending to ignore the situation allows you to keep your eyes and ears open as you might accidentally overhear more throughout the course of your class.

Now that you've decided to ignore at the present and address the issue at a later time, how do you plan to address the issue?

Address the students who are suspected as being the bullies or doing the bullying

Address the student who is being bullied

Address both the bully and the target, but not at the same time.

Address by sharing the issue with a counselor or and administrator 
If you chose, Address the students who are suspected as doing the bullying

You should NOT address these students as bullies, because although it is likely they were talking about Jessica, there still is not proof of wrong doing. It's best not to say anything yet, because if you do, it can be considered accusatory.

If you chose, Address the student who is being bullied

This is NOT considered the best response at this time. However, if you feel you have a good rapport with the student, it cannot hurt to pull the student aside and ask her if there is anything she needs to talk to you about. If the student is being bullied and is ready to talk, she might feel as if you are someone she can trust. Even so, this is not considered the best option.

If you chose, Address both, but not at the same time

It is NOT a good idea to address both the suspected bullies and the target at this time. You still have no proof of bullying behavior. Your suspicion is just that, a suspicion.

You should have chosen to Address by referring the situation to a counselor or an administrator

Yes, this is the best response for this situation. You cannot address the issue yourself, because at this time, you only suspect there is a problem. Addressing it any other way could be accusatory. Counselors and Administrators are trained to investigate or handle these types of scenarios. By continuing to be aware of a possible bullying situation, you can continue to collect information to share with the counselor or administration.

\section{Part III:}

The bell for the next class just sounded, and you are watching as all of the students are exiting the room. This time you overhear one of the group members say to another group member, "Who are we going to accuse Jessica of sleeping with this time?"

\section{What do you do now?}

» Respond immediately utilizing gesture

» Respond immediately utilizing verbal directive

$\gg$ Ignore completely 
» Ignore, or choose not to respond immediately, with the intention of addressing the issue at a later time

Explain why you have chosen the response indicated.

\section{If you chose, Respond immediately utilizing gesture}

You cannot gesture to students, because they are exiting the classroom. This is not the best answer. This last comment is proof that there is an issue of bullying, and it is an issue that may require counseling. We know Jessica is being accused of sleeping with people, but we don't know who or why. This is a very sensitive issue for teenage girls and it could also be affecting the young boys' she is being accused of sleeping with. It is best to consult a counselor or an administrator in this situation.

\section{If you chose, Respond immediately utilizing verbal directive}

When a group of students are exiting the classroom at the same time, verbally directing any of them to your attention is likely not a good choice. Besides, there is still not much for you to say to these students. This last comment is proof that there is an issue of bullying, and it is an issue that may require a counselor or administrator. It's best to refer the situation immediately.

\section{If you chose, Ignore Completely}

You cannot ignore the situation at this point. You have proof that the students are bullying Jessica. This last comment is proof that there is an issue of bullying and it is an issue that may require a counselor or administrator. It is unethical to ignore the situation.

You should have chosen to Ignore, or choose not to respond immediately, with the intention of addressing the issue at a later time

This is considered to be the best response in this situation. Pretending to ignore the situation allows you to keep your eyes and ears open as you might accidentally overhear more throughout the course of your class. 
Now that you've decided to ignore at the present and address the issue at a later time, how do you plan to address the issue?

Address the students who are suspected as being the bullies or doing the bullying

Address the student who is being bullied

Address both the bully and the target, but not at the same time.

Address by sharing the issue with a counselor or and administrator

If you chose, Address the students who are suspected as being the bullying

Although you are now certain there is something going on, you still do not have the whole story and you still do not know exactly who is involved. The correct answer is to refer to a counselor or an administrator. This last comment is proof that there is an issue of bullying and it is an issue that may require counseling. This is not the best response.

\section{If you chose, Address the student who is being bullied}

Once again, if you feel as if you have developed a good rapport with the student you can choose to counsel her yourself. However, this is NOT the best option. This last comment is proof that there is an issue of bullying and it is an issue that may require counseling from someone who is considered a professional in the field of counseling.

\section{If you chose, Address both, but not at the same time}

This last comment is proof that there is an issue of bullying and it is an issue that may require counseling. However, because of the nature of the bullying incident it is recommended that you consult an actual counselor.

\section{You should have chosen to Address by referring the situation to a counselor or an administrator}

This the best response. The last comment is proof that there is an issue of bullying and it is an issue that may require professional counseling. We know Jessica is being accused of sleeping with people, but we don't know who or why. This is a very sensitive issue for teenage girls and it could also be affecting the young boys she is being accused of sleeping with. It is best to consult a counselor in this situation. If you were to refer this to an administrator, the administrator will most likely also refer it to a counselor. 
Now that you have responded to each behavior and read the feedback describing the most appropriate responses, do you still believe your original response was the best response or would you choose to respond differently if faced with a similar situation in the future?

Answer for each of the three behaviors.

For behavior 1, You hear a group of students planning to follow another group of students home. After reading the feedback, do you still believe that your original response was the best response?

Yes

No

Explain

For behavior 2, You hear one of the students ask Jessica if she is planning to walk home. After reading the feedback, do you still believe that your original response was the best response?

Yes

No

\section{Explain}


For behavior 3, You overhear a student say to another, "Who are we going to accuse Jessica of sleeping with today?". After reading the feedback, do you still believe that your original response was the best response?
Y Yes
No

\section{Explain}




\section{Appendix B}

\section{Role Play/Peer Discussion Scenarios}

* Participants will not have access to the recommended appropriate responses until after their peer discussion and before they begin to complete the last part of their After Action Reports.

Here is the list of possible responses to bullying behaviors:

Respond immediately utilizing gesture

Respond immediately utilizing verbal directive

Ignore Completely

Ignore, or choose to not to respond immediately, with the intention of addressing the issue at a later time

Address the students who are suspected as being the bullying

Address the student who is being bullied

Address both, but not at the same time

Address by referring the situation to a counselor or an administrator.

\section{Teacher:}

For each of the three scenarios, you will wait outside until your group is ready for you to walk in. When they are ready, you will walk into the classroom, close the door, and begin preparing for instruction.

You are teaching a vocabulary lesson in scenario one, reviewing the lesson in scenario two, and giving a quiz in scenario three. You can introduce vocabulary of your own choice, or you can go with the ones I have provided.

Abandon- to desert or leave completely, and with no intention of returning

Desolate- barren, deprived, dreary, alone

Forbid- not allow

Defend- take up for

Escalate- to increase in intensity; to raise 
The children were forbidden to set foot in the desolate streets of the abandoned alley. Crime often escalates in that part of town. There would be no one there to help defend them from danger.

Do your best to stay "in role" until the person who is playing the part of the bully says, "out of role." This will happen as soon as you have had the opportunity to respond to all three behaviors.

You will lead the discussion, but first everyone will need to complete the first part of the AAS.

1. Pass out After Action Summaries to your group. Make sure everyone finishes the first part before you begin the actual discussion.

2. To begin discussion, describe the type of scenario, and ask what the three target behaviors were.

3. Tell them how you responded to each of the three behaviors and why.

4. Ask them how they would have responded and why.

5. Discuss what the group as a whole believes the best response would be. It's ok if you agree to disagree.

6. Open the folder with the recommended responses. Talk about that for minute.

7. As soon as your are finished, Complete the second part of the AAS.

8. Put all of your materials back inside the BIG envelope provided, you can leave it for me to pick up.

9. Move on to your next activity.

\section{Scenario One: Preventing Bullying Behaviors}

Bully and Bystander

\section{Description of Scenario:}

In this role play the bully is trying to exclude the target from her group of friends. We do not know why the target is being excluded, but we are to assume this is something that has been going on for some time.

You only have three group members, so in this scenario you are pretending that there is a "target" student in the room. One of you will play the part of bully, and the other will play the part of bystander.

Do your best to stay "in role" for the duration of the activity. It's ok to deviate from the script. Just make sure the three behaviors are addressed. If you are playing the part of Bully, you are responsible for saying, "out of role," to end the role play scenario. Make sure you have given the teacher the opportunity to respond to all three of the behaviors before ending role play. 
Behavior One: The participant playing the part of teacher walks into the classroom, closes the door, and begins preparing her class for instruction. Before she has a chance to get the door closed she overhears one student say to another, "You better not talk to her anymore."

Behavior Two: After noticing the participant playing the part of bystander nod to the target and say, "Hi," the participant playing the part of bully throws her book (or hands) down on her desk as loud as she can and lightly nudges the girl whom she just told not to be speaking to the target student.

Behavior Three: The participant playing the part of bully stares intently and makes eye contact with the participant who is playing the part of target.

*Remember.... It's ok to let some of the lesson go on. Let the teacher start the lesson before everything "blows out of proportion."

Bully: As soon as the teacher walks in, say to the bystander, "You better not talk to her anymore."

Bystander: When you think the bully is not paying attention, quietly turn to where the target would be sitting, nod, and say, "Hi."

Bully: Immediately after noticing the bystander say hi to the Imaginary target, you should loudly throw your hands or your books on the desk and lightly nudge the shoulder of the bystander.

Bully: $\quad$ Make a point to stare intently in the direction of where the imaginary target should be sitting for a long period of time.

Bystander: fidget a little in your seat. Look uncomfortable, and eventually say something to the bully. You might say something like leave her alone, stop staring, or you're making her uncomfortable......

\section{Recommended Responses for Scenario One}

The recommended responses for each behavior are in Bold print. They are the responses that are considered correct for the purposes of this study. You do not have to agree with them, but please use them when you are completing Part II of the AAS.

In this role play the bully is trying to exclude the target from her group of friends. We do not know why the target is being excluded, but we are to assume this is something that has been going on for some time. 
The participant playing the part of teacher walks into the classroom, closes the door, and begins preparing her class for instruction. Before she has a chance to get the door closed she overhears one student say to another, "You better not talk to her anymore."

Behavior One: The participant playing the part of bully says to another student, "You better not talk to her anymore."

Most Appropriate Response: The teacher is just walking into the room and has no idea what the conversation is about. It is best he/she ignore the comment and begin instruction. However, it is also important that although the behavior was ignored, it is not forgotten. The teacher should be alert to the fact that maybe there is something going on.

Behavior Two: After noticing the participant playing the part of bystander nod to the target and say, "Hi," the participant playing the part of bully throws her book down on her desk as loud as she can and lightly nudges the back of the girl whom she just told not to be speaking to the target student.

Most Appropriate Response: The teacher should respond at this point with a verbal directive. The student should understand that his/her behavior is not acceptable. That is the most immediate response; it is what should have happened in the moment. However, it's probably also a good idea to keep the student after class for a short conference. The teacher should definitely document what he/she has noticed, as well as describe the content of the conversation that takes place during the conference. This conference is the teacher's opportunity to find out what is going on and possibly prevent a bullying situation from continuing to occur.

Behavior Three: The participant playing the part of bully stares intently and makes eye contact with the participant who is playing the part of target.

Most Appropriate Response: At this point, classroom instruction has already been disrupted once. The most appropriate response in that moment would be to gesture toward the bully to focus on the lesson. However, although you are already planning to conference with this student, it is probably a good idea to follow up by reporting it to the school counselor. The school counselor may also be able to find out what is going on and prevent a bullying situation from occurring.

\section{Scenario Two: Responding to Bullying Behaviors}

Bully and Target

\section{Description of Scenario:}

In this role play, a student with special needs who sometimes stutters is being bullied. This is an issue that has been going on for several months. The teachers at this school have 


\section{decided anytime they notice this student being bullied that they should respond immediately.}

Do your best to stay "in role" for the duration of the activity. It's ok to deviate from the script. Just make sure the three behaviors are addressed. If you are playing the part of Bully, you are responsible for saying, "out of role," to end the role play scenario. Make sure you have given the teacher the opportunity to respond to all three of the behaviors before ending role play.

In the beginning: As the participant playing the part of teacher walks into the room, she notices the participant playing the part of bully get out of his/her desk and pick up a crumpled piece of paper that is on the floor beside the targets desk. The participant playing the part of teacher see's this, thinks nothing, and goes ahead to start the day's lesson. (Review of last week's vocabulary)

Behavior One: After picking up the piece of paper, the participant playing the part of bully proceeds to the trash can and says, "let me th..th..throw this away for you."

Behavior Two: During the lesson, the participant playing the part of target student will volunteer to answer a question about one of the vocabulary words. As he/she is speaking she will get stuck on one of the sounds and "stutter" slightly. As the target student is stuttering, the bully will take his pencil and poke the target student on the shoulder. When this happens, the participant playing the part of target should respond by saying, "Don't touch me!"

Behavior Three: As the teacher continues with the lesson, the participant playing the part of bully is going to kick, or push, the belongings of the participant who is playing the part of target out of, or away from, his desk. This time the participant playing the part of target will say, “Leave my st..tu..tuff alone," and the participant playing the part of bully will grin.

Bully: $\quad$ As soon as the teacher walks in and is paying attention, pick up the piece of trash from the floor and go back to your seat.

Bully: Wait a minute or so, then proceed to the trash can while saying, "let me th..th..throw this away for you."

Target: $\quad$ Part way through the vocabulary review, you will try to answer a question or make a statement. Be sure to stutter a little.

Bully: As the Target is stuttering lightly poke him/her on the shoulder or back. Try not to make it extremely noticeable.

Target: $\quad$ Turn to the bully and say, "don't touch me!" 
Bully: $\quad$ Try to let the lesson go on for a bit and then push or kick the stuff off from the Targets desk. If you can, make it seem like an "on purpose" accident.

Target: $\quad$ Say to the bully, "Leave my st..st...stuff alone."

Bully: Grin

\section{Recommended Responses for Scenario Two}

The recommended responses for each behavior are in Bold print. They are the responses that are considered correct for the purposes of this study. You do not have to agree with them, but please use them when you are completing Part II of the AAS.

In this role play, a student with special needs who sometimes stutters is being bullied. This is an issue that has been going on for several months. The teachers at this school have decided anytime they notice this student being bullied that they should respond immediately.

Behavior One: After picking up the piece of paper, the participant playing the part of bully proceeds to the trash can and says, "let me th..th,,throw this away for you."

Most Appropriate Response: The teacher at this point should gesture to the student so that he knows his comment did not go unnoticed, but in an effort of not embarrassing the target student any further, the teacher should continue with the lesson.

Behavior Two: During the lesson, the participant playing the part of target student will volunteer to answer a question about one of the vocabulary words. As he/she is speaking she will get stuck on one of the sounds and "stutter" slightly. As the target student is stuttering, the bully will take his pencil and poke the target student on the shoulder. When this happens, the participant playing the part of target should respond by saying, "Don't touch me!"

Most Appropriate Response: This time the teacher should respond with a verbal directive. The teacher should tell the student bully that he is to keep his hands and all other objects to himself. The teacher should also document what is happening. Your school is already aware of the problem. You are expected to respond anytime you notice anything. Therefore, you should be documenting everything.

Behavior Three: As the teacher continues with the lesson, the participant playing the part of bully is going to kick the belongings of the participant who is playing the part of target out of or away from his desk. This time the participant playing the part of target will say, "Leave my st..tu..tuff alone," and the participant playing the part of bully will grin. 
Most Appropriate Response: The most appropriate response at this point is a verbal directive. Most teachers would send the bully directly to the office. The teacher should either send the student to the office immediately or ask the student to stay after class. The teacher can address this issue with the target at a later time. The most important thing at this point, is to try to stop the bullying behavior from occurring.

\title{
Scenario Three: Preventing Bullying Behaviors
}

\author{
Bully and Target
}

\section{Description of Scenario:}

In this role play, the teacher does not really understand what is going on, but he/she has heard that one of the students in this classroom has been a target of bullying.

Do your best to stay "in role" for the duration of the activity. It's ok to deviate from the script. Just make sure the three behaviors are addressed. If you are playing the part of Bully, you are responsible for saying, "out of role," to end the role play scenario. Make sure you have given the teacher the opportunity to respond to all three of the behaviors before ending role play.

The bully in this situation has started a rumor about the target. This rumor affects the target and the bystander. The bystander is upset and has left before class started to go to the bathroom. The bully looks at the target and says, "I heard you were saying things about her that aren't true." The target tries to deny that he/she has said anything, but the bystander interrupts, "She's done with you this time."

Behavior One: As the teacher walks into the classroom, she notices that two students, a bully and a target, are arguing.

Behavior Two: As soon as she begins her lesson. The participant playing the part of bully interrupts and says to the teacher, "Layla went to the bathroom!" then turn to the target and says, "What did you do to her this time?"

Behavior Three: As the lesson continues, the participant playing the part of bully passes a note or sends a text to the participant playing the part of target. Short after, the participant playing the part of target begins to cry slow tears. He/she lays her head down for a minute, but then looks up and it is evident that he/she has been trying to wipe away tears.

Bully: $\quad$ As the teacher is walking into the classroom, you are arguing with the target. You will say, "I heard you were saying things about her that aren't true." You will also say, "She's done with you this time." 
Target: $\quad$ Meanwhile, you are denying anything and telling the bully to leave you alone. You should be argumentative.

Bully: $\quad$ Soon after the teacher's lesson starts; interrupt by saying to the teacher, "Oh, I forgot! Layla went to the bathroom!" then turn to the target at say, "What did you do to her this time?"

Target: If there is a chance you can respond by saying that you didn't do anything. If the teacher responds first that's ok too.

Bully: $\quad$ You will either pretend to sneak and send a text to the target, or you will sneak a note to the target.

Target: $\quad$ Read the text, or the note, and then begin to cry a little. Put your head down as if trying to hide your tears. It should be evident that you are trying to wipe them away.

Bully: $\quad$ Make sure the teacher can see that the target is crying. If you can see that the teacher notices you do not need to do anything. You can give him or her time to respond and then end role play.

If you don't think the teacher has noticed that the target is crying, bring it to their attention before ending role play.

\section{Recommended Responses for Scenario Three}

The recommended responses for each behavior are in Bold print. They are the responses that are considered correct for the purposes of this study. You do not have to agree with them, but please use them when you are completing Part II of the AAS.

In this role play, the teacher does not really understand what is going on, but he/she has heard that one of the students in this classroom has been a target of bullying.

The bully in this situation has started a rumor about the target. This rumor affects the target and the bystander. The bystander is upset and has left before class started to go to the bathroom. The bully looks at the target and says, "I heard you were saying things about her that aren't true." The target tries to deny that he/she has said anything, but the bystander interrupts, "She's done with you this time."

Behavior One: As the teacher walks into the classroom, she notices that two students, a bully and a target, are arguing. 
Most Appropriate Response: The teacher should give a verbal directive at this point by telling both students she is ready to begin class. She cannot ignore the fact that two students are arguing. Most likely they are looking at one another and not at her, so she will have no choice but to tell them to quit arguing or redirect them to listen as she begins the days instruction.

Behavior Two: As soon as she begins her lesson. The participant playing the part of bully interrupts and says to the teacher, "Layla went to the bathroom!" then turn to the target and says, "What did you do to her this time?"

Most Appropriate Response: The teacher should respond verbally by redirecting both students to not speak to one another. She should then continue with her lesson. In addition to responding verbally, the teacher should also be considering what she will do about the situation once class is over.

Behavior Three: As the lesson continues, the participant playing the part of bully passes a note or sends a text to the participant playing the part of target. Short after, the participant playing the part of target begins to cry slow tears. He/she lays her head down for a minute, but then looks up and it is evident that he/she has been trying to wipe away tears.

Most Appropriate Response: The most appropriate response to this situation is to ignore what is happening in the moment with the intention of referring the incident to an administrator or counselor. As soon as class is over the incident should be reported to an administrator or a counselor. This type of situation could lead to a fight between the bystander and the target, at which time they both become victims of the bully. 


\section{Appendix C}

\section{Virtual Simulation/Instructor Feedback Scenarios}

*Virtual Simulation Scenarios are all set in a virtual middle school classroom. This classroom has five students: CJ, Ed, Kevin, Maria, and Sean. During all bullying scenarios one of the two characters, CJ or Kevin, will be playing the part of bully. Ed will be playing the part of bystander, and either a student not in the room or Sean will be playing the part of target.

*The lessons being taught during virtual simulation are vocabulary lessons. Participants will be introducing 5 vocabulary words of their choice that directly align with their own area of certification. If participants are uncertain as to what words to present, they can use the following: abandoned, desolate, forbid, defend, and escalate. Most likely, because of the bullying behaviors, the actual lesson will never occur.

*Comments listed on this document are possible comments. TeachLive actors may come up with their own comments that more accurately reflect the personality of the characters they portray as long as the three behaviors are somehow included in the scenario.

Here is the list of possible participant responses to bullying behaviors:

Respond immediately utilizing gesture

Respond immediately utilizing verbal directive Ignore Completely

Ignore, or choose to not to respond immediately, with the intention of addressing the issue at a later time

Address the students who are suspected as being the bullying

Address the student who is being bullied

Address both, but not at the same time

Address by referring the situation to a counselor or an administrator

\section{Scenario One: Preventing Bullying Behaviors}

In this scenario, Abigail is absent from school, and one of the students is spreading gossip. Some possible character comments are listed.

Playing the part of Bully: CJ 
Playing the part of Target: Abigail, a student who is actually absent from school

Behavior 1: $\quad$ Starting the gossip

Behavior 2: Continuing to gossip and upsetting Sean

Behavior 3: Sending a text to Abigail

CJ's Comments: Did you hear about what Abigail did yesterday?

Oh my god, I can't believe you didn't hear about it. Why else do you think she's not here today?

She'll never be able to face Sean again.

I'm going to text Maria now! This is going to be great.

Ed's Comments: Really!

Here we go again!

Sean, you can't believe a word she says.

Kevin's Comments: You heard the teach.

C'mon let it go.

Sean's Comments: What does anything have to do with me?

You're scaring me?

Oh god, why do you have to say these things.

Maria is my friend.

Scenario Two: Responding to Bullying Behaviors

In this scenario, the class is getting ready to take their vocabulary quiz. It's no secret that one of the students, Sean, will most likely not do well on this test. Sean is a good student, but he struggles to get his work done as fast as the rest of the class.

Playing the part of Bully: Kevin

Playing the part of Target: Sean

Behavior 1: $\quad$ Stupid Jokes 
Behavior 2: Let's Make a Deal

Behavior 3: Can We Please Move On

Kevin's Comments: Hey CJ, how many Seans's does it take to pass a vocab test? (And any other stupid jokes)

Yo, Teach, Let's make a deal! Even though we know there is at least ONE of us who will not pass this test. Can we agree, if we all pass, we get to go to lunch 3 minutes early?

Should have known, do we REALLY have to WAIT for him to finish?

About time

So Sean, how'd you do on that test?

CJ's Comments: Shouldn't we all be done by now?

I'm hungry

Ed's Comments: Why do you always let them get to you man.

It's not worth it.

Sean's Comments: I'm trying to finish

Stop!

I can't work like this.

If he would just stop, I could get my work done. Would you just tell him? This just isn't right. I really studied for this test. I know what I'm doing. Maria's Comments: It's ok Sean, just finish your test.

\section{Scenario Three: Referring Bullying Behaviors to Counselors or Administrators}

In this scenario, $\mathrm{CJ}$ has her cell phone out and is texting. As she is texting, she is commenting about Sean's clothing and how he always raises his hand to speak. Sean receives a text, and when he reads it begins to cry.

Playing the part of Bully: CJ

Playing the part of Target: Sean 
Behavior 1: $\quad$ Texting

Behavior 2: Inappropriate Comments

Behavior 3: Crying

CJ's Comments: There he goes again (raising his hand)

Hey Sean, where'd you get that shirt?

Hey Kev (acting as if pointing out something about Sean)

I'll know what to do (sends a text that cues Sean's crying episode)

Kevins's Comments: I know, I know, Never fails... Here he goes again

Why does he always have to answer

Ed's Comments: He's going to cry again.

Why can't you just leave him alone?

Sean's Comments: (Sean will try to answer all of the teacher's questions)

(After getting the text), "that's just not true!" ...

I'm just trying to be a good student.

Maria's Comments: Sean, can you please calm down. 


\section{Appendix D}

\section{Peer Discussion Guidelines}

Peer discussion should be considered a formal discussion by which a specific agenda has been set. It is the responsibility of all participants involved in peer discussion to ensure everyone remains focused while discussing the intended content of the session.

During each of the Role-Play scenarios there will be a teacher, a student bully, a student target, and a student bystander.

The participant who plays the role of teacher will be responsible for leading peer discussion. The following peer discussion guidelines must be adhered to:

1. Discuss the type of scenario. What were the bullying behaviors? How often did the behavior occur? Who was involved?

*It is important that participants allow the peer playing the part of "teacher" to describe his/her answer to number 2 in detail before responding. Give him/her a chance to state a case.

2. Did I, the participant playing the part of teacher, respond to each of the three bullying behaviors? How did I respond and why?

Discuss each incident of behavior separately. For example, if the behavior were name calling, and I, the teacher, ignored it the first time I would explain that I heard it, but ignored and why. I would then acknowledge that I heard it the second time, describe my response and why I chose to respond the way I did. Finally, I would do the same thing for my response to the third behavior.

3. Do you, the other participants, my peers, agree or disagree with my response? Is there something I could have done differently and why?

Once again, discuss each incident of behavior separately

*At the end of the discussion, after all participants have had the opportunity to discuss their own opinions on appropriate responses, the participant playing the role of teacher will open an envelope with the responses that are considered to be most appropriate and a short rationale. The participant will then complete the final portion of his/her AAS. 


\section{Appendix E \\ Treatment Integrity Checklist \\ for video recordings of role play sessions}

Place a " $\sqrt{ }$ " in the box to signify a task has been completed, and an " $\mathrm{x}$ " in the box to signify a task has not been completed.

Participants playing the parts of students practiced their role play in advance.

Role play began as soon as the participant playing the part of teacher entered the classroom.

Script was used as written

$\square$ Participants stayed in role for the duration of all three bullying behaviors to occur If not, how many did occur?

The participant playing the part of teacher lead peer discussion

The participant playing the part of teacher was not interrupted by peers when discussing his/her responses to the three behaviors and a rationale for those choices.

All participants were actively involved in the discussion

Peer discussion guidelines were used to guide discussion 


\section{Treatment Integrity Checklist \\ for virtual simulation sessions}

Place a "ل" in the box to signify a task has been completed, and an " $x$ " in the box to signify a task has not been completed.

Avatars acted out the first behavior and the participant had the opportunity to respond

Avatars acted out the second behavior and the participant had the opportunity to respond

$\square$ Avatars acted out the third behavior and the participant had the opportunity to respond

The participant stayed in role for the duration of all three bullying behaviors to occur

$\square$ During instructor feedback, the instructor allowed each participant to explain his/her response to each of the three behaviors.

All participants were actively involved in the discussion

$\square$ The instructor provided a rationale for all responses that were considered to be most appropriate.

The instructor allowed participants to ask questions related to the scenarios described in this study, but discouraged questions that were not directly related to the study.

The instructor did not allow the conversation to become distracted. He/she lead a very focused discussion. 


\section{Appendix F}

\section{AAS for Role Play Scenarios}

\section{Scenario One: Preventing Bullying Behaviors}

Part I: To be completed as soon as you are finished with the activity.

Behavior 1: "You better not talk to her anymore"

How did you respond?

Why?

Behavior 2: Throws books down and nudges bystander

How did you respond?

Why?

Behavior 3: Stare

How did you respond?

Why?

Part II: To be completed after you have participated in your feedback session.

Now that you know the recommended response for each behavior, did you respond correctly or incorrectly?

Behavior 1: Correct Response __ Incorrect Response

Behavior 2: Correct Response __ Incorrect Response

Behavior 3: Correct Response __ Incorrect Response

After participating in discussion/feedback, would you change your response? (yes or no)

Behavior 1 
Behavior 2

Explain

Behavior 3

Explain

Scenario Two: Responding to Bullying Behaviors

Part I: To be completed as soon as you are finished with the activity.

Behavior 1: "Let me th..th..throw this away for you"

How did you respond?

Why?

Behavior 2: Bully nudges the target when he stutters

How did you respond?

Why?

Behavior 3: Bully kicks the target's belongings

How did you respond?

Why?

Part II: To be completed after you have participated in your feedback session.

Now that you know the recommended response for each behavior, did you respond correctly or incorrectly?

Behavior 1: Correct Response Incorrect Response

Behavior 2: Correct Response Incorrect Response

Behavior 3: Correct Response Incorrect Response 
After participating in discussion/feedback, would you change your original response? (yes or no)

Behavior 1 Explain

Behavior 2 Explain

Behavior 3 Explain

Scenario Three: Referring Bullying Behaviors

Part I: To be completed as soon as you are finished with the activity.

Behavior 1: Two students are arguing

How did you respond?

Why?

Behavior 2: Bully says to the teacher, "Layla went to the bathroom!" then turns to the target and says, "what did you do to him/her this time?"

How did you respond?

Why?

Behavior 3: The bully passes a note to the target. He/she reads the note and begins to cry. How did you respond?

Why?

Part II: To be completed after you have participated in your feedback session.

Now that you know the recommended response for each behavior, did you respond correctly or incorrectly? 
Behavior 1: Correct Response Incorrect Response

Behavior 2: Correct Response Incorrect Response

Behavior 3: Correct Response Incorrect Response After participating in discussion/feedback, would you change your original response? (yes or no)

Behavior 1 Explain

Behavior 2 Explain

Behavior 3 Explain 


\section{Appendix G}

\section{AAS for Virtual Simulation Scenarios}

\section{Scenario One: Preventing Bullying Behaviors}

Part I: To be completed as soon as you are finished with the activity.

Behavior 1: Starting the gossip

How did you respond?

Why?

Behavior 2: Continuing to gossip and upsetting Sean

How did you respond?

Why?

Behavior 3: Sending a text to Abigail

How did you respond?

Why?

Part II: To be completed after you have participated in your feedback session.

Now that you know the recommended response for each behavior, did you respond correctly or incorrectly?

Behavior 1: Correct Response __ Incorrect Response

Behavior 2: Correct Response __ Incorrect Response

Behavior 3: Correct Response __ Incorrect Response

After participating in discussion/feedback, would you change your response? (yes or no)

Behavior 1 _ Explain 
Behavior 2

Explain

Behavior 3

Explain

Scenario Two: Responding to Bullying Behaviors

Part I: To be completed as soon as you are finished with the activity.

Behavior 1: Stupid Jokes

How did you respond?

Why?

Behavior 2: "Let's make a deal"

How did you respond?

Why?

Behavior 3: "Can we please move on?"

How did you respond?

Why?

Part II: To be completed after you have participated in your feedback session.

Now that you know the recommended response for each behavior, did you respond correctly or incorrectly?

Behavior 1: Correct Response __ Incorrect Response

Behavior 2: Correct Response __ Incorrect Response

Behavior 3: Correct Response __ Incorrect Response

After participating in discussion/feedback, would you change your response? (yes or no) 
Behavior 1 Explain

Behavior 2 Explain

Behavior 3 Explain

Scenario Three: Referring Bullying Behaviors

Part I: To be completed as soon as you are finished with the activity.

Behavior 1: Texting

How did you respond?

Why?

Behavior 2: Inappropriate Comments

How did you respond?

Why?

Behavior 3: Crying

How did you respond?

Why?

Part II: To be completed after you have participated in your feedback session.

Now that you know the recommended response for each behavior, did you respond correctly or incorrectly? 
Behavior 1: Correct Response Incorrect Response

Behavior 2: Correct Response Incorrect Response

Behavior 3: Correct Response Incorrect Response

After participating in discussion/feedback, would you change your response? (yes or no) Behavior 1 Explain

Behavior 2 Explain

Behavior 3 Explain 


\section{Appendix H}

\section{Demographic and Prior Experience Questionnaire}

1. Participant age: $\square$ 18-21 $\square$ 22-30 $\square 31$ or older

2. Participant gender: $\square$ male $\square$ female

3. Number of years enrolled in Teacher Education: $\square$ 0-2 $\square 3-4 \square 5$ or more

4. What is your major course of study?

5. What is your minor course of study?

6. When do you expect to graduate?

7. What, in your opinion, is the likelihood of you encountering bullying issues in your future career? $\square$ not likely $\square$ somewhat likely $\square$ very likely

8. How prepared do you think you are to effectively respond to bullying situations as a teacher?

$\square$ not prepared $\square$ somewhat prepared $\square$ very prepared

9. Have you had prior training related to bullying response or prevention? If so, how long ago?

$\square$ within the last year $\square$ within the last 2-5 years $\square$ more than 5 years ago

10. Do you have prior experience, in a professional role, dealing with bullying situations?

If so, what is the extent of your experience? 


\section{Appendix I}

\section{Participant Pretest}

1. Which of the following statements describe bullying?
a. Bullying Is negative behavior toward another person
b. A behavior that is repeated over time
c. An imbalance of power
d. A,B, and C

2. Which of the following scenarios does not represent an example of bullying behavior?

a. Jane, a really good basketball player, had a really terrible game. The next day at school, you overhear a few people say to her, "way to blow another game yesterday!"

b. Jeff, a student who has always struggled with weight, has been constantly reminded of his weight by a group of boys who are always telling fat jokes.

c. Kyle has complained at least once a week for a semester that a specific student is taking his notebook from him in science class and hiding it. When it comes time to turn in his lab work, Kyle cannot find his notebook.

3. There are no federal or state policies that require teachers participate in bullying response and prevention professional development opportunities or training.
a. True
b. False

4. In order for school-based violence prevention programs to be effective in reducing bullying behaviors, they must be designed to address the needs of
a. Teachers
b. Administrators
c. Students
d. Parents
e. Community
f. A,B, and C
g. All of the above

5. Federal law directly states that state legislatures will implement bullying prevention programs into their local school districts.
b. True
b. False

6. Bullying is defined in the same category as harassment, and is therefore an issue that must be addressed by public school districts, according to federal guidelines.
c. True
b. False

7. When responding to occurrences of bullying, teachers should sit together with the target and the bully so that they can work out their differences.
d. True
b. False 


\section{Appendix J}

\section{Social Validity Questionnaire}

On a scale of 1 to 5, with 1 being least prepared and 5 being more prepared, rate your response:

1. As a result of participating in this study, I feel as if I am better prepared to respond to bullying behaviors I may encounter in the actual classroom.

$\begin{array}{llllll}1 & 2 & 3 & 4 & 5\end{array}$

On a scale of 1 to 5, with 1 being the least amount of effectiveness, and 5 being the most amount of effectiveness:

2. Rate the effectiveness of Case study/Automated Feedback application activities in preparing you to accurately respond to bullying situations.

$\begin{array}{lllll}1 & 2 & 3 & 4 & 5\end{array}$

3. Rate the effectiveness of Role Play/ Peer Discussion application activities in preparing you to accurately respond to bullying situations.

$\begin{array}{llllll}1 & 2 & 3 & 4 & 5\end{array}$

What role did you play in each of the three scenario types? (teacher, bully, bystander) Prevention:

Response:

Referral:

4. Rate the effectiveness of Virtual Simulation/Instructor Feedback application activities in preparing you to accurately respond to bullying situations.

$\begin{array}{lllll}1 & 2 & 3 & 4 & 5\end{array}$

In considering your answers to numbers 2, 3, and 4, which application activity(s) did you report as the most beneficial, and why? What aspects of the activity were most useful to you as a learner?

In considering your answers to numbers 2, 3, and 4, which application activity(s) did you report as the least beneficial, and why? What aspects of the activity were not useful to you as a learner? 
On a scale of 1 to 5, with 1 being no relationship and 5 being a high possibility of relationship:

5. Do you feel like there is a relationship between the order of participation in application activities for each scenario and effectiveness of those activities in preparing you to respond to bullying situations?
1
2
3
4
5

Explain: What order do you feel was most effective and why?

6. What do you perceive as the pros and cons of each type of application activity for effectively preparing you to respond to bullying situations?

\begin{tabular}{|l|l|l|}
\hline & Pro's & Con's \\
\hline $\begin{array}{l}\text { Case } \\
\text { study/Automated } \\
\text { Feedback }\end{array}$ & & \\
\hline Role Play/Peer & & \\
Feedback & & \\
\hline & & \\
Virtual & & \\
Simulation/Instructor & & \\
Feedback & & \\
\hline
\end{tabular}

7. What aspects of the application activities designed in this study did you consider to be most beneficial in preparing you for response and prevention in a real classroom setting? 
8. What aspect of the application activities designed in this study did you consider to be the least beneficial in preparing you for response and prevention in a real classroom setting? 


\section{Vita}

Crystal Smith

8097 WV Hwy 5E Burnsville, WV, 26335 * (304) 575-6755* (304) 462-4305 * csmit112@mix.wvu.edu

Education

Experience
West Virginia University, Morgantown, WV

August 2010-August 2014

Doctorate, Special Education

Major: Personnel Preparation in Special Education

Minor: Curriculum \& Instruction in Technology

Marshall University, South Charleston, WV

2001-2003

Masters of Arts in Special Education

Major: Learning Disabilities

2004-2007

Additional Certification: Multi-Categorical including Autism

Concord University, Athens, WV

1997-2001

Bachelor of Science in Elementary Education

Major: Multi-Subject (K-8)

Doctoral Candidate/Teaching Assistant

West Virginia University

Collaboration-Consultation/ Inclusion Strategies, Second Life, Spring 2013

Doctoral Candidate/Teaching Assistant

Glenville State College

Teaching Students with LD and BD, Spring 2013

Special Education Teacher

Gilmer County Schools

August 2012 - current

- Inclusion for English and Math grades

- Special Education English/Language Arts 9-12

- Case Management grade 7 and 12

- Provide Autism related services.

Teacher

Federal Correctional Institute Gilmer, Glenville, WV

July 2010- August 2012

- Basic, Pre, and Advanced GED

- Special Learning Needs(SLN) portion of EP

- ACE Coordinator

- GED Lab Coordinator

- Quarterly Dockets

- Annual Tutor Training/ Tutor Evaluations 
Special Education Teacher

Fayette County Schools

August 2008-June 2010 Ansted Middle School, Ansted, WV

- Co-Teacher for $7^{\text {th }}$ and $8^{\text {th }}$ grade Reading, Language, Math

- Student Assistance Team Coordinator

- Leadership/Curriculum Committee

- After-School Tutoring Teacher

- Student Council Advisor

Special Education Teacher

Braxton County Schools

August 2005 - June 2008 Sutton Elementary School, Sutton, WV

- K-4 Resource Room (LD, BD, MI, Autism)

Service Coordinator

West Virginia Birth to Three (WVBTT)

December 2005 - July 2006 Skill Builders LLC, WVBTT, Morgantown, WV

- Coordinated Team Meetings with organizations, practitioners, and families

- Assisted Parents in Finding Service Providers

- Coordinated with United Summit Center to write Grants to help meet family needs

Special Education Teacher

Fayette County Schools

August 2003-June 2005 Ansted Middle School, Ansted, WV

- Special Education Resource Room Multi-Subject (5-8)

- Student Assistance Team Coordinator

- Safe and Drug Free Schools Site Coordinator

Kindergarten Teacher

Fayette County Schools

August 2002-June 2003 Meadow Bridge Elementary, Meadow Bridge, WV

- Full-Time Substitute Teacher

- Grant Writer and Teacher for WV Summer Science Grant (2003)

(Awarded \$10,000 for Elementary, and \$10,000 for Middle School)

Grammar and Literature Teacher

Upward Bound Program

Summer 2002 Concord College, Athens, WV

- Provide Language Arts Instruction to Upward Bound Students, Grade 9-12

Tutor/Mentor

Upward Bound Program

Summer 1998 and 1999 WVUIT, Montgomery, WV

- Provide Guidance for High School Students from various backgrounds

- Reside with students for 6 weeks as Tutor/Advisor/Chaperone

\section{Research} Interests

Dissertation, Summer 2014, WVU

Application Activities Designed to Prepare Preservice Special Education Teachers for Response and Prevention of Bullying Behaviors 
Dissertation Chair, Dr. Kim Floyd

Dissertation Committee Members, Dr. Michael Mayton, Dr. Christian Coogle, Dr. Ugur

Kale, and Dr. Richard Walls

Research, Spring 2013

TeachLive: Addressing Bullying in Virtual Environments

In Collaboration with Dr. Kimberly Floyd, Assistant Professor Special Education, WVU, and Dr. Chris Schimmel, Assistant Professor, Counseling, WVU

Literature Review and Professional Development Plan, Fall 2012

Professional Development Models and Technology Integration: An Online Collaboration Model Proposed for Integrating Multimedia as a form of Content Delivery

Proposal, Spring 2012

Identification of Assistive Technology Needs in Post-Secondary Education

Accomplishment Scholar, Gamma Beta Phi, Concord College 2001

Scholar, McNair Scholar Program, Concord College, 2001

(Research Presented at Penn State University, 2001)

\section{Additional Training:}

RESA 7, Co-Teaching Workshop, November 2012

Braxton County Schools, Acuity/Odyssey, August 2012

Braxton County Schools, Common Core Curriculum, August 2012

FCI Gilmer, WV Division of Rehabilitation Services, August 2011

FCI Gilmer, Correctional Education Association Conference, July 2011

FLETC, Phase II Correctional Training, April 2011

FCI Gilmer, Phase I Correctional Training, July 2010

Fayette County Schools, Math Academy, Summer 2009

Fayette County Schools, Teacher Leadership, Summer 2009

Fayette County Schools, Dropout Prevention, 2009

Fayette County Schools, IEP Compliance Training, 2009

Fayette County Schools, Odyssey Training, 2009

Fayette County Schools, Edline/TechSteps/Writing Roadmap 2, 2008/2009

WVDE, SETLA, summer 2008

Braxton County Schools, CPI, 2006 \& 2008

Braxton County Schools, Alternate Assessment Training, 2006-2007

Braxton County Schools, CPR, 2006

Braxton County Schools, Dibbles/RTI, 2005-2008

WVBTT, Service Coordinator Training, 2005

Fayette County Schools, Max Thompson Learning Strategies, 2005

Fayette County Schools, SAS In School Training, 2005

Fayette County Schools, Writing Workshop, 2003-2005

Fayette County Schools, QUILT Training, 2004-2005

Fayette County Schools, Differentiated Learning, 2004-2005

Fayette County Schools, Dr. Forget Learning Strategies, 2003-2004

Fayette County Schools, Alternate Assessment, 2003-2005

Fayette County Schools, Project Charlie/Respect and Protect, 2003-2004

Marshall University, Mediation Certification, 2002

Concord College, Sign Language Courses, 2000 